Postprint of The Journal of Nutritional Biochemistry Volume 57, July 2018, Pages 45-55 DOI: https://doi.org/10.1016/j.jnutbio.2018.03.010

- A high-saturated fat meal acutely regulates miRNA expression in human leukocytes.

- This involves a higher number of upregulated (43) than downregulated (36) miRNAs.

- Multiple signalling events for cancer and other diseases are likely affected.

- A miRNA dysregulation in the postprandial state is reported for the first time. 


\section{A microRNA expression signature of the postprandial state in response to a high-saturated fat challenge}

Sergio Lopez ${ }^{1,2, *}$, Beatriz Bermudez ${ }^{2}$, Sergio Montserrat-de la Paz ${ }^{1,3}$, Rocio Abia ${ }^{1}$, Francisco J.G. Muriana ${ }^{1, *}$

${ }^{1}$ Laboratory of Cellular and Molecular Nutrition, Instituto de la Grasa, CSIC, Seville, Spain

${ }^{2}$ Department of Cell Biology, School of Biology, University of Seville, Seville, Spain

${ }^{3}$ Department of Medical Biochemistry, Molecular Biology and Immunology, School of Medicine, University of Seville, Seville, Spain

* Corresponding author at: Laboratory of Cellular and Molecular Nutrition, Instituto de la Grasa, CSIC, Ctra. de Utrera Km. 1, Edificio 46, Campus Universitario Pablo de Olavide, 41013 Seville, Spain. Tel.: +34 954611550; fax: +34 954616790; E-mail: serglom@ig.csic.es, muriana@ig.csic.es

Running title: High-fat meal on miRNAs

Funding: This work was supported by grants from the Spanish Ministry of Economy, Industry and Competitiveness [AGL2011-29008 and AGL2016-80852-R]. SL acknowledges financial support from the Spanish Research Council (CSIC)/Juan de 
la Cierva [JCI-2012-13084]. SL, BB, and SMP had the benefit of the "V Own

Research Plan" of the University of Seville and SMP of a FPI fellowship [BES-2012056104] of MICINN. 


\section{Abstract}

The postprandial hypertriglyceridemia is an important and largely silent disturbance involved in the genesis of numerous pathological conditions. Exaggerated and prolonged states of postprandial hypertriglyceridemia are frequently related to the ingestion of meals enriched in saturated fatty acids (SFAs). MicroRNAs are noncoding RNAs that function as gene regulators and play significant roles in both health and disease. However, differential miRNA expression between fasting and postprandial states has never been elucidated. Here we studied the impact of a highsaturated fat meal, mainly rich in palmitic acid, on the miRNA signature in peripheral blood mononuclear cells (PBMCs) of nine male healthy individuals in the postprandial period by using a two-step analysis, miRNA array and validation through qRT-PCR.

Compared with miRNA expression signature in PBMCs at fasting, 36 miRNAs were downregulated and 43 miRNAs were upregulated in PBMCs at postprandial hypertriglyceridemic peak. Six chromosomes $(3,7,8,12,14$, and 19) had nearly a half (48.1\%) of dysregulated miRNA-gene-containing regions. Downregulated miR300 and miR-369-3p and upregulated miR-495-3p, miR-129-5p, and miR-7-2-3p had the highest number of target genes. The differentially expressed miRNAs and their predicted target genes involved pathways in cancer, MAPK signalling pathway, endocytosis, and axon guidance. Only downregulated miRNAs notably targeted PI3K-Akt signalling pathways, whereas only upregulated miRNAs targeted focal adhesion, Wnt signalling pathway, transcriptional misregulation in cancer, and ubiquitin-mediated proteolysis. This is the first study of miRNA expression analysis of human PBMCs during postprandial hypertriglyceridemia and offers insight into new potential mechanisms by which dietary SFAs influence on health or disease. 


\section{Introduction}

Exaggerated and prolonged states of postprandial hypertriglyceridemia due to the ingestion of multiple fat-enriched meals during the course of a day are emerging as important causes of atherosclerosis, including coronary artery disease, stroke, and subsequent sudden death [1-3]. In the current paradigm, the inflammatory disease of atherosclerosis is characterized by the initial endothelial dysfunction and monocyte recruitment, accumulation of lipids in infiltrated macrophages within the arterial wall, plaque development, and eventual plaque rupture [4]. In contrast, recent studies suggest that circulating monocytes may start interacting with postprandial triglyceride-rich lipoproteins before their migration to arterial wall, which results in transcriptional regulation of genes involved in lipid homeostasis and inflammation [5, 6]. However, the mechanisms underlying postprandial effects of dietary fats in cardiovascular and other diseases are largely unknown.

MicroRNAs (miRNAs) are a set of endogenous and small non-coding single-stranded RNAs approximately 22 nucleotides in length that comprise a novel class of gene expression regulators [7]. miRNAs bind to their target genes in the 3' untranslated regions (UTRs), thus mediating negative posttranscriptional regulation. They can also repress mRNA targets through binding to other regions, including 5'-UTRs or protein coding sequences, and in some cases may even activate translation [8]. In humans, several miRNAs have been shown implicated in controlling lipid homeostasis and inflammation $[9,10]$, which has led to several studies of miRNA profiling as noninvasive biomarkers for early detection of asymptomatic and symptomatic atherosclerotic lesions [11, 12]. Importantly, miRNAs are responsive to environmental factors [13] and exhibit temporal expression patterns [14], supporting the possibility of acute changes in miRNA expression during fed states. Because the consumption 
of saturated fatty acids (SFAs) has been linked with larger and longer postprandial hypertriglyceridemic response [15] and increased risk for several chronic diseases such as cardiovascular disease and cancer $[16,17]$, the aims of this study were to explore whether a high-saturated fat meal, mainly rich in palmitic acid, could change the miRNA signature in peripheral blood mononuclear cells (PBMCs) from healthy individuals in the postprandial period and to establish the role of miRNA signature as a novel tool to predict clinical outcomes linking the postprandial metabolism of dietary SFAs with pathophysiological processes.

\section{Materials and Methods}

\subsection{Participants and design}

Nine healthy Caucasian non-smoking males, aged 18-23 y were recruited by advertising (Table 1). Participants were excluded if they have established coronary heart disease, renal impairment, hypothyroidism, or liver dysfunction based on clinical chemistry testing. None of the participants consumed special diets, or took medication known to alter gastric emptying or lipoprotein metabolism. The participants were reported to the Clinic Experimental Research Unit for Vascular Risk at the University Hospital Virgen del Rocio (UHVR, Seville) at 0800 in a 12-h fasted state. On arrival, a blood sample was taken $(t=0)$. The high-saturated meal consisted in an oral emulsion prepared according with the procedure described in the patent PCT/ES2014/070427, with $30 \mathrm{~g}$ of sucrose $/ \mathrm{m}^{2}$ and $50 \mathrm{~g}$ of cow's milk cream $/ \mathrm{m}^{2}$ of body surface area. The average total energy provided was $\sim 800 \mathrm{kcal}$, with a macronutrient profile of $77 \%$ fat and $23 \%$ carbohydrate. The fatty acid composition of the milk cream is described in Table 2. The emulsion was consumed 
within $10 \mathrm{~min}$, and subsequently, blood samples were collected hourly over $6 \mathrm{~h}$ in tubes containing clot activator and gel separation for serum for the measurements of triglycerides, or sodium citrate cell preparation tubes (BD Vacutainer $\mathrm{CPT}^{\mathrm{TM}}$ ) for the isolation of peripheral blood mononuclear cells (PBMCs). PBMCs were only isolated from blood samples at fasting and at hypertriglyceridemic postprandial peak $(\sim 2 \mathrm{~h})$. In this study, each participant served as his own control. Prior to the beginning of the study, all participants provided their informed consent using protocols approved by the Human Clinical Commission and Ethics Committee of UHVR. The investigation conformed to the principles outlined in the Helsinki Declaration of the World Medical Association. This study was registered with clinicaltrials.gov (NCT02061267).

\subsection{Fatty acid analysis of dietary fat}

Fatty acid composition was determined according to the method described in EC/796/2002 [18] with a gas chromatography system (HP-5890; Hewlett-Packard, Palo Alto, CA) with a flame ionization detector and an SP-2380 (Supelco, Bellefonte, PA) fused silica capillary column (50 $\mathrm{m} \times 0.25 \mathrm{~mm}$ internal diameter) coated with cyanopropylpolysiloxane $(0.25 \mu \mathrm{m}$ film thickness). The oven temperature program was isothermal at $165^{\circ} \mathrm{C}$ for $10 \mathrm{~min}$ before rising to $200{ }^{\circ} \mathrm{C}$ at $1.5^{\circ} \mathrm{C} / \mathrm{min}$. The injector and detector temperatures were $220^{\circ} \mathrm{C}$ and $250^{\circ} \mathrm{C}$, respectively. Hydrogen was used as the carrier gas at a column head pressure of $130 \mathrm{kPa}$. Sample injections were performed in the split mode.

\subsection{Biochemical determinations}


Glucose was immediately measured using a DAX-96 autoanalyser (Bayer Diagnostics, Milan, Italy). Total cholesterol and triglycerides were determined by enzymatic methods (CHOD-PAP and GPO-PAP, respectively; Roche Diagnostics, Basel, Switzerland). HDL-cholesterol was determined after precipitation with phosphotungstic acid. LDL-cholesterol was measured using an Advia 2400 Clinical Chemistry System (Siemens Healthcare Diagnostics, Erlangen, Germany).

\subsection{Peripheral blood mononuclear cell (PBMC) isolation and total RNA isolation}

PBMCs were isolated by using the BD Vacutainer® CPT $^{\text {тм }}$ Cell Preparation Tubes according to the manufacturer's instructions. Total RNA from PBMCs was isolated by using TRIsure $®$ and quantified with a Nanodrop ND 1000 spectrophotometer (Nanodrop Technologies, Wilmington, DE). RNA integrity and miRNA content were determined with an Agilent 2100 Bioanalyser with RNA 6000 Nano chips (Agilent Technologies, Santa Clara, CA). The RNA integrity of the samples was above 9.

\section{5 miRNA microarray and data analysis}

RNA samples were pooled to randomly create four $(2+2+2+3$, referred to as \#1, $2,3,4)$ fasting (F1, F2, F3, F4) and postprandial (P1, P2, P3, P4) specimens. For each sample, $300 \mathrm{ng}$ of total RNA were labelled using miRNA Microarray with miRNA Complete Labelling and Hyb Kit (5190-0456; Agilent Technologies). The samples were hybridized for 20 h onto a human miRNA Microarray v3.0, Release $15.0,8 \times 15$ K containing 955 human mature miRNA probes (Agilent Technologies) and processed at the Andalusian Center for Molecular Biology and Regenerative Medicine (CABIMER) Genomics Core Facility. Data was subjected to a background 
correction and quantile normalization [19], and then transformed to a linear scale for statistical analysis [20]. Only miRNA with a $p<0.05$ and fold change $<-1.2$ or $>1.2$ were considered for further investigation. A list of putative miRNA targets was identified using the prediction algorithm DNA Intelligent Analysis (DIANA) DIANAmicroT-CDS (v5.0). To explore the function of dysregulated miRNAs, the DIANAmiRPath (v2.0) was used to identify functional pathways according to Kyoto Encyclopaedia of Genes and Genomes (KEGG) [21]. The Gene Ontology (GO) analysis was performed to investigate the biological processes, cellular components, and specific molecular function of differentially expressed miRNA using DAVID (Database for Annotation, Visualization and Integrated Discovery) database.

\subsection{Quantitative real time PCR (qRT-PCR)}

miRNA expression levels were analysed using the BioMark 48.48 Dynamic Array Nanofluidic Chip (Fluidigm Inc, San Francisco, CA). Briefly, miRNA was reversed transcribed with the TaqMan microRNA Reverse Transcription Kit (Applied Biosystems, Foster City, CA) and then pre-amplified using the TaqManR PreAmp Master Mix (2x) (Applied Biosystems). Following hydraulic chip priming, pre-amplified cDNA samples plus one no template standard were mixed with a mild detergent loading solution to allow capillary flow, and the samples were added to the sample inlets of the Nanofluidic Chip. Ten individual Taqman primer-probe mixtures (Applied Biosystems) specific for individual selected transcripts along with assay loading solution were also added into the above inlets, allowing a combination of each sample to mix with each primer-probe assay in every possible combination (a total of 2304 reactions). The chip was then thermo-cycled through 40 cycles and Taqman primer-probe fluorescence in the FAM (6-carboxyfluorescein) channel was detected 
using the CCD (charge-coupled device) camera attached to a BioMark HD System, normalized by ROX (6-carboxy-X-rhodamine) intensity.

\subsection{Statistical analysis}

Statistical analysis was performed using the SPSS software v19.0 (IBM Corporation, NY). Differentially expressed miRNA (peak vs baseline) were obtained by paired comparisons using the Limma package [22]. For qRT-PCR analysis, a paired t-test was used to determine significant differences between peak and baseline values. The level of significance was set at 0.05 .

\section{RESULTS}

\subsection{Identification of dysregulated miRNAs on PBMCs in the postprandial state}

To identify miRNAs expressed in the blood of human in the postprandial state, we conducted miRNA expression profiling in PBMCs from blood of nine healthy volunteers before and after the ingestion of a standardized high-saturated fat meal. According to the time course of changes in serum triglycerides, the serum triglyceride concentration peaked at $2 \mathrm{~h}$ postprandial (Figs. S1 and 1A). Total RNA samples of PBMCs from fasting were pooled as indicated above and the same was done with samples at $2 \mathrm{~h}$ postprandial. Of the total 866 -screened human miRNAs, comparison of miRNA expression patterns in PBMCs between fasting and postprandial states revealed an exclusive detection of 856 miRNAs in PBMCs either at fasting or postprandial (Table S1). A hierarchical clustering was conducted and a combined dendrogram/heat map was generated for statistically significant and differentially regulated miRNAs (Fig. 1B). While 79 miRNAs with differential regulation were 
expressed in both PBMCs from fasting and postprandial states, the number of downregulated miRNAs (36, 4.2\% of all screened targets) was slightly lower than upregulated miRNAs ( $43,5.0 \%$ of all screened targets). It is interesting to note that the ingestion of the high-saturated fat meal had a scattering effect on miRNA expression level in PBMCs, thus two different major clusters among the downregulated or upregulated miRNAs were recognized (see letters $\alpha-\delta$, Fig. 1B). The cluster $\alpha$ had more signal intensity but less fold change than the cluster $\beta$ for the expression of downregulated miRNAs, whereas the cluster $\gamma$ had less signal intensity but more fold change than the cluster $\delta$ for the expression of upregulated miRNAs (see also Table S2). Differences in the expression levels of miRNAs between the fasting and the postprandial state following the criteria of $>1.2$-fold under- or overexpression and statistical significance ( $p$ value less than 0.05 ) were analysed with a volcano plot (Fig. 1C). Based on these criteria, we identified 9 downregulated (miR-613, -629-3p, -24-2-5p, -555, -148a-5p, -621, -875-3p, -513c-5p, -1226; 25.7\% of all downregulated targets) and 9 upregulated (miR-653, -19b-1-5p, -363-5p, -885$3 p,-339-3 p,-938,-148 b-5 p,-593-5 p,-24-2-5 p,-200 b-5 p ; 20.9 \%$ of all upregulated targets) miRNAs in the postprandial state when compared to the fasting state (Fig. 1D). In addition, there were significant correlations between fasting and postprandial values for expression intensity of downregulated (Fig. S2A) and upregulated (Fig. S2B) miRNAs. Furthermore, fold change was also correlated with fasting values for expression intensity in upregulated (Fig. S2C) and downregulated (Fig. S2D) miRNAs.

Expression of randomly selected miRNAs (downregulated: miR-629-3p, -24-2-5p, 555, -621; upregulated: miR-653, -363-5p, -593-5p, -200b-5p; non-regulated: miR103-3p, -16) was further verified by quantitative miRNA RT-PCR technology (Table 
3). These data were consistent with the expression patterns observed by miRNA array profiling.

In order to evaluate the reproducibility and variability of the results, an exploratory multivariate analysis was applied to the dataset of the total screened human miRNAs in total RNA samples of PBMCs both at fasting (F1, F2, F3, F4) and at postprandial (P1, P2, P3, P4). Based on the Euclidean distance, Fig. 2A shows the hierarchical clustering dendrogram and heat map of miRNA expression, whereas Fig. 2B shows the 3D tree map for the hierarchical clustering of miRNAs under the first principal component for fasting and postprandial sample groups. The optimal level of division calculated indicates two clusters corresponding to the fasting (F1 to F4) and postprandial (P1 to P4) states. These clusters were also evident after a factorial correspondence analysis (Fig. 2C) or a principal components analysis (Fig. 2D) of all of the miRNAs observed.

\subsection{Genome location of dysregulated miRNAs on PBMCs in the postprandial state}

The miRNA genes are integral components of chromosomes. To map the chromosomal location of downregulated and upregulated miRNAs in the postprandial state, we detailed the location of each dysregulated miRNA in the geography of human chromosomes by examination of the miRBase database (http://www.mirbase.org/) and using ideograms (Fig. 3). Whereas chromosome 18 was not affected (chromosome $Y$ has no reported miRNA genes), chromosomes 1, 3, $5,6-9,11-17,19,20,22$, and $\mathrm{X}$ had both downregulated and upregulated miRNAgene-containing regions. However, only upregulated miRNAs were mapped in chromosomes 2, 4, 10, and 21. The chromosomal distribution of dysregulated 
miRNAs was extremely biased, with $74.7 \%$ of the repertoire (35 downregulated and 24 upregulated miRNAs) focusing in the larger (q) arm of the affected chromosomes, mainly in centromere distal areas. In addition, 3p-arm-annotated miRNAs were more frequent than those derived from the $5^{\prime}(5 p)$ strand region of the mature miRNA hairpin precursors. Six chromosomes $(3,7,8,12,14$, and 19) had nearly a half $(48.1 \%)$ of all the dysregulated miRNAs. The most affected chromosomes were 7 and 14 , which had scattered 8 miRNA loci each.

Furthermore, $63(79.8 \%)$ of the dysregulated miRNAs were individually distributed across chromosomes, including 19 single miRNAs within different cluster regions, whereas the rest (16 miRNAs, 20.2\%) was grouped with at least 2 miRNAs in seven clusters on chromosomes $8,13,14$, and 19 (Table 4). Three of these clusters (clusters 2, 3, and 7 on chromosomes 8, 13, and 19, respectively) comprised miRNAs with concerted dysregulation (co-upregulation). However, in the miR875/599 cluster (cluster 1 on chromosome 8), miR-875 showed reverse directions of dysregulation in the $5 \mathrm{p} / 3 \mathrm{p}$ species. Reverse dysregulation between miRNAs of the same cluster was also observed in the miR-665/136, -379/495, and -299/1185-1 clusters (clusters 4, 5, and 6, respectively) on chromosome 14. Genome structure analysis indicated that these seven clusters had homologous miRNAs (clusters: miR30d/30b, -518f/521-2) and heterologous miRNAs (clusters: miR-875/599, -17/92a-1, $665 / 136,-379 / 495,-299 / 1185-1)$; non-clustered miRNAs of the same gene family were also encoded in independent transcripts located on the same chromosome (miR-1323/1283-1 and -1283-1/520c clusters of the miR-515 family on chromosome 19) or on different chromosomes, forming groups of paralogous miRNAs (miR-181a2-3p and -181c-3p of the miR-181 family on chromosomes 9 and 19; miR-138-1-3p and $-138-2-3 p$ of the miR-138 family on chromosomes 3 and 16; miR-148a-5p and - 
148b-5p of the miR-148 family on chromosomes 7 and 12, respectively) (Fig. 4A). The miR-17/92a-1 cluster (on chromosome 13) and its two paralogous miR-106b/25 (on chromosome 7) and -106a/363 (on chromosome X), known as oncomiR-1, were affected with the upregulation of four miRNA members (miR-18a-3p, -19b-1-5p, -25$5 p,-363-5 p)$ that contained partially homologous sequences (Fig. 4B).

\subsection{In silico miRNA target prediction and pathway enrichment analysis of dysregulated miRNAs on PBMCs in the postprandial state}

To establish a possible underlying biological implication with downregulated and upregulated miRNAs in the postprandial state after the ingestion of the highsaturated fat meal, DIANA-microT-CDS (for predicted target genes), DIANA-mirPath (for KEGG pathways), and DAVID (for GO categories) databases were applied. All of the dysregulated miRNAs had target genes in the database (Table S3). Among the downregulated miRNAs, miR-300 and $-369-3 p$ of the miR-154 family (q32.31 cluster region on chromosome 14) had the highest number of target genes (1293 and 1195, respectively), whereas miR-523-3p had only 2 target genes. Among the upregulated miRNAs, miR-495-3p of the miR-299 family (q32.31 cluster region on chromosome 14), miR-129-5p of the miR-129 family (q22.1 region on chromosome 7 ), and miR-72-3p of the miR-7 family (q26.1 cluster region on chromosome 15) had the highest number of target genes $(2618,1605$, and 1448 , respectively), whereas miR-181c-3p had only 4 target genes. The total number of target genes coupled with upregulated miRNAs was greater than with downregulated miRNAs (16330 vs 11114). Fig. 5 shows the KEGG pathways overrepresented among these predicted target genes. It revealed the enrichment of 31 KEGG targeted categories, nine potentially affected by both downregulated and (especially by) upregulated miRNAs, five by only 
downregulated miRNAs, and seventeen by only upregulated miRNAs. Most target genes of dysregulated miRNAs were enriched in the "Pathways in cancer" category, which was coupled to 6 downregulated miRNAs (miR-148a-5p, -646, -300, -369-3p, 875-3p, -1226-3p) and 8 upregulated miRNAs (miR-616-3p, -138-2-3p, -519e-3p, $665,-7-2-3 p,-519 d,-495-3 p,-129-5 p)$. A total of 96 target genes in the "PI3K-Akt signalling pathway" category were identified as potentially affected by only 6 downregulated miRNAs (miR-148a-5p, -302e, -646, -300, -369-3p, 629-3p). The "Focal adhesion”, "Wnt signalling pathway", "Transcriptional misregulation in cancer", and "Ubiquitin-mediated proteolysis" were the main enriched KEGG pathway categories by only upregulated miRNAs. The most prominent miRNAs in annotating the greater number of KEGG pathways enriched in the postprandial state were miR495-3p, $-519 d, 129-5 p$, and $-7-2-3 p$ (all of them upregulated miRNAs). These miRNAs were respectively coupled to $20,19,17$, and 16 KEGG pathways, mainly those associated with MAPK, TGF-beta, neurotrophin, and ErbB signalling. The total number of target genes that enriched KEGG pathways coupled with upregulated miRNAs was more than twice that with downregulated miRNAs (1130 vs 508). On the basis of the downregulated miRNAs, the five high-enrichment GO functions were PI3K cascade, VEGF receptor signalling pathway, pathways-restricted SMAD protein phosphorylation, patterning of blood vessels, and BMP signalling pathway (Table S4). For upregulated miRNAs, the five high-enrichment GO functions were regulation of lipid kinase activity, Wnt receptor signalling pathway through beta-catenin, regulation of erythrocyte differentiation, thymus development, and gammaaminobutyric acid signalling pathway.

\section{DISCUSSION}


Here, we hypothesized that a high-saturated fat meal may have an important effect on miRNA expression profiling in human PBMCs. To test this hypothesis, we conducted what is to the best of our knowledge the first study on the microRNA expression signature in the postprandial state in humans. We compared PBMC miRNA profiles of healthy volunteers before and after the ingestion of a standardized high-fat meal enriched in SFAs, mainly palmitic acid. PBMCs were obtained from blood samples at fasting and at the postprandial time $(\sim 2 \mathrm{~h})$ corresponding to the hypertriglyceridemic peak. It was noteworthy the detection of 856 miRNAs (of the total 866-screened human miRNAs), 79 of which were differently expressed (36 downregulated and 43 upregulated) between fasting and postprandial states, i.e., in only 2-3 $\mathrm{h}$ in response to the ingestion of a standardized high-fat meal. By setting cut off limits at absolute fold change greater than 1.2 ( $p$ value less than 0.05$), 9$ miRNAs were downregulated (miR-613, -629-3p, -24-2-5p, -555, -148a-5p, -621, -875-3p, $513 c-5 p,-1226)$ and 9 were upregulated (miR-653, -19b-1-5p, -363-5p, -885-3p, $339-3 p,-938,-148 b-5 p,-593-5 p,-24-2-5 p,-200 b-5 p)$ in the postprandial state when compared to the fasting state, suggesting the relevance of these miRNAs to the acute metabolism of dietary fats in humans. These profiles were maintained in a set of randomly selected miRNAs after validation by quantitative miRNA microfluidic RTPCR technology, indicating that our findings are reliable and not a result of the false positive characteristic of high throughput technologies. We found that dysregulated miRNAs were distributed across most chromosomes, with the exception of pair 18 (pair $\mathrm{Y}$ has no reported miRNAs), mainly in $\mathrm{q}$ arm and centromere distal regions. This observation is consistent with previous reports that transcription start sites of miRNA genes were typically associated with dense heterochromatic loci embedded in pericentromeric regions of chromosome arms [23, 24]. 
Recent evidence has disclosed the potential contribution of 69 miRNAs in human genomic regions associated with elevated fasting plasma concentrations of lipids by a genome-wide association meta-analysis [25]. Genetic predisposition to high fasting triglycerides was linked to 24 miRNAs, of which only 2 miRNAs (miR-148a on chromosome 7 and miR-138-2 on chromosome 16) were coincident with dysregulated miRNAs in our study. Two miRNAs (miR-629-3p on chromosome 15 and miR-25-5p on chromosome 7) of the top ten whole blood miRNAs associated with fasting triglycerides in a recent cross-sectional analysis of the Framingham Heart Study [26] were also only shared by our miRNA signature in the postprandial period. These observations suggest that fasting and postprandial triglycerides play a different regulatory role on circulating non-coding RNAs. There is indeed a growing recognition that non-fasting triglyceride concentrations may be more relevant than fasting concentrations in the assessment of some metabolic disorders [27]. Thus, it is very likely that the composition and number of plasma particles containing triglycerides in the postprandial state may otherwise regulate the miRNA genome from a clinical setting of elevated plasma triglycerides in the fasting state.

It was striking the repertoire of clustered miRNAs in the location q32.2 and q32.31 on the acrocentric chromosome 14, the most affected chromosome together with the chromosome 7 in the postprandial state. Human chromosome $14 q 32.2$ is an imprinted region that carries paternally expressed genes including DLK1 and RTL1, and maternally expressed genes including MEG3/GTL2, MEG8, and antisense RTL1, along with the germline-derived DLK1-MEG3 intergenic differentially methylated region (IG-DMR) and the postfertilization-derived MEG3-DMR [28]. Of note, the maternally but not the paternally inherited $14 q 32.2$ imprinted region harbours one of the largest miRNA clusters in the human genome consisting of 54 miRNAs that 
response to epigenetic regulatory mechanisms [29]. The miR-665 within this cluster was upregulated in the postprandial state, suggesting that the vital region hosted at the DLK1-DIO3 locus was responsive to the ingestion of the high-saturated fat meal. Aberrant expression of miR-665 has been implicated in the chronic heart failure [30], inflammatory bowel disease [31], apoptosis of nerve cells [32], and pathogenesis of several tumours such as prostate cancer [33], breast cancer [34], and intestinal gastric adenocarcinoma [35]. We also found that $3 p$ species of miR-136 located on DLK1-DIO3 locus was downregulated in the postprandial state. Mechanistic studies have defined miR-136 as a multifunctional regulator of innate immunity [36], tumour sensitivity [37, 38], tumour suppression [39, 40], and wound healing [41]. Regarding to the location $14 q 32.31,6$ intergenic miRNAs were alternating upregulation (miR411-3p, -495-3p, -1185-1-5p) and downregulation (miR-299-3p, -300, -369-3p), giving rise to a conjugated system that connected 3 close miRNA clusters, two of them paralogous (miR-379/495, -299/1185-1) and one homologous (miR-323b/656). Based on their own unique promoters, intergenic miRNAs may be independently transcribed [42]. Interestingly, such miRNA clusters are embedded in the miR-379 miRNA megacluster that was recently associated to endoplasmic reticulum stress [43]. In addition, increased expression of miR-411 and -1185 has been involved in the pathogenesis of cardiovascular disease [44, 45] and miR-495-3p in tumour sensitivity [46]. Decreased expression of miR-299-3p and $-369-3 p$ has been linked to tumorigenesis $[47,48]$ and miR-300 to poor prognosis in patients with cancer [49]. We also observed discordant $5 p$ (increasing)/3p (decreasing) regulation of miR-875. It is known that $5 p$ and $3 p$ miRNA species may be selectively co- or cross-regulated [50] according to differences in the sequence of 5' and 3' arms of the mature miRNA hairpin duplex [51]. A decreased expression of miR-875-3p has been implicated in 
cardiac myopathy [52]. We further found a biased 3p-arm selection of dysregulated miRNAs, which is indicative that targets of these $3 p$ species may be biologically prominent in the response to the ingestion of dietary SFAs.

Two miRNAs (miR-18a-3p, -19b-1-5p) from the miR-17/92a-1 polycistronic oncomiR1 and one miRNA from each of its two paralogous miR-106b/25 (miR-25-5p) and 106a/363 (miR-363-5p) clusters were also overrepresented upon challenge with the high-saturated fat meal. Differential expression of oncomiR-1 components has been previously reported at different posttranscriptional levels by Drosha or Dicer cleavage [53], miR-19b being required to recapitulate the oncogenic properties of the entire cluster [54]. The amplification or overexpression of miR-18a-3p has been associated to the development of epidermal skin cancer [55], while miR-25-5p to the inflammatory response in several types of cancer cells [56]. However, the biological role of miR-363-5p on tumorigenesis remains unclear [57]. Previous research reported long-term regulatory effects of dietary fatty acids on several miRNAs, including miR-19b and -18a [58]. Therefore, our study indicates that oncomiR-1 cluster is also closely related to acute metabolism of dietary fatty acids, thus providing a further level of complexity and a new perspective in the epigenetic mechanisms underlying the control of circulating miRNA profile during non-fasting conditions. The oncomiR-1 cluster has been recently associated with cardiovascular system [59] and we have previously reported the critical role of the predominant class of dietary fatty acids in postprandial triglyceride-rich lipoproteins on cardiovascular risk factors $[15,60]$. This lead to the hypothesis that oncomiR-1 cluster and its paralogous may serve as a potential target for exploring the role of different dietary fatty acids to fine-tune transcriptional levels of genes involved in metabolic disorders that are common to relevant degenerative diseases. An attractive possibility is the 
reciprocal control of miRNA expression and peroxisome proliferator-activated receptors [61], which are a family of transcriptional factors responsive to dietary fatty acids from postprandial triglyceride-rich lipoproteins in myeloid cells $[5,62,63]$.

We used several computational algorithms to establish miRNA targets and functional enrichment analysis. Most of the predicted genes ( 60\%) were affected by upregulated miRNAs, which suggests an increase of transcriptional gene repression in response to the ingestion of the high-saturated fat meal. Two downregulated miRNAs such as miR-300 and -369-3p located at the same chromosomal region (14q32.31) and three upregulated miRNAs such as miR-495-3p, -129-5p, and -7-2$3 p$ at distant chromosomal regions (14q32.31,7q22.1, and 15q26.1, respectively) had the highest number of enriched targets. Our study unveiled four major categories of pathways and biological processes (pathways in cancer, MAPK signalling pathway, endocytosis, and axon guidance) as those enriched by both downregulated and upregulated miRNAs. PI3K-Akt signalling pathway was notably targeted by only downregulated miRNAs, which is in accordance with the activation of PI3K and Akt by postprandial triglyceride-rich lipoproteins containing SFAs in human vascular smooth muscle cells [64]. The PI3K-Akt signalling pathway is frequently involved in cell proliferation, survival, migration, autophagy, and oxidative status [65]. The main enriched KEGG pathway categories impacted by only upregulated miRNAs were focal adhesion, Wnt signalling pathway, transcriptional misregulation in cancer, and ubiquitin-mediated proteolysis. Integrative focal adhesion and wnt/beta-catenin signalling pathways predicted by miRNAs have been involved in artery ischemia, brain injury, and metastasis [66]. Dysregulation of the ubiquitin-proteasome pathway by miRNAs has been shown to result in uncontrolled proliferation and genomic instability [67]. 
The conclusions that are drawn from the current study are limited by the small sample size and will need to be confirmed in large-scale studies. Nevertheless, the study illustrates miRNA profile differences between fasting and postprandial states by a within-subject study design that enabled the subjects to act as their own control.

In summary, we herein propose that dietary SFAs could be pivotal molecular players in acutely regulating a wide spectrum of miRNAs associated with human pathophysiology, including cancer, atherosclerosis, inflammation, immunity, epigenetic, and neural regulation. These findings on miRNA biogenesis also suggest that miRNAs may serve as biomarkers of fasting and non-fasting status, even of compliance for assessing dietary SFA intake. However, more in-depth studies are still warranted to provide further understanding of how dietary fatty acids, including others than SFAs, may cause miRNA dysregulation and this may serve to orchestrate biological processes and regulatory functions during the postprandial state, that is, each time we eat. Whether miRNAs in concert with such repetitive spikes of exogenous lipids may have consequences on any disease progression, particularly in people who suffer from pathologically exacerbated and delayed postprandial responses will be of future interest.

\section{REFERENCES}

[1] Nakamura K, Miyoshi T, Yunoki K, Ito H. Postprandial hyperlipidemia as a potential residual risk factor. J Cardiol 2016;67:335-9.

[2] Nordestgaard BG. Triglyceride-rich lipoproteins and atherosclerotic cardiovascular disease: new insights from epidemiology, genetics, and biology. Circ Res 2016;118,547-63. 
[3] Manochehri M, Moghadam AJ. Studying the relation of postprandial triglyceride with coronary artery disease (CAD). Med Arch 2016;70,261-4.

[4] Tabas I, Bornfeldt KE. Macrophage phenotype and function in different stages of atherosclerosis. Circ Res 2016;118,653-67.

[5] Varela LM, Ortega-Gomez A, Lopez S, Abia R, Muriana FJ, Bermudez B. The effects of dietary fatty acids on the postprandial triglyceride-rich lipoprotein/apoB48 receptor axis in human monocyte/macrophage cells. J Nutr Biochem 2013;24,20319.

[6] Varela LM, Ortega A, Bermudez B, Lopez S, Pacheco YM, Villar J, Abia R, Muriana FJ. A high-fat meal promotes lipid-load and apolipoprotein B-48 receptor transcriptional activity in circulating monocytes. Am J Clin Nutr 2011;93,918-25. [7] Catalanotto C, Cogoni C, Zardo G. MicroRNA in control of gene expression: an overview of nuclear functions. Int J Mol Sci 2016;17,E1712.

[8] Lee S, Vasudevan S. Post-transcriptional stimulation of gene expression by microRNAs. Adv Exp Med Biol 2013;768,97-126.

[9] Rottiers V, Näär AM. MicroRNAs in metabolism and metabolic disorders. Nat Rev Mol Cell Biol 2012;13,239-50.

[10] Arner P, Kulyté A. MicroRNA regulatory networks in human adipose tissue and obesity. Nat Rev Endocrinol 2015;11,276-88.

[11] Gao Y, Peng J, Ren Z, He NY, Li Q, Zhao XS, Wang MM, Wen HY, Tang ZH, Jiang ZS, Wang GX, Liu LS. Functional regulatory roles of microRNAs in atherosclerosis. Clin Chim Acta 2016;460,164-71. 
[12] Navickas R, Gal D, Laucevičius A, Taparauskaitè A, Zdanytė M, Holvoet P. Identifying circulating microRNAs as biomarkers of cardiovascular disease: a systematic review. Cardiovasc Res 2016;111,322-37.

[13] Ramalingam S, Subramaniam D, Anant S. Manipulating miRNA expression: a novel approach for colon cancer prevention and chemotherapy. Curr Pharmacol Rep $2015 ; 1,141-53$.

[14] Zampetaki A, Willeit P, Tilling L, Drozdov I, Prokopi M, Renard JM, Mayr A, Weger S, Schett G, Shah A, Boulanger CM, Willeit J, Chowienczyk PJ, Kiechl S, Mayr M. Prospective study on circulating MicroRNAs and risk of myocardial infarction. J Am Coll Cardiol 2012;60,290-9.

[15] Ortega A, Varela LM, Bermudez B, Lopez S, Abia R, Muriana FJ. Dietary fatty acids linking postprandial metabolic response and chronic diseases. Food Funct 2012;3:22-7.

[16] Hammad S, Pu S, Jones PJ. Current evidence supporting the link between dietary fatty acids and cardiovascular disease. Lipids 2016;51,507-17.

[17] Zobel EH, Hansen TW, Rossing P, von Scholten BJ. Global changes in food supply and the obesity epidemic. Curr Obes Rep 2016;5,449-55.

[18] EEC. Commission regulation (EEC) nº 796/02 of 6 May 2002 amending regulation EEC2568/91 on the characteristics of olive oil and olive residue oil and on the relevant methodology analysis. Off J Eur Commun 2002;L128:8-28.

[19] Ritchie ME, Silver J, Oshlack A, Holmes M, Diyagama D, Holloway A, Smyth GK. A comparison of background correction methods for two-colour microarrays. Bioinformatics 2007;23:2700-7. 
[20] Zhao Y, Wang E, Liu H, Rotunno M, Koshiol J, Marincola FM, Landi MT, McShane LM. Evaluation of normalization methods for two-channel microRNA microarrays. J Transl Med 2010;8:69.

[21] Vlachos IS, Kostoulas N, Vergoulis T, Georgakilas G, Reczko M, Maragkakis M, Paraskevopoulou MD, Prionidis K, Dalamagas T, Hatzigeorgiou AG. DIANA miRPath v.2.0: investigating the combinatorial effect of microRNAs in pathways. Nucleic Acids Res 2012;40:W498-504.

[22] Smyth GK. Linear models and empirical bayes methods for assessing differential expression in microarray experiments. Stat Appl Genet Mol Biol 2004;3:Article3.

[23] Barski A, Jothi R, Cuddapah S, Cui K, Roh TY, Schones DE, Zhao K. Chromatin poises miRNA- and protein-coding genes for expression. Genome Res 2009;19:1742-51.

[24] Oliveira RA, Kotadia S, Tavares A, Mirkovic M, Bowlin K, Eichinger CS, Nasmyth K, Sullivan W. Centromere-independent accumulation of cohesin at ectopic heterochromatin sites induces chromosome stretching during anaphase. PLoS Biol 2014;12:e1001962.

[25] Wagschal A, Najafi-Shoushtari SH, Wang L, Goedeke L, Sinha S, deLemos AS, Black JC, Ramírez CM, Li Y, Tewhey R, Hatoum I, Shah N, Lu Y, Kristo F, Psychogios N, Vrbanac V, Lu YC, Hla T, de Cabo R, Tsang JS, Schadt E, Sabeti PC, Kathiresan S, Cohen DE, Whetstine J, Chung RT, Fernández-Hernando C, Kaplan LM, Bernards A, Gerszten RE, Näär AM. Genome-wide identification of microRNAs regulating cholesterol and triglyceride homeostasis. Nat Med 2015;21:1290-7.

[26] McManus DD, Rong J, Huan T, Lacey S, Tanriverdi K, Munson PJ, Larson MG, Joehanes R, Murthy V, Shah R, Freedman JE, Levy D. Messenger RNA and 
MicroRNA transcriptomic signatures of cardiometabolic risk factors. BMC Genomics 2017;18:139.

[27] Mora S, Rifai N, Buring JE, Ridker PM. Fasting compared with nonfasting lipids and apolipoproteins for predicting incident cardiovascular events. Circulation 2008;118:993-1001.

[28] Ogata T, Kagami M. Kagami-Ogata syndrome: a clinically recognizable upd(14)pat and related disorder affecting the chromosome 14q32.2 imprinted region. J Hum Genet 2016;61:87-94.

[29] Benetatos L, Hatzimichael E, Londin E, Vartholomatos G, Loher P, Rigoutsos I, Briasoulis E. The microRNAs within the DLK1-DIO3 genomic region: involvement in disease pathogenesis. Cell Mol Life Sci 2013;70:795-814.

[30] Li H, Fan J, Yin Z, Wang F, Chen C, Wang DW. Identification of cardiac-related circulating microRNA profile in human chronic heart failure. Oncotarget 2016;7:33-45.

[31] Li M, Zhang S, Qiu Y, He Y, Chen B, Mao R, Cui Y, Zeng Z, Chen M. Upregulation of miR-665 promotes apoptosis and colitis in inflammatory bowel disease by repressing the endoplasmic reticulum stress components XBP1 and ORMDL3. Cell Death Dis 2017;8:e2699.

[32] Sun WC, Liang ZD, Pei L. Propofol-induced rno-miR-665 targets BCL2L1 and influences apoptosis in rodent developing hippocampal astrocytes. Neurotoxicology 2015;51:87-95.

[33] Sadeghi M, Ranjbar B, Ganjalikhany MR, Khan F, Schmitz U, Wolkenhauer O, Gupta SK. MicroRNA and transcription factor gene regulatory network analysis reveals key regulatory elements associated with prostate cancer progression. PLoS One 2016;11:e0168760. 
[34] Nygren MK, Tekle C, Ingebrigtsen VA, Mäkelä R, Krohn M, Aure MR, NunesXavier CE, Perälä M, Tramm T, Alsner J, Overgaard J, Nesland JM, Borgen E, Børresen-Dale AL, Fodstad Ø, Sahlberg KK, Leivonen SK. Identifying microRNAs regulating B7-H3 in breast cancer: the clinical impact of microRNA-29c. Br J Cancer 2014;110:2072-80.

[35] Chen J, Sun D, Chu H, Gong Z, Zhang C, Gong B, Li Y, Li N, Jiang L. Screening of differential microRNA expression in gastric signet ring cell carcinoma and gastric adenocarcinoma and target gene prediction. Oncol Rep 2015;33:2963-71.

[36] Zhao L, Zhu J, Zhou H, Zhao Z, Zou Z, Liu X, Lin X, Zhang X, Deng X, Wang R, Chen $\mathrm{H}$, Jin M. Identification of cellular microRNA-136 as a dual regulator of RIG-Imediated innate immunity that antagonizes H5N1 IAV replication in A549 cells. Sci Rep 2015;5:14991.

[37] Gao H, Song X, Kang T, Yan B, Feng L, Gao L, Ai L, Liu X, Yu J, Li H. Long noncoding RNA CRNDE functions as a competing endogenous RNA to promote metastasis and oxaliplatin resistance by sponging miR-136 in colorectal cancer. Onco Targets Ther 2017;10:205-16.

[38] Zhao H, Liu S, Wang G, Wu X, Ding Y, Guo G, Jiang J, Cui S. Expression of miR-136 is associated with the primary cisplatin resistance of human epithelial ovarian cancer. Oncol Rep 2015;33:591-8.

[39] Jeong JY, Kang H, Kim TH, Kim G, Heo JH, Kwon AY, Kim S, Jung SG, An HJ. MicroRNA-136 inhibits cancer stem cell activity and enhances the anti-tumor effect of paclitaxel against chemoresistant ovarian cancer cells by targeting Notch3. Cancer Lett 2017;386:168-78. 
[40] Yan M, Li X, Tong D, Han C, Zhao R, He Y, Jin X. miR-136 suppresses tumor invasion and metastasis by targeting RASAL2 in triple-negative breast cancer. Oncol Rep 2016;36:65-71.

[41] Zhang D, Wang J, Wang Z, Zhang T, Shi P, Wang X, Zhao F, Liu X, Lin X, Pang X. miR-136 modulates TGF- $\beta 1$-induced proliferation arrest by targeting PPP2R2A in keratinocytes. Biomed Res Int 2015;2015:453518.

[42] Ramalingam $P$, Palanichamy JK, Singh A, Das $P$, Bhagat $M$, Kassab MA, Sinha S, Chattopadhyay P. Biogenesis of intronic miRNAs located in clusters by independent transcription and alternative splicing. RNA 2014;20:76-87.

[43] Kato M, Wang M, Chen Z, Bhatt K, Oh HJ, Lanting L, Deshpande S, Jia Y, Lai JY, O'Connor CL, Wu Y, Hodgin JB, Nelson RG, Bitzer M, Natarajan R. An endoplasmic reticulum stress-regulated IncRNA hosting a microRNA megacluster induces early features of diabetic nephropathy. Nat Commun 2016;7:12864.

[44] Stather PW, Sylvius N, Sidloff DA, Dattani N, Verissimo A, Wild JB, Butt HZ, Choke E, Sayers RD, Bown MJ. Identification of microRNAs associated with abdominal aortic aneurysms and peripheral arterial disease. Br J Surg 2015;102:75566.

[45] Deng H, Song Z, Xu H, Deng X, Zhang Q, Chen H, Wang Y, Qin Y, Li Y. MicroRNA-1185 promotes arterial stiffness though modulating VCAM-1 and ESelectin expression. Cell Physiol Biochem 2017;41:2183-93.

[46] Chen X, Xu Y, Liao X, Liao R, Zhang L, Niu K, Li T, Li D, Chen Z, Duan Y, Sun J. Plasma miRNAs in predicting radiosensitivity in non-small cell lung cancer. Tumour Biol 2016;37:11927-36. 
[47] He H, Wang L, Zhou W, Zhang Z, Wang L, Xu S, Wang D, Dong J, Tang C, Tang $\mathrm{H}, \mathrm{Yi} X, \mathrm{Ge} \mathrm{J}$. MicroRNA expression profiling in clear cell renal cell carcinoma: Identification and functional validation of key miRNAs. PLoS One 2015;10:e0125672. [48] Shahar T, Granit A, Zrihan D, Canello T, Charbit H, Einstein O, Rozovski U, Elgavish S, Ram Z, Siegal T, Lavon I. Expression level of miRNAs on chromosome $14 q 32.31$ region correlates with tumor aggressiveness and survival of glioblastoma patients. J Neurooncol 2016;130:413-22.

[49] He FY, Liu HJ, Guo Q, Sheng JL. Reduced miR-300 expression predicts poor prognosis in patients with laryngeal squamous cell carcinoma. Eur Rev Med Pharmacol Sci 2017;21:760-4.

[50] Nguyen PN, Huang CJ, Sugii S, Cheong SK, Choo KB. Selective activation of miRNAs of the primate-specific chromosome 19 miRNA cluster (C19MC) in cancer and stem cells and possible contribution to regulation of apoptosis. J Biomed Sci 2017;24:20.

[51] Kuo WT, Ho MR, Wu CW, Fang WL, Huang KH, Lin WC. Interrogation of microRNAs involved in gastric cancer using $5 p$-arm and 3p-arm annotated microRNAs. Anticancer Res 2015;35:1345-52.

[52] Enes Coşkun M, Kervancıoğlu M, Öztuzcu S, Yılmaz Coşkun F, Ergün S, Başpınar O, Kılınç M, Temel L, Coşkun MY. Plasma microRNA profiling of children with idiopathic dilated cardiomyopathy. Biomarkers 2016;21:56-61.

[53] Olive V, Li Q, He L. mir-17-92: a polycistronic oncomir with pleiotropic functions. Immunol Rev 2013;253:158-66. 
[54] Mu P, Han YC, Betel D, Yao E, Squatrito M, Ogrodowski P, de Stanchina E, D'Andrea A, Sander C, Ventura A. Genetic dissection of the miR-17 92 cluster of microRNAs in Myc-induced B-cell lymphomas. Genes Dev 2009;23:2806-11.

[55] Sand M, Hessam S, Amur S, Skrygan M, Bromba M, Stockfleth E, Gambichler T, Bechara FG. Expression of oncogenic miR-17-92 and tumor suppressive miR-143145 clusters in basal cell carcinoma and cutaneous squamous cell carcinoma. J Dermatol Sci 2017;86:142-8.

[56] Mei Z, Chen S, Chen C, Xiao B, Li F, Wang Y, Tao Z. Interleukin-23 facilitates thyroid cancer cell migration and invasion by inhibiting SOCS4 expression via microRNA-25. PLoS One 2015;10:e0139456.

[57] Khuu C, Sehic A, Eide L, Osmundsen H. Anti-proliferative properties of miR-20b and miR-363 from the miR-106a-363 cluster on human carcinoma cells. Microrna 2016;5:19-35.

[58] Ortega FJ, Cardona-Alvarado MI, Mercader JM, Moreno-Navarrete JM, Moreno M, Sabater M, Fuentes-Batllevell N, Ramírez-Chávez E, Ricart W, Molina-Torres J, Pérez-Luque EL, Fernández-Real JM. Circulating profiling reveals the effect of a polyunsaturated fatty acid-enriched diet on common microRNAs. J Nutr Biochem 2015;26:1095-101.

[59] Liu F, Li R, Zhang Y, Qiu J, Ling W. Association of plasma MiR-17-92 with dyslipidemia in patients with coronary artery disease. Medicine (Baltimore) 2014;93:e98.

[60] Montserrat-de la Paz S, Bermudez B, Cardelo MP, Lopez S, Abia R, Muriana FJ. Olive oil and postprandial hyperlipidemia: implications for atherosclerosis and metabolic syndrome. Food Funct 2016;7:4734-44. 
[61] Portius D, Sobolewski C, Foti M. MicroRNAs-dependent regulation of PPARs in metabolic diseases and cancers. PPAR Res 2017;2017:7058424.

[62] Bermudez B, Lopez S, Varela LM, Ortega A, Pacheco YM, Moreda W, MorenoLuna R, Abia R, Muriana FJ. Triglyceride-rich lipoprotein regulates APOB48 receptor gene expression in human THP-1 monocytes and macrophages. J Nutr $2012 ; 142: 227-32$

[63] Varela LM, Lopez S, Ortega-Gomez A, Bermudez B, Buers I, Robenek H, Muriana FJ, Abia R. Postprandial triglyceride-rich lipoproteins regulate perilipin-2 and perilipin-3 lipid-droplet-associated proteins in macrophages. J Nutr Biochem 2015;26:327-36.

[64] Varela LM, Bermudez B, Ortega-Gomez A, Lopez S, Sanchez R, Villar J, Anguille C, Muriana FJ, Roux P, Abia R. Postprandial triglyceride-rich lipoproteins promote invasion of human coronary artery smooth muscle cells in a fatty-acid manner through PI3k-Rac1-JNK signaling. Mol Nutr Food Res 2014;58:1349-64.

[65] Faes S, Dormond O. PI3K and AKT: Unfaithful partners in cancer. Int J Mol Sci $2015 ; 16: 21138-52$

[66] Zhuang Y, Peng H, Mastej V, Chen W. MicroRNA regulation of endothelial junction proteins and clinical consequence. Mediators Inflamm 2016;2016:5078627. [67] Cao J, Ge MH, Ling ZQ. Fbxw7 tumor suppressor: A vital regulator contributes to human tumorigenesis. Medicine (Baltimore) 2016;95:e2496. 


\section{LEGENDS TO FIGURES}

Figure 1. A) Box-and-whisker plots of serum triglyceride concentrations at fasting and after the ingestion of a high-saturated fat meal in male healthy individuals ( $n=$ 9). B) Hierarchical clustering of postprandially changed (downregulated and upregulated) miRNAs. Colours represent the intensity value of each miRNA at fasting and at postprandial. C) Volcano plot of detectable miRNAs. The x-axis shows the $\log _{2}$ fold change in miRNAs' expression between fasting and postprandial, while the $y$-axis shows the $-\log _{10}$ of the adjusted $p$-value for each miRNA. D) Description of the number of downregulated (green) and upregulated (orange) miRNAs that are represented in B and the number of these miRNA that are represented in C.

Figure 2. A) Heatmap expression of total miRNAs from fasting ( $F$, red) and postprandial (P, black) samples \#1, 2, 3, and 4. B) Three-dimensional hierarchical cluster analysis for the principal components performed after correspondence analysis (COA). Colours represent the intensity value of each miRNA at fasting and at postprandial. C) Two-dimensional factorial representation of the COA with means of the clusters. D) Scatter plot of miRNA data by principal component analysis.

Figure 3. Chromosome localization of the downregulated (green) and upregulated (orange) miRNAs in the postprandial state when compared to the fasting state.

Figure 4. Genomic representation of dysregulated miRNAs encoded in clusters or in paralogous groups. A) Organization of precursors and mature forms of affected miRNAs. Two types of paralogous groups of miR-30 and -181 precursors can be 
identified: miR-30b, -181a-2/c (light green) and miR-30d, -181b-2/d (brown). The names of miRNA precursors are denoted below de boxes. The positions of mature miRNAs are indicated by coloured boxes (aero, yellow, cyan) with labels (5p: $5 p$ specie, 3p: 3p specie, asterisk: one arm of the hairpin) written above. Green, orange or black label means decreased, increased, or not changed expression, respectively. B) Sequence alignment of mature miRNA members of the miR-17/92a-1 cluster and its two paralogous miR-106b/25 and $-106 a / 363$ that were dysregulated. Conservation of each nucleotide position is denoted by the colour according to ClustalW software.

Figure 5. KEGG pathways enriched by the target genes of the downregulated (green) and upregulated (orange) miRNAs in the postprandial state when compared to the fasting state. The number of dysregulated miRNAs involved in each KEGG pathway is indicated in brackets. 
A

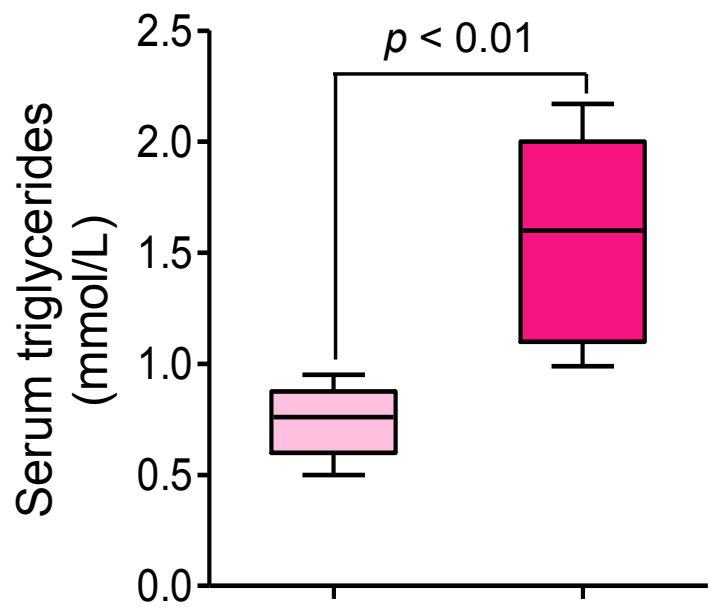

Fasting Postprandial

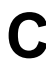

37 Postprandial vs fasting miR-613 miR-629-3p

$\frac{\widehat{d}}{\frac{2}{\sigma}}$

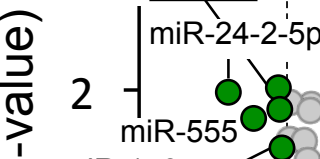
궁 miR-148a-5p

1

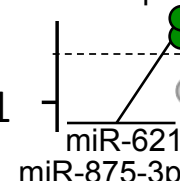
miR-513c-5p miR-1226-3p

0

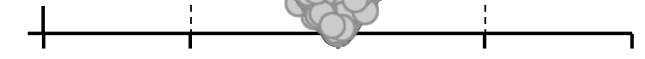
$-0,5$
$-0,25$
0
$0,25 \quad 0,5$

$\log _{2}$ (fold change)

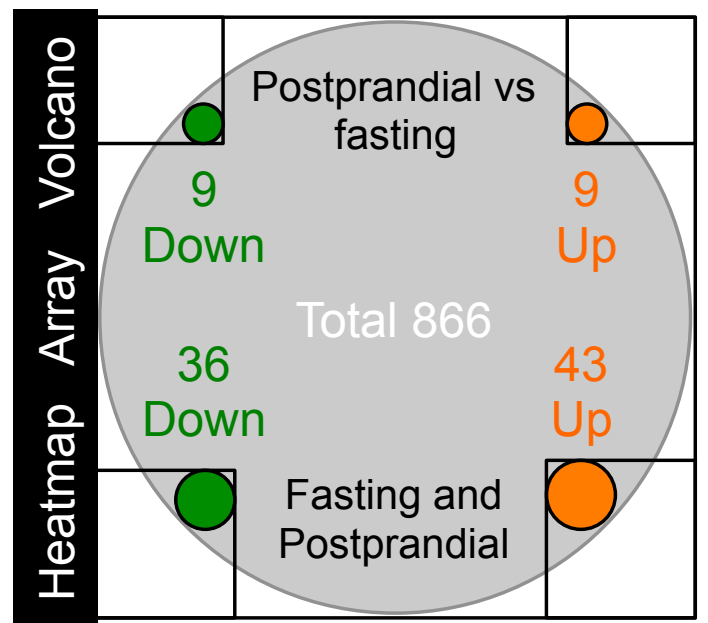

Downregulated miRNAs

Fasting Postprandial

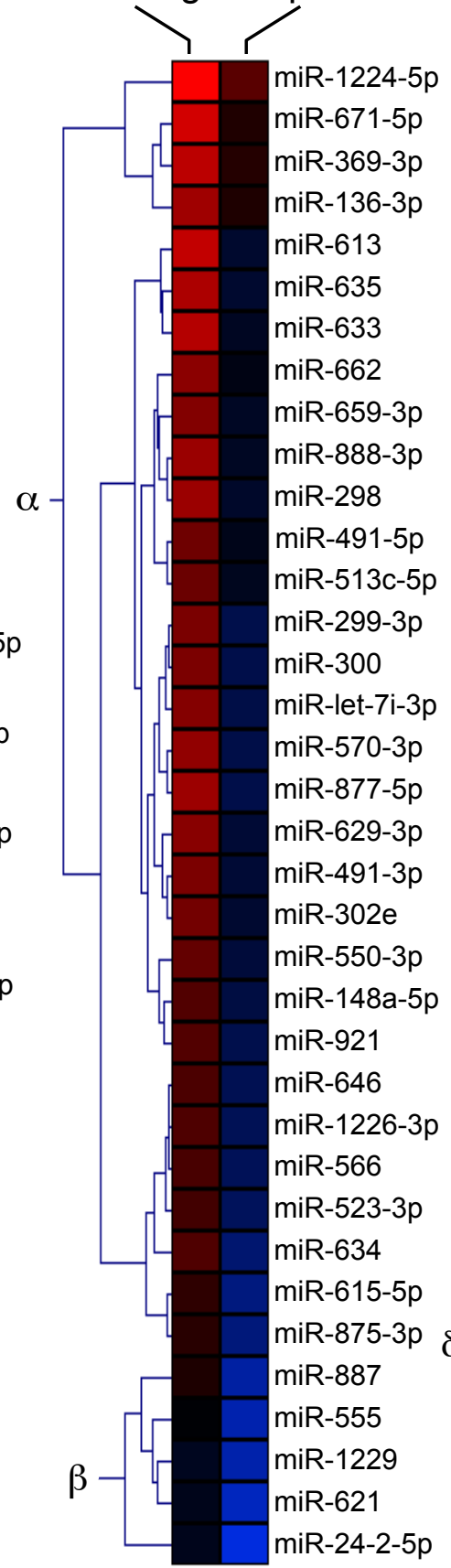

Mean signal intensity

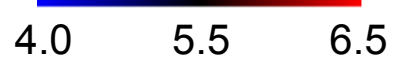

\section{Upregulated} miRNAs

Fasting Postprandial miR-19b-1-5p miR-339-3p miR-138-1-3p miR-647 miR-363-5p miR-1468 miR-181c-3p miR-593-5p miR-200b-5p miR-148b-5p miR-885-3p miR-653 miR-802 miR-297 miR-588 miR-1237 miR-632 miR-1286 miR-941 miR-411-3p miR-7-2-3p miR-30d-3p miR-649 miR-616-3p miR-519d miR-665 miR-518c-3p miR-129-5p miR-599 miR-143-3p miR-519e-3p miR-1185-5p miR-18a-3p miR-562 miR-146a-3p miR-938 miR-30b-3p miR-138-2-3p miR-25-5p miR-495-3p miR-875-5p miR-26b-3p miR-181a-2-3p 

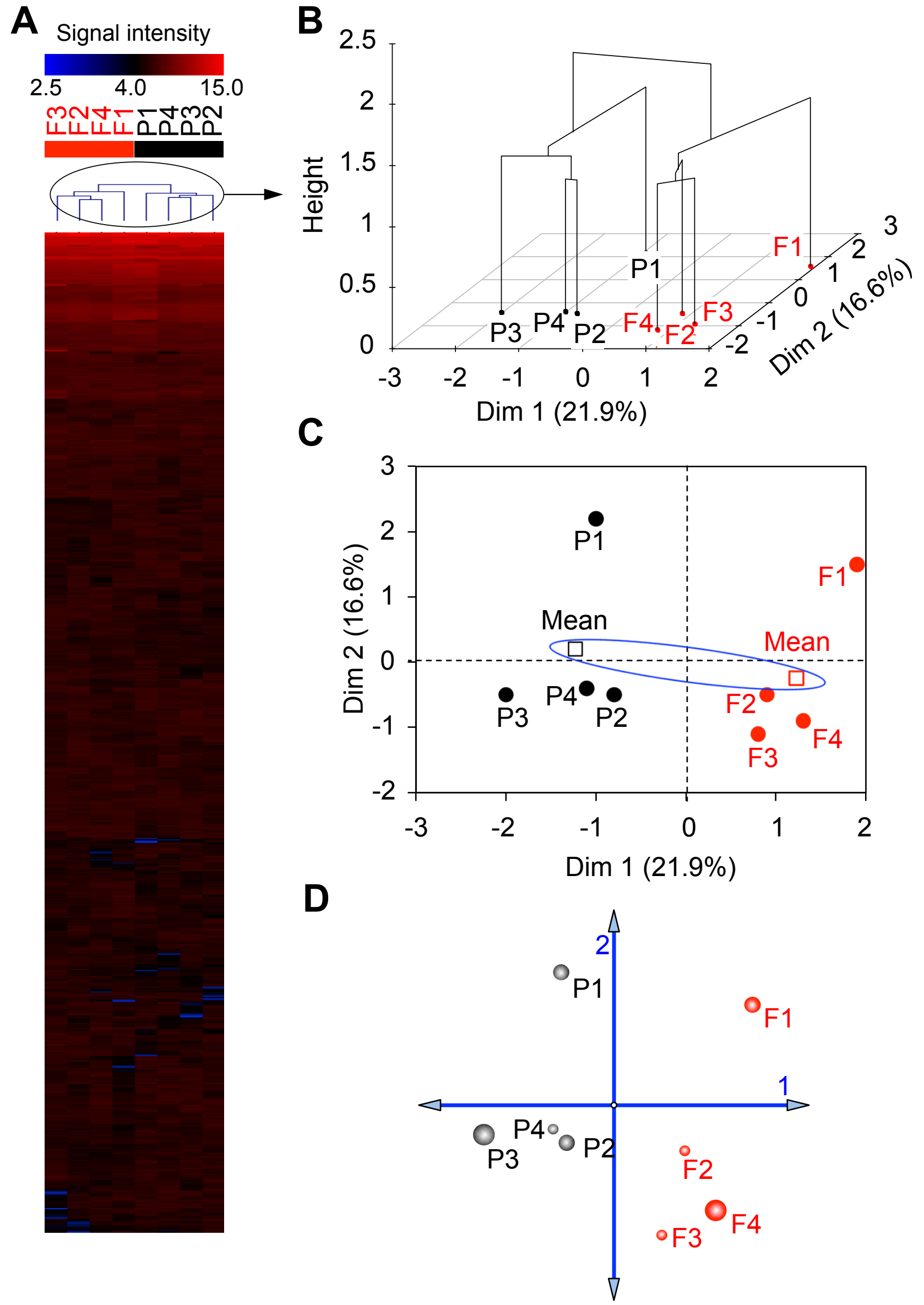

Figure 2 

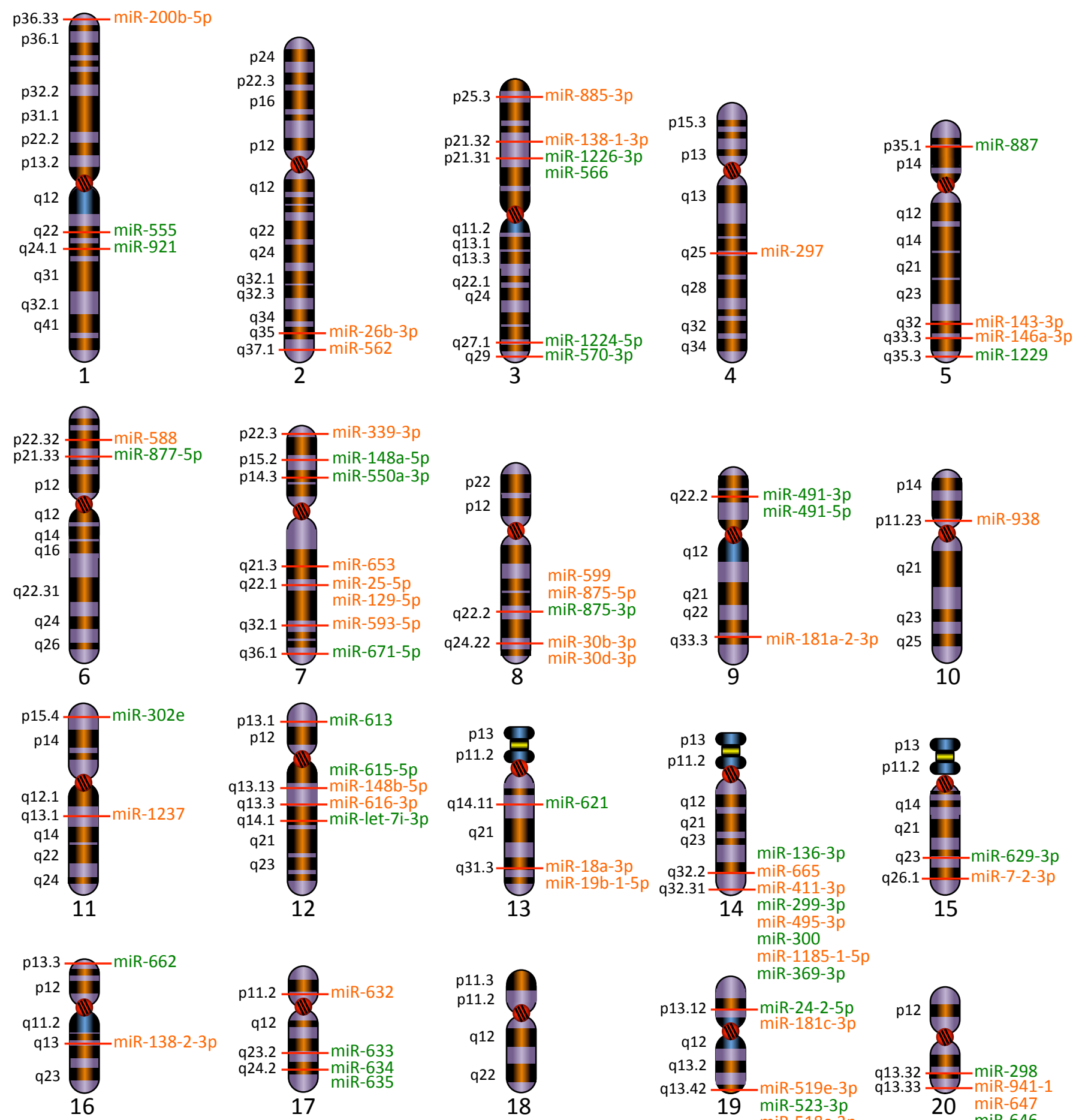
miR-300
miR-1185-1-5p
miR-369-3p
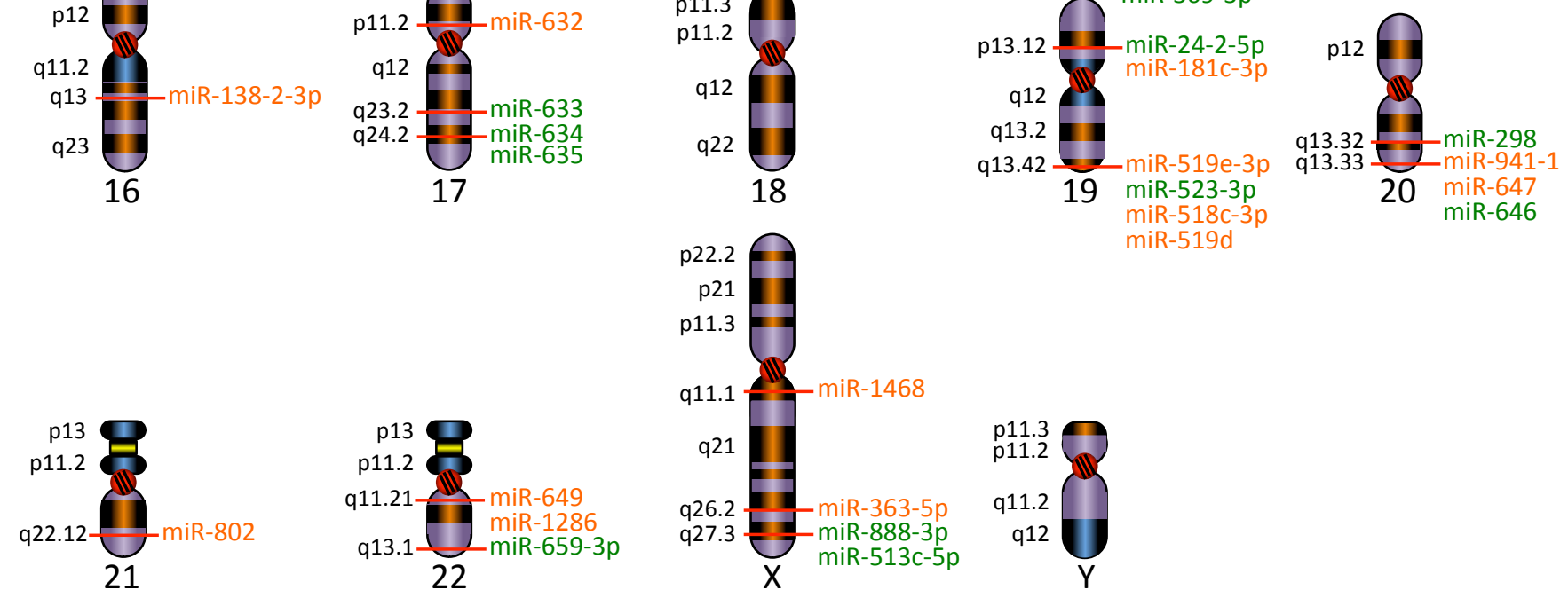

Figure 3 
A

Chr 8q22.2

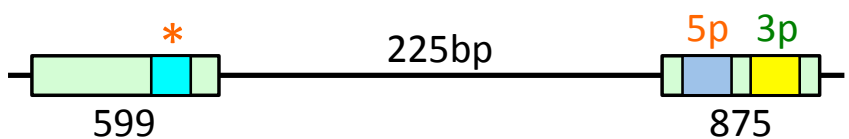

Chr 8q24.22

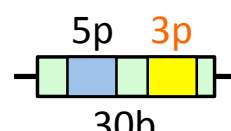

$\leftarrow 4425 \mathrm{bp} \rightarrow$

$30 \mathrm{~b}$

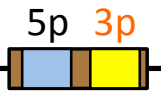

$30 \mathrm{~d}$

Chr 9q33.3

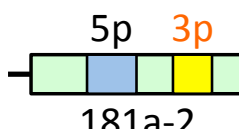

$\leftarrow 1159 \mathrm{bp} \rightarrow$

$5 p$

181b-2

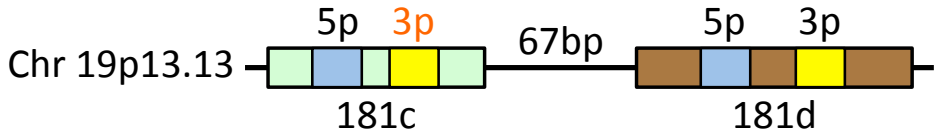

Chr 13q31.3

$\underset{-18 a}{5 p \quad 3 p}$

371bp

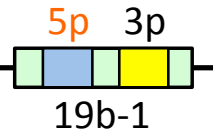

Chr 14q32.2

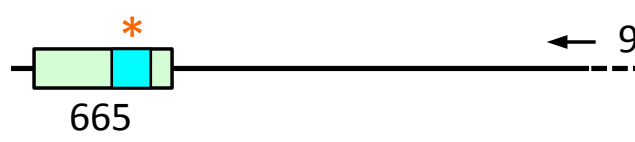

9598bp

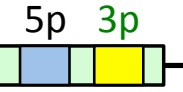
136

Chr 14q32.31
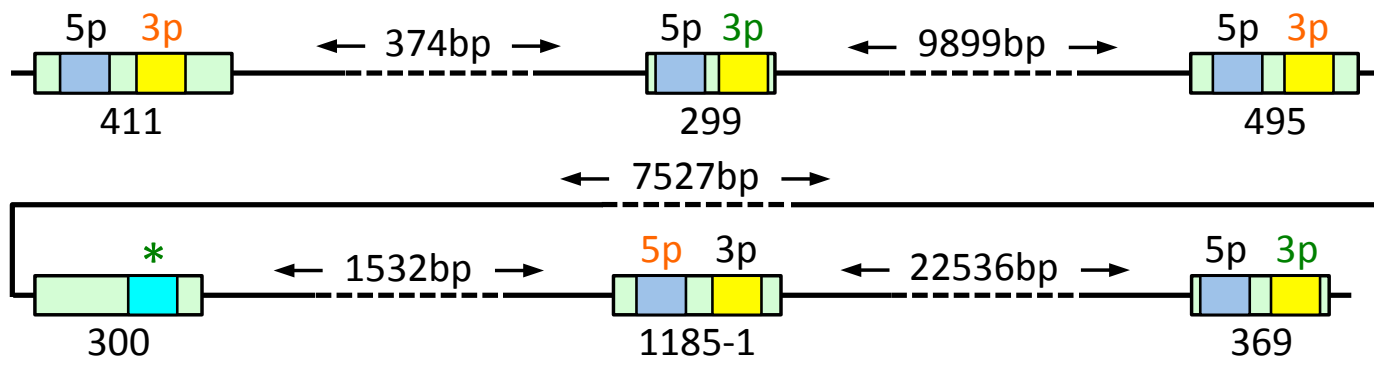

$\leftarrow 7527 \mathrm{bp} \rightarrow$

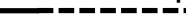

Chr 19p13.42
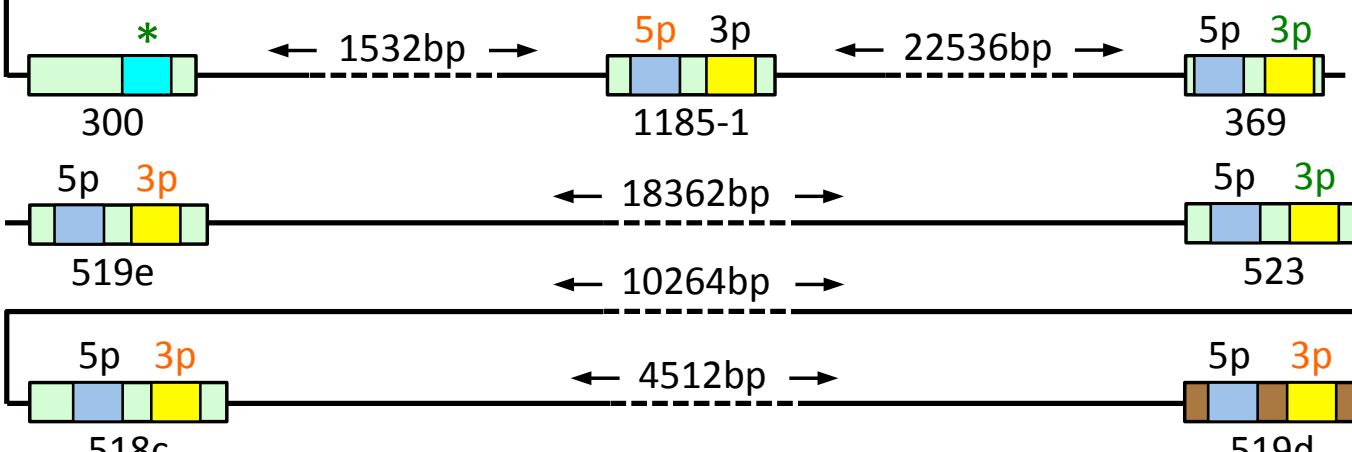

Chr 3p21.32

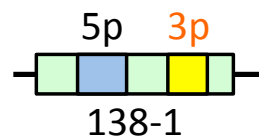

B

\section{miRNA}

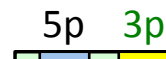

523

$\leftarrow 10264 \mathrm{bp}$

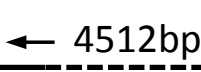

$5 p$

519d

Chr 16q13

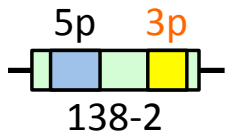

Chr 7p15.2 $-\frac{5 p \quad 3 p}{-148 a}-$

Chr 12q13.13 - $\frac{5 p \quad 3 p}{148 b}$

18a-3p - - - - A CUGCC CUAAGUGCUCCUUCUGG 19b-1-5p AGUUUUG CAGGUUUG CAUCCAGC---- 25-5p AGG--CGGAGA CUUGGG--CAAUUG-- - [363-5p CGG---GUGGAUCA CGAUGCAAUUU----

\section{Cluster}

$10 \rightarrow$

- 17/92a-1

$-106 \mathrm{~b} / 25$

$106 a / 363$

Figure 4 


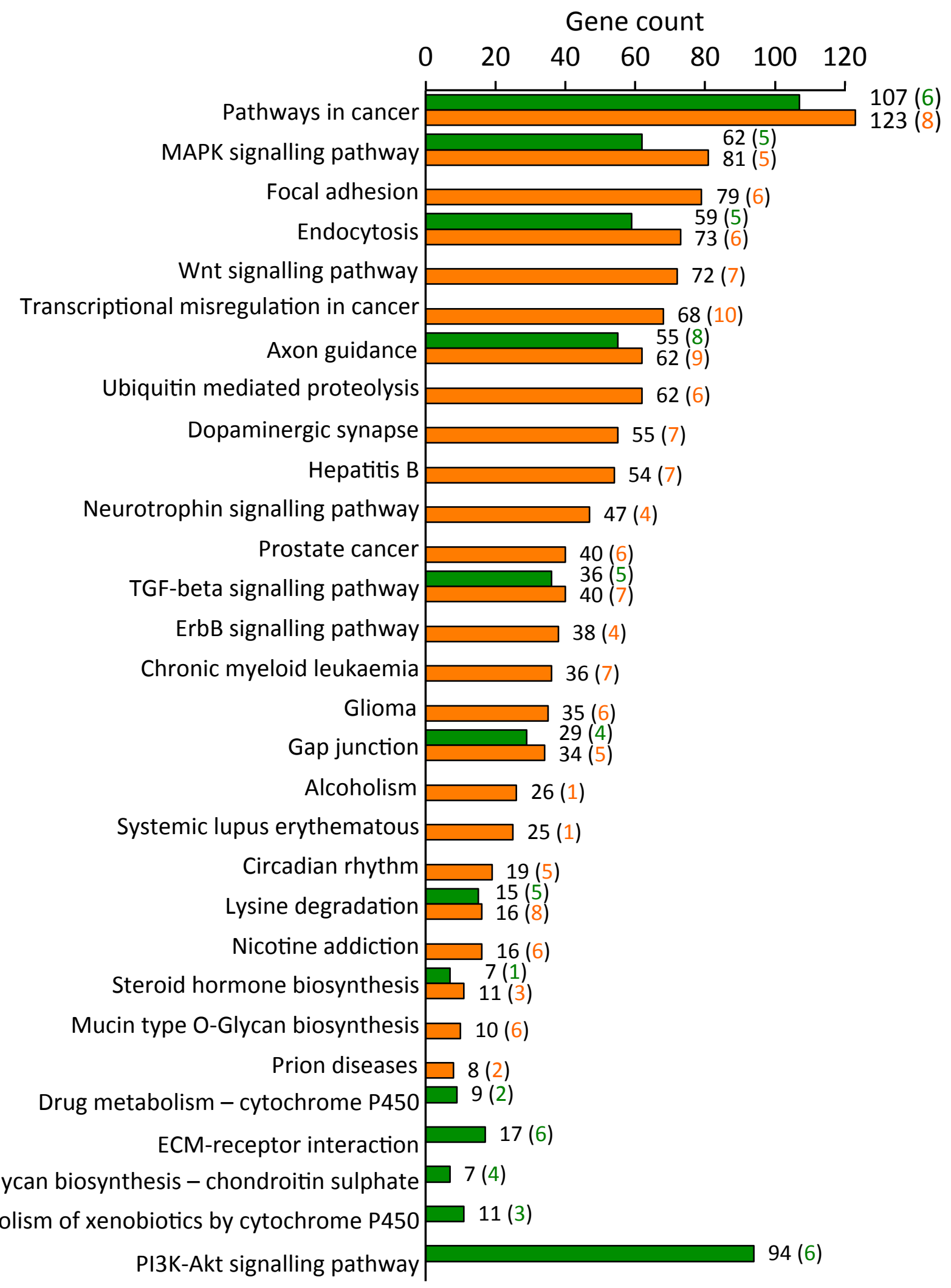




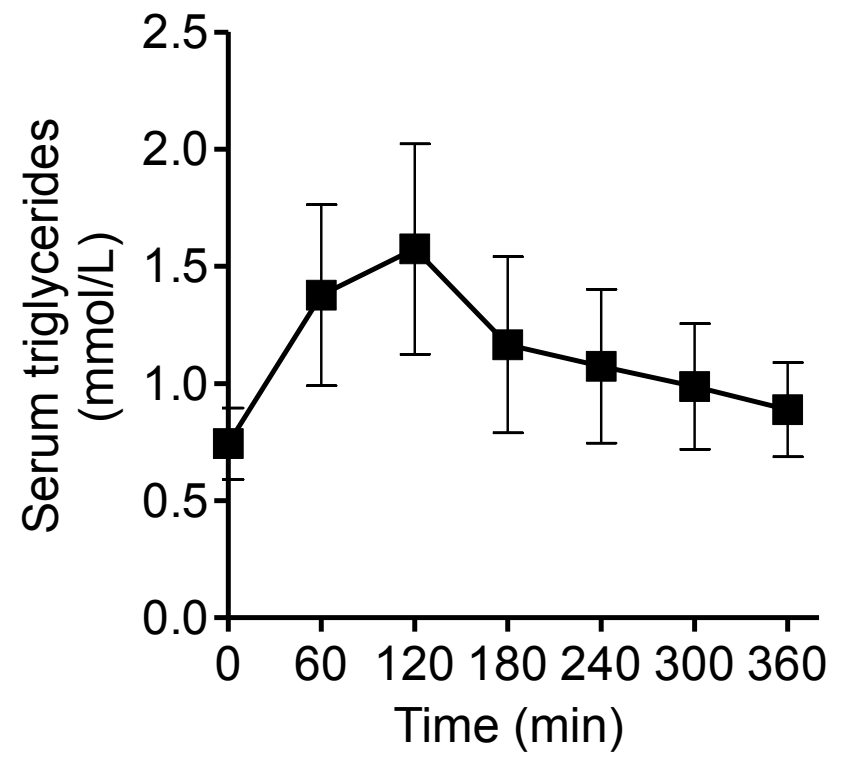

Figure S1. Mean $( \pm S D)$ serum triglyceride concentration during the test meal enriched in saturated fatty acids in male healthy individuals, $n=9$. 


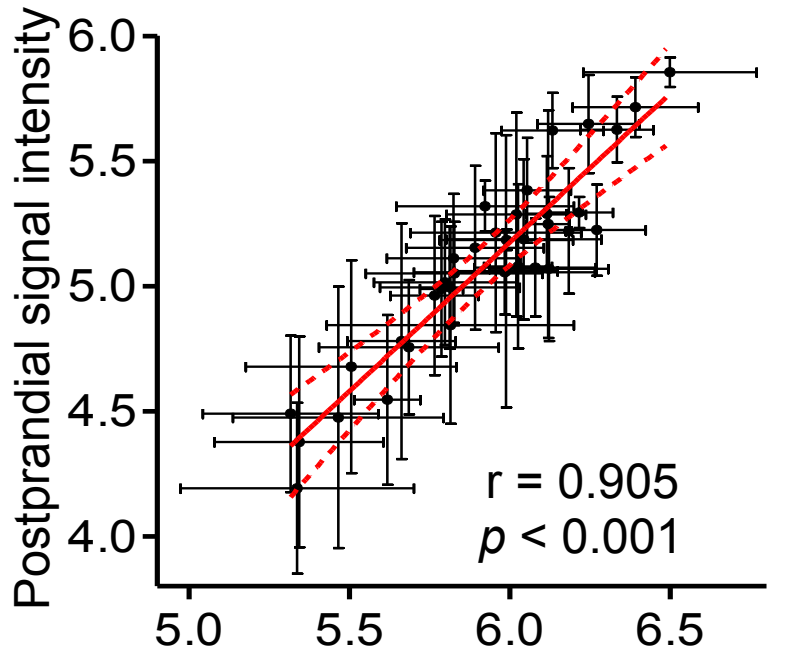

Fasting signal intensity

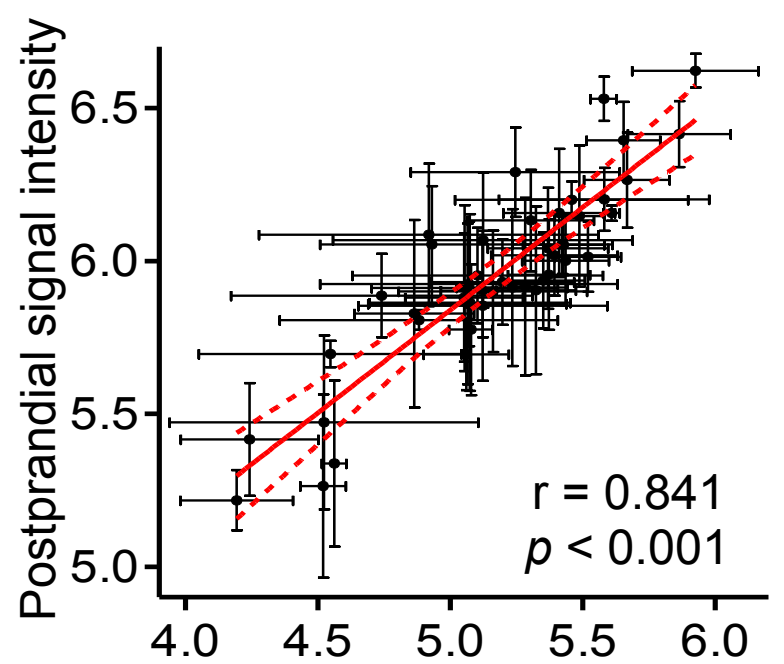

Fasting signal intensity

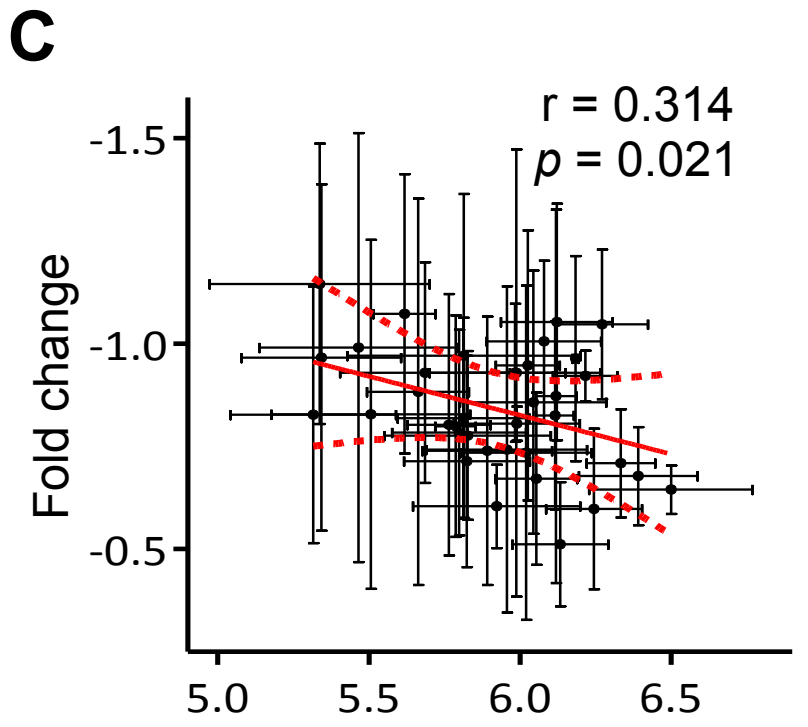

Fasting signal intensity

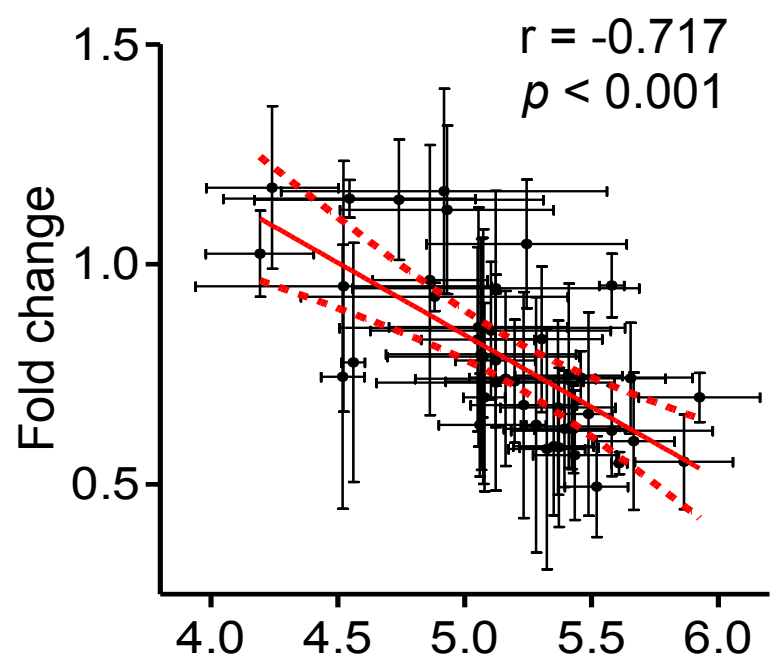

Fasting signal intensity

Figure S2. Pearson correlation analysis of fasting vs postprandial intensity values of upregulated $(\mathrm{A})$ and downregulated $(\mathrm{B})$ miRNAs, and fasting intensity values vs fold change of upregulated (C) and dowregulated (D) miRNAs. 
Table 1. Subject characteristics.

\begin{tabular}{lc}
\hline Characteristic & \\
\hline Age $(\mathrm{y})$ & $20.3 \pm 1.5$ \\
Weight $(\mathrm{kg})$ & $72.2 \pm 6.4$ \\
Waist $(\mathrm{m})$ & $0.9 \pm 0.2$ \\
Hip $(\mathrm{m})$ & $0.9 \pm 0.2$ \\
Body mass index $\left(\mathrm{kg} / \mathrm{m}^{2}\right)$ & $22.9 \pm 1.9$ \\
Fasting glucose $(\mathrm{mmol} / \mathrm{L})$ & $4.3 \pm 0.5$ \\
Fasting total cholesterol $(\mathrm{mmol} / \mathrm{L})$ & $3.7 \pm 0.5$ \\
Fasting LDL-cholesterol & $2.0 \pm 0.5$ \\
Fasting HDL-cholesterol & $1.3 \pm 0.2$ \\
Fasting triglycerides $(\mathrm{mmol} / \mathrm{L})$ & $0.8 \pm 0.3$ \\
\hline
\end{tabular}

Data are expressed as mean $\pm \operatorname{SD}(n=9)$. 
Table 2. Fatty acid composition of the milk cream.

\begin{tabular}{lc}
\hline Fatty acid & \\
\hline $4: 0$, butyric & $0.83 \pm 0.16$ \\
$6: 0$, caproic & $0.25 \pm 0.02$ \\
8:0, caprylic & $0.61 \pm 0.07$ \\
10:0, capric & $2.47 \pm 0.13$ \\
12:0, lauric & $3.09 \pm 0.42$ \\
14:0, myristic & $10.9 \pm 0.91$ \\
16:0, palmitic & $35.50 \pm 0.82$ \\
$16: 1 \omega-7$, palmitoleic & $3.60 \pm 0.32$ \\
$18: 0$, stearic & $11.54 \pm 0.75$ \\
18:1 $\omega-9$, oleic & $25.33 \pm 0.71$ \\
18:2 $\omega-6$, linoleic & $4.27 \pm 0.82$ \\
$18: 3 \omega-3, \alpha-$ linolenic & $0.39 \pm 0.05$ \\
Others & $0.96 \pm 0.42$ \\
Saturated fatty acids & $65.19 \pm 5.12$ \\
Monounsaturated fatty acids & $28.93 \pm 1.34$ \\
Polyunsaturated fatty acids & $4.66 \pm 0.56$ \\
\hline
\end{tabular}

Data are expressed as mean \pm SD ( $n=3$ samples of the same lot). 
Table 3. Validation of microarray data by qRT-PCR analysis.

\begin{tabular}{lcc}
\hline \multirow{2}{*}{ hsa-miRNA } & Array & Fluidigm-qRT-PCR \\
\cline { 2 - 3 } & Fold change & Fold change \\
\hline miR-629-3p & $-0.26 \pm 0.15$ & $-1.18 \pm 0.20$ \\
miR-24-2-5p & $-0.35 \pm 0.21$ & $-1.21 \pm 0.27$ \\
miR-555 & $-0.32 \pm 0.11$ & $-0.78 \pm 0.21$ \\
miR-621 & $-0.31 \pm 0.23$ & $-0.82 \pm 0.24$ \\
miR-653 & $0.31 \pm 0.17$ & $1.41 \pm 0.28$ \\
miR-363-5p & $0.35 \pm 0.22$ & $0.97 \pm 0.20$ \\
miR-593-5p & $0.28 \pm 0.13$ & $1.64 \pm 0.36$ \\
miR-200b-5p & $0.26 \pm 0.10$ & $2.54 \pm 0.47$ \\
miR-103-3p & $-0.01 \pm 0.03$ & $0.05 \pm 0.07$ \\
miR-16 & $0.00 \pm 0.04$ & $0.03 \pm 0.04$ \\
\hline
\end{tabular}

Data are expressed as mean $\pm \mathrm{SD}(n=9)$. 
Table 4. The 35 dysregulated miRNAs that were distributed either individually or grouped within chromosome cluster regions.

\begin{tabular}{|c|c|c|c|c|}
\hline Cluster & Chromosome & miRNA cluster & miRNAs dysregulated in postprandial vs basal PBMCs & miRNA gene family \\
\hline & Chr 1p36.33 & $\mathrm{miR}-200 \mathrm{~b} / 429$ (3) & miR-200b-5p & $\mathrm{miR}-8$ \\
\hline & Chr $5 q 32$ & $\operatorname{miR}-143 / 145(2)$ & $\operatorname{miR}-143-3 p$ & miR-143 \\
\hline & Chr $7 q 21.3$ & miR-489/653 (2) & miR-653 & miR-653 \\
\hline & Chr 7q22.1 & $\mathrm{miR}-106 \mathrm{~b} / 25(3)$ & miR-25-5p & miR-25 \\
\hline 1 & Chr 8q22.2 & miR-875/599 (2) & miR-875-5pa, miR-875-3pa, miR-599b & miR-875a, miR-599b \\
\hline \multirow[t]{3}{*}{2} & Chr 8q24.22 & $\mathrm{miR}-30 \mathrm{~d} / 30 \mathrm{~b}(2)$ & miR-30d-3p, miR-30b-3p & $\operatorname{miR}-30$ \\
\hline & Chr 9q33.3 & miR-181a-2/181b-2 (2) & miR-181a-2-3p & miR-181 \\
\hline & Chr $12 q 13.3$ & miR-616/6758 (2) & miR-616-3p & miR-616 \\
\hline 3 & Chr $13 q 31.3$ & $\operatorname{miR}-17 / 92 a-1(6)$ & miR-18a-3pa, miR-19b-1-5pb & $\operatorname{miR}-17^{a}, \operatorname{miR}-19^{b}$ \\
\hline 4 & Chr 14q32.2 & $\mathrm{miR}-665 / 136(6)$ & miR-665a miR-136-3p & $\operatorname{miR}-665^{a}, \mathrm{miR}-136^{\mathrm{b}}$ \\
\hline $5^{*}$ & Chr 14q32.31 & miR-379/495 (13) & miR-411-3pa, miR-299-3pb, miR-495-3pc & miR-379a $, m i R-299^{b}, m_{i R}-329^{c}$ \\
\hline \multirow[t]{7}{*}{$6^{*}$} & Chr 14q32.31 & miR-299/1185-1 (18) & 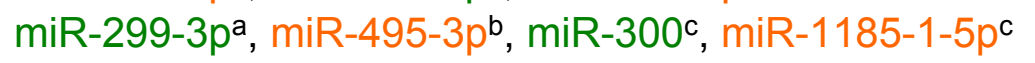 & $\operatorname{miR}-299^{a}, \mathrm{miR}-329^{b}, \mathrm{miR}-154^{c}$ \\
\hline & Chr 14q32.31 & miR-323b/656 (10) & miR-369-3p & $\operatorname{miR}-154$ \\
\hline & Chr $15 q 26.1$ & miR-1179/3529 (3) & miR-7-2-3p & $\operatorname{miR}-7$ \\
\hline & Chr 19p13.12 & miR-23a/24-2 (3) & miR-24-2-5p & miR-24 \\
\hline & Chr 19p13.12 & miR-181c/118d (2) & $\operatorname{miR}-181 c-3 p$ & miR-181 \\
\hline & Chr 19q13.42 & miR-1323/1283-1 (9) & $\operatorname{miR}-519 e-3 p$ & $\operatorname{miR}-515$ \\
\hline & Chr 19q13.42 & miR-1283-1/520c (11) & miR-523-3p & miR-515 \\
\hline \multirow[t]{8}{*}{7} & Chr 19q13.42 & miR-518f/521-2 (10) & miR-518c-3pa, miR-519da & $\operatorname{miR}-515^{a}$ \\
\hline & Chr 20q13.32 & miR-298/296 (2) & $\operatorname{miR}-298$ & miR-298 \\
\hline & Chr 20q13.33 & miR-941-1/941-5 (5) & miR-941-1 & miR-941 \\
\hline & Chr 20q13.33 & miR-647/1914 (2) & miR-647 & miR-647 \\
\hline & Chr 22q13.1 & miR-659/658 (2) & miR-659-3p & $?$ \\
\hline & Chr Xq26.2 & $\mathrm{miR}-106 a / 363(6)$ & miR-363-5p & miR-363 \\
\hline & Chr Xq27.3 & miR-891b/892c (6) & miR-888-3p & miR-743 \\
\hline & Chr Xq27.3 & miR-513b/513c (2) & $\operatorname{miR}-513 c-5 p$ & miR-506 \\
\hline
\end{tabular}

Cluster genes that share miRNAs are indicated with asterisks. The number of members in each miRNA cluster ( $<10 \mathrm{~kb})$ is indicated in

brackets. The same lowercase superscript letter is used to indicate membership of each miRNA with its corresponding miRNA gene family.

Downregulated miRNAs are depicted in green colour, while upregulated miRNAs in orange colour. 

Table S1. Detected miRNAs in PBMCs of healthy volunteers at fasting and after the ingestion of a standardized high-saturated fat meal.

\begin{tabular}{lcccc}
\hline & At fasting & \multicolumn{2}{c}{ At postprandial } \\
\cline { 2 - 5 } miRNA & Signal intensity & SD & Signal intensity & SD \\
\hline hsa-let-7a-5p & 12.20 & 0.18 & 12.24 & 0.23 \\
hsa-let-7a-3p & 6.27 & 0.18 & 5.73 & 0.48 \\
hsa-let-7b-5p & 10.08 & 0.31 & 10.18 & 0.38 \\
hsa-let-7b-3p & 5.54 & 0.33 & 5.97 & 0.55 \\
hsa-let-7c-5p & 9.25 & 0.25 & 9.33 & 0.31 \\
hsa-let-7c-3p & 6.16 & 0.25 & 5.39 & 0.65 \\
hsa-let-7d-5p & 10.46 & 0.16 & 10.59 & 0.34 \\
hsa-let-7d-3p & 5.41 & 0.45 & 5.76 & 0.88 \\
hsa-let-7e-5p & 6.92 & 0.36 & 6.63 & 0.37 \\
hsa-let-7e-3p & 5.12 & 0.80 & 5.52 & 0.83 \\
hsa-let-7f-1-5p & 10.52 & 0.61 & 10.60 & 0.73 \\
hsa-let-7f-1-3p & 5.86 & 0.60 & 5.39 & 0.20 \\
hsa-let-7f-2-3p & 5.54 & 0.34 & 5.85 & 0.25 \\
hsa-let-7g-5p & 12.77 & 0.21 & 12.95 & 0.18 \\
hsa-let-7g-3p & 5.09 & 0.57 & 5.62 & 0.53 \\
hsa-let-7i-5p & 10.69 & 0.25 & 10.46 & 0.21 \\
hsa-let-7i-3p & 5.96 & 0.53 & 5.21 & 0.79 \\
hsa-miR-1-3p & 5.75 & 0.37 & 5.58 & 1.06 \\
hsa-miR-100-5p & 5.79 & 0.48 & 6.04 & 0.15 \\
hsa-miR-100-3p & 5.73 & 0.59 & 5.31 & 0.68 \\
hsa-miR-101-3p & 9.68 & 0.16 & 9.55 & 0.24 \\
hsa-miR-101-5p & 6.01 & 0.54 & 5.77 & 0.51 \\
hsa-miR-103a-3p & 11.60 & 0.14 & 11.53 & 0.23 \\
hsa-miR-103b & 6.16 & 0.53 & 5.70 & 0.29 \\
hsa-miR-105-5p & 5.35 & 0.72 & 6.05 & 0.33 \\
hsa-miR-105-3p & 5.93 & 0.36 & 5.47 & 1.12 \\
hsa-miR-106a-3p & 5.63 & 0.37 & 6.06 & 0.33 \\
hsa-miR-106b-5p & 10.69 & 0.10 & 10.73 & 0.23 \\
hsa-miR-106b-3p & 6.09 & 0.39 & 5.54 & 0.83 \\
hsa-miR-107 & 9.64 & 0.27 & 9.72 & 0.44 \\
hsa-miR-10a-5p & 6.48 & 0.32 & 6.21 & 0.42 \\
hsa-miR-10a-3p & 6.14 & 0.39 & 5.69 & 0.31 \\
hsa-miR-10b-5p & 5.95 & 0.23 & 5.92 & 0.44 \\
hsa-miR-10b-3p & 5.91 & 0.33 & 5.52 & 0.20 \\
hsa-miR-1178-3p & 5.82 & 0.35 & 5.33 & 0.27 \\
hsa-miR-1179 & 6.05 & 0.36 & 5.99 & 0.35 \\
hsa-miR-1180-3p & 5.73 & 0.44 & 5.49 & 0.46 \\
hsa-miR-1181 & 5.95 & 0.44 & 5.48 & 0.31 \\
hsa-miR-1182 & 5.64 & 0.55 & 5.84 & 0.27
\end{tabular}




\begin{tabular}{|c|c|c|c|c|}
\hline hsa-miR-1183 & 6.11 & 0.58 & 5.77 & 0.49 \\
\hline hsa-miR-1184 & 5.42 & 0.46 & 5.63 & 0.58 \\
\hline hsa-miR-1185-5p & 5.52 & 0.25 & 6.01 & 0.23 \\
\hline hsa-miR-1197 & 6.02 & 0.48 & 5.68 & 0.24 \\
\hline hsa-miR-1200 & 5.38 & 0.26 & 5.48 & 0.31 \\
\hline hsa-miR-1201 & 5.99 & 0.41 & 5.76 & 0.48 \\
\hline hsa-miR-1202 & 8.50 & 0.52 & 8.14 & 0.47 \\
\hline hsa-miR-1203 & 5.56 & 0.48 & 5.51 & 0.25 \\
\hline hsa-miR-1204 & 5.46 & 0.25 & 5.87 & 0.37 \\
\hline hsa-miR-1205 & 6.02 & 0.32 & 5.79 & 0.45 \\
\hline hsa-miR-1206 & 5.95 & 0.25 & 6.20 & 0.13 \\
\hline hsa-miR-1207-3p & 5.10 & 0.24 & 4.63 & 0.44 \\
\hline hsa-miR-1207-5p & 8.14 & 0.59 & 8.04 & 0.43 \\
\hline hsa-miR-1208 & 5.55 & 0.79 & 5.93 & 0.50 \\
\hline hsa-miR-122-5p & 6.08 & 0.41 & 5.79 & 0.42 \\
\hline hsa-miR-122-3p & 5.30 & 0.21 & 5.64 & 0.44 \\
\hline hsa-miR-1224-3p & 5.09 & 0.47 & 4.26 & 1.12 \\
\hline hsa-miR-1224-5p & 6.50 & 0.54 & 5.86 & 0.12 \\
\hline hsa-miR-1225-3p & 5.82 & 0.52 & 5.56 & 0.33 \\
\hline hsa-miR-1225-5p & 7.90 & 0.58 & 7.55 & 0.13 \\
\hline hsa-miR-1226-3p & 5.47 & 0.66 & 4.48 & 1.05 \\
\hline hsa-miR-1226-5p & 6.41 & 0.32 & 6.55 & 0.36 \\
\hline hsa-miR-1227-3p & 5.74 & 0.59 & 5.38 & 0.78 \\
\hline hsa-miR-1228-3p & 6.49 & 0.17 & 6.35 & 0.22 \\
\hline hsa-miR-1228-5p & 5.68 & 0.41 & 6.10 & 0.27 \\
\hline hsa-miR-1229-3p & 5.32 & 0.55 & 4.49 & 0.63 \\
\hline hsa-miR-1231 & 5.19 & 0.44 & 5.49 & 0.32 \\
\hline hsa-miR-1233-3p & 5.20 & 0.32 & 5.46 & 0.14 \\
\hline hsa-miR-1234-3p & 6.05 & 0.35 & 6.30 & 0.19 \\
\hline hsa-miR-1236-3p & 5.27 & 0.79 & 5.91 & 0.40 \\
\hline hsa-miR-1237-3p & 5.12 & 0.31 & 5.90 & 0.30 \\
\hline hsa-miR-1238-3p & 6.12 & 0.49 & 6.46 & 0.08 \\
\hline hsa-miR-124-3p & 5.51 & 0.61 & 5.05 & 0.67 \\
\hline hsa-miR-124-5p & 5.36 & 0.61 & 5.79 & 0.47 \\
\hline hsa-miR-1243 & 5.79 & 0.45 & 6.20 & 0.33 \\
\hline hsa-miR-1244 & 5.75 & 0.32 & 6.10 & 0.62 \\
\hline hsa-miR-1245a & 5.84 & 0.22 & 5.54 & 0.39 \\
\hline hsa-miR-1246 & 7.49 & 0.70 & 6.95 & 0.37 \\
\hline hsa-miR-1247-5p & 5.49 & 0.38 & 4.99 & 0.40 \\
\hline hsa-miR-1248 & 6.31 & 0.19 & 5.80 & 0.19 \\
\hline hsa-miR-1249-3p & 5.50 & 0.21 & 5.64 & 0.09 \\
\hline hsa-miR-1250-5p & 5.82 & 0.11 & 5.67 & 0.69 \\
\hline hsa-miR-1251-5p & 5.69 & 0.25 & 5.12 & 0.44 \\
\hline hsa-miR-1252-5p & 6.01 & 0.39 & 5.81 & 0.38 \\
\hline hsa-miR-1253 & 5.88 & 0.20 & 5.35 & 0.38 \\
\hline hsa-miR-1254 & 5.65 & 0.16 & 5.39 & 0.16 \\
\hline
\end{tabular}




\begin{tabular}{|c|c|c|c|c|}
\hline hsa-miR-1255a & 5.69 & 0.43 & 6.08 & 0.46 \\
\hline hsa-miR-1255b-5p & 5.65 & 0.43 & 5.86 & 0.67 \\
\hline hsa-miR-1256 & 5.63 & 0.51 & 5.72 & 0.45 \\
\hline hsa-miR-1257 & 5.82 & 0.28 & 5.66 & 0.08 \\
\hline hsa-miR-1258 & 5.89 & 0.24 & 5.70 & 0.35 \\
\hline hsa-miR-1259 & 5.83 & 0.34 & 6.30 & 0.17 \\
\hline hsa-miR-125a-3p & 6.63 & 0.31 & 6.75 & 0.40 \\
\hline hsa-miR-125a-5p & 7.09 & 0.26 & 6.93 & 0.22 \\
\hline hsa-miR-125b-5p & 6.00 & 0.70 & 6.03 & 0.26 \\
\hline hsa-miR-125b-1-3p & 5.15 & 0.49 & 5.85 & 0.59 \\
\hline hsa-miR-125b-2-3p & 5.65 & 0.02 & 5.79 & 0.39 \\
\hline hsa-miR-126-3p & 9.07 & 0.46 & 9.00 & 0.62 \\
\hline hsa-miR-126-5p & 6.44 & 0.54 & 6.55 & 0.45 \\
\hline hsa-miR-1260a & 12.61 & 0.53 & 12.55 & 0.55 \\
\hline hsa-miR-1261 & 6.06 & 0.42 & 5.77 & 0.38 \\
\hline hsa-miR-1262 & 5.99 & 0.47 & 6.20 & 0.24 \\
\hline hsa-miR-1263 & 5.51 & 0.34 & 5.17 & 0.35 \\
\hline hsa-miR-1264 & 5.59 & 0.44 & 5.94 & 0.28 \\
\hline hsa-miR-1265 & 5.53 & 0.09 & 5.99 & 0.33 \\
\hline hsa-miR-1266-5p & 6.05 & 0.44 & 5.51 & 0.38 \\
\hline hsa-miR-1267 & 5.59 & 0.23 & 5.92 & 0.47 \\
\hline hsa-miR-1268a & 7.11 & 0.35 & 6.91 & 0.23 \\
\hline hsa-miR-1269a & 5.77 & 0.15 & 5.44 & 0.19 \\
\hline hsa-miR-1270 & 5.71 & 0.51 & 5.88 & 0.33 \\
\hline hsa-miR-1271-5p & 5.34 & 0.57 & 5.00 & 0.56 \\
\hline hsa-miR-1272 & 5.51 & 0.49 & 5.86 & 0.40 \\
\hline hsa-miR-1273a & 5.59 & 0.59 & 6.03 & 0.20 \\
\hline hsa-miR-127-3p & 5.99 & 0.49 & 5.74 & 0.47 \\
\hline hsa-miR-1274a & 10.19 & 0.47 & 10.36 & 0.47 \\
\hline hsa-miR-1274b & 12.55 & 0.48 & 12.57 & 0.32 \\
\hline hsa-miR-1275 & 7.27 & 0.18 & 6.94 & 0.32 \\
\hline hsa-miR-127-5p & 5.51 & 0.24 & 6.14 & 0.50 \\
\hline hsa-miR-1276 & 5.74 & 0.44 & 5.51 & 0.46 \\
\hline hsa-miR-1277-3p & 6.23 & 0.11 & 6.23 & 0.12 \\
\hline hsa-miR-1278 & 5.53 & 0.43 & 5.96 & 0.27 \\
\hline hsa-miR-1279 & 5.56 & 0.38 & 5.84 & 0.26 \\
\hline hsa-miR-128-3p & 6.96 & 0.15 & 6.78 & 0.13 \\
\hline hsa-miR-1280 & 9.78 & 0.35 & 9.88 & 0.54 \\
\hline hsa-miR-1281 & 6.64 & 0.23 & 6.09 & 0.35 \\
\hline hsa-miR-1282 & 5.73 & 0.15 & 6.07 & 0.21 \\
\hline hsa-miR-1283 & 6.13 & 0.39 & 5.65 & 0.37 \\
\hline hsa-miR-1284 & 5.07 & 0.97 & 5.52 & 0.46 \\
\hline hsa-miR-1285-3p & 5.71 & 0.49 & 6.06 & 0.32 \\
\hline hsa-miR-1286 & 5.07 & 0.76 & 5.86 & 0.58 \\
\hline hsa-miR-1287-5p & 6.04 & 0.40 & 5.96 & 0.29 \\
\hline hsa-miR-1288-3p & 7.24 & 0.40 & 7.22 & 0.34 \\
\hline
\end{tabular}




\begin{tabular}{|c|c|c|c|c|}
\hline hsa-miR-1289 & 5.66 & 0.11 & 5.46 & 0.68 \\
\hline hsa-miR-129-1-3p & 5.29 & 0.92 & 5.59 & 0.77 \\
\hline hsa-miR-1290 & 6.62 & 0.20 & 6.40 & 0.24 \\
\hline hsa-miR-1291 & 5.47 & 0.52 & 5.91 & 0.13 \\
\hline hsa-miR-1292-5p & 5.57 & 0.26 & 5.35 & 0.26 \\
\hline hsa-miR-1293 & 6.00 & 0.46 & 5.80 & 0.27 \\
\hline hsa-miR-129-2-3p & 5.02 & 0.33 & 5.38 & 0.43 \\
\hline hsa-miR-1294 & 5.93 & 0.26 & 6.05 & 0.45 \\
\hline hsa-miR-1295a & 6.05 & 0.30 & 5.85 & 0.50 \\
\hline hsa-miR-129-5p & 5.37 & 0.45 & 6.04 & 0.40 \\
\hline hsa-miR-1296-5p & 5.48 & 0.56 & 5.33 & 0.30 \\
\hline hsa-miR-1297 & 5.76 & 0.65 & 6.32 & 0.33 \\
\hline hsa-miR-1298-5p & 5.51 & 0.37 & 5.71 & 0.39 \\
\hline hsa-miR-1299 & 6.01 & 0.34 & 5.96 & 0.44 \\
\hline hsa-miR-1301-3p & 5.44 & 0.42 & 5.65 & 0.44 \\
\hline hsa-miR-1302 & 5.78 & 0.33 & 6.06 & 0.57 \\
\hline hsa-miR-1303 & 5.67 & 0.42 & 5.80 & 0.41 \\
\hline hsa-miR-1304-5p & 5.82 & 0.44 & 5.61 & 0.44 \\
\hline hsa-miR-1305 & 8.62 & 0.56 & 8.50 & 0.48 \\
\hline hsa-miR-1306-3p & 6.07 & 0.46 & 5.76 & 0.25 \\
\hline hsa-miR-1307-3p & 5.47 & 0.61 & 5.95 & 0.29 \\
\hline hsa-miR-1308 & 8.06 & 1.57 & 7.10 & 0.35 \\
\hline hsa-miR-130a-3p & 9.03 & 0.17 & 8.80 & 0.30 \\
\hline hsa-miR-130a-5p & 5.58 & 0.49 & 6.12 & 0.51 \\
\hline hsa-miR-130b-3p & 7.12 & 0.16 & 7.04 & 0.18 \\
\hline hsa-miR-130b-5p & 5.37 & 0.61 & 4.89 & 0.53 \\
\hline hsa-miR-132-3p & 6.27 & 0.57 & 6.40 & 0.24 \\
\hline hsa-miR-132-5p & 5.59 & 0.35 & 5.68 & 0.46 \\
\hline hsa-miR-1321 & 5.90 & 0.30 & 6.11 & 0.18 \\
\hline hsa-miR-1322 & 4.99 & 0.78 & 5.63 & 0.22 \\
\hline hsa-miR-1323 & 5.72 & 0.30 & 5.96 & 0.28 \\
\hline hsa-miR-1324 & 5.57 & 0.35 & 6.11 & 0.21 \\
\hline hsa-miR-133a-3p & 4.85 & 1.05 & 5.46 & 0.29 \\
\hline hsa-miR-133b & 5.38 & 0.35 & 5.51 & 0.40 \\
\hline hsa-miR-134-5p & 6.29 & 0.59 & 6.11 & 0.34 \\
\hline hsa-miR-135a-5p & 6.28 & 0.12 & 5.97 & 0.25 \\
\hline hsa-miR-135a-3p & 5.76 & 0.23 & 5.10 & 0.35 \\
\hline hsa-miR-135b-5p & 6.04 & 0.27 & 6.36 & 0.32 \\
\hline hsa-miR-135b-3p & 5.15 & 0.35 & 5.64 & 0.34 \\
\hline hsa-miR-136-5p & 6.65 & 0.23 & 6.46 & 0.33 \\
\hline hsa-miR-136-3p & 6.13 & 0.32 & 5.62 & 0.30 \\
\hline hsa-miR-137 & 6.15 & 0.24 & 5.63 & 0.33 \\
\hline hsa-miR-138-5p & 5.74 & 0.53 & 5.54 & 0.42 \\
\hline hsa-miR-138-1-3p & 4.52 & 0.17 & 5.26 & 0.60 \\
\hline hsa-miR-138-2-3p & 5.58 & 0.79 & 6.20 & 0.21 \\
\hline hsa-miR-139-3p & 6.61 & 0.27 & 6.46 & 0.30 \\
\hline
\end{tabular}




\begin{tabular}{|c|c|c|c|c|}
\hline hsa-miR-139-5p & 6.39 & 0.34 & 6.17 & 0.36 \\
\hline hsa-miR-140-3p & 8.17 & 0.37 & 7.96 & 0.30 \\
\hline hsa-miR-140-5p & 8.45 & 0.30 & 8.53 & 0.38 \\
\hline hsa-miR-141-3p & 6.92 & 0.18 & 6.53 & 0.54 \\
\hline hsa-miR-141-5p & 6.00 & 0.40 & 5.43 & 0.43 \\
\hline hsa-miR-142-3p & 12.72 & 0.54 & 12.73 & 0.48 \\
\hline hsa-miR-142-5p & 11.30 & 0.39 & 11.18 & 0.14 \\
\hline hsa-miR-143-3p & 5.43 & 0.31 & 6.05 & 0.20 \\
\hline hsa-miR-143-5p & 5.58 & 0.30 & 5.69 & 0.34 \\
\hline hsa-miR-144-3p & 6.48 & 0.23 & 6.16 & 0.35 \\
\hline hsa-miR-144-5p & 5.49 & 0.37 & 5.84 & 0.49 \\
\hline hsa-miR-145-5p & 5.98 & 0.53 & 6.21 & 0.16 \\
\hline hsa-miR-145-3p & 5.86 & 0.27 & 5.90 & 0.36 \\
\hline hsa-miR-1468-5p & 5.06 & 0.32 & 5.69 & 0.23 \\
\hline hsa-miR-1469 & 5.30 & 0.23 & 5.03 & 0.20 \\
\hline hsa-miR-146a-5p & 9.87 & 0.42 & 9.94 & 0.51 \\
\hline hsa-miR-146a-3p & 5.30 & 0.48 & 6.13 & 0.33 \\
\hline hsa-miR-146b-3p & 5.70 & 0.32 & 5.45 & 0.31 \\
\hline hsa-miR-146b-5p & 8.90 & 0.48 & 9.11 & 0.63 \\
\hline hsa-miR-147a & 6.20 & 0.17 & 5.91 & 0.23 \\
\hline hsa-miR-1470 & 5.40 & 0.13 & 5.62 & 0.43 \\
\hline hsa-miR-1471 & 5.82 & 0.40 & 5.48 & 0.25 \\
\hline hsa-miR-147b & 5.45 & 0.54 & 6.21 & 0.40 \\
\hline hsa-miR-148a-3p & 7.59 & 0.31 & 7.69 & 0.12 \\
\hline hsa-miR-148a-5p & 5.69 & 0.56 & 4.76 & 0.54 \\
\hline hsa-miR-148b-3p & 6.59 & 0.27 & 6.34 & 0.43 \\
\hline hsa-miR-148b-5p & 4.74 & 1.14 & 5.89 & 0.27 \\
\hline hsa-miR-149-5p & 5.41 & 0.26 & 5.63 & 0.23 \\
\hline hsa-miR-149-3p & 6.06 & 0.16 & 5.70 & 0.41 \\
\hline hsa-miR-150-5p & 14.15 & 0.56 & 13.98 & 0.18 \\
\hline hsa-miR-150-3p & 6.38 & 0.54 & 6.10 & 0.41 \\
\hline hsa-miR-151-3p & 7.51 & 0.25 & 7.56 & 0.32 \\
\hline hsa-miR-151a-5p & 9.14 & 0.31 & 9.10 & 0.29 \\
\hline hsa-miR-152-3p & 5.41 & 0.63 & 5.51 & 0.24 \\
\hline hsa-miR-153-3p & 5.69 & 0.37 & 5.37 & 0.28 \\
\hline hsa-miR-1537-3p & 5.97 & 0.38 & 5.57 & 0.20 \\
\hline hsa-miR-1538 & 5.67 & 0.61 & 5.87 & 0.46 \\
\hline hsa-miR-1539 & 5.31 & 0.36 & 5.77 & 0.53 \\
\hline hsa-miR-154-5p & 6.01 & 0.39 & 6.31 & 0.21 \\
\hline hsa-miR-154-3p & 5.68 & 0.37 & 5.71 & 0.39 \\
\hline hsa-miR-155-5p & 8.66 & 0.16 & 8.35 & 0.93 \\
\hline hsa-miR-155-3p & 5.26 & 0.46 & 5.95 & 0.38 \\
\hline hsa-miR-15a-5p & 11.47 & 0.36 & 11.38 & 0.24 \\
\hline hsa-miR-15a-3p & 6.12 & 0.29 & 5.67 & 0.54 \\
\hline hsa-miR-15b-5p & 11.06 & 0.24 & 10.92 & 0.25 \\
\hline hsa-miR-15b-3p & 5.48 & 0.32 & 5.88 & 0.42 \\
\hline
\end{tabular}




\begin{tabular}{|c|c|c|c|c|}
\hline hsa-miR-16-5p & 12.88 & 0.17 & 12.91 & 0.28 \\
\hline hsa-miR-16-1-3p & 5.74 & 0.27 & 5.38 & 0.10 \\
\hline hsa-miR-16-2-3p & 6.05 & 0.24 & 5.93 & 0.61 \\
\hline hsa-miR-17-5p & 7.60 & 0.37 & 7.68 & 0.37 \\
\hline hsa-miR-17-3p & 6.34 & 0.22 & 6.09 & 0.48 \\
\hline hsa-miR-181a-5p & 8.63 & 0.49 & 8.79 & 0.59 \\
\hline hsa-miR-181a-3p & 6.61 & 0.14 & 6.29 & 0.44 \\
\hline hsa-miR-181a-2-3p & 5.93 & 0.48 & 6.62 & 0.11 \\
\hline hsa-miR-181b-5p & 7.82 & 0.29 & 7.74 & 0.11 \\
\hline hsa-miR-181c-5p & 6.83 & 0.19 & 7.02 & 0.15 \\
\hline hsa-miR-181c-3p & 5.08 & 0.16 & 5.78 & 0.43 \\
\hline hsa-miR-181d-5p & 6.11 & 0.63 & 6.25 & 0.46 \\
\hline hsa-miR-182-5p & 5.65 & 0.58 & 5.88 & 0.35 \\
\hline hsa-miR-182-3p & 5.76 & 0.44 & 6.17 & 0.27 \\
\hline hsa-miR-1825 & 5.91 & 0.48 & 5.83 & 0.41 \\
\hline hsa-miR-1826 & 6.25 & 0.42 & 6.08 & 0.63 \\
\hline hsa-miR-1827 & 6.03 & 0.44 & 5.62 & 0.58 \\
\hline hsa-miR-183-5p & 5.86 & 0.27 & 5.25 & 1.44 \\
\hline hsa-miR-183-3p & 4.72 & 1.15 & 5.08 & 0.47 \\
\hline hsa-miR-184 & 6.04 & 0.42 & 5.53 & 0.58 \\
\hline hsa-miR-185-5p & 8.05 & 0.28 & 8.15 & 0.51 \\
\hline hsa-miR-185-3p & 4.99 & 0.92 & 5.66 & 0.48 \\
\hline hsa-miR-186-5p & 8.03 & 0.53 & 8.18 & 0.70 \\
\hline hsa-miR-186-3p & 5.28 & 0.57 & 5.54 & 0.32 \\
\hline hsa-miR-187-3p & 4.64 & 0.71 & 5.34 & 0.76 \\
\hline hsa-miR-187-5p & 5.42 & 0.58 & 4.84 & 0.23 \\
\hline hsa-miR-188-3p & 5.80 & 0.60 & 5.33 & 0.58 \\
\hline hsa-miR-188-5p & 6.65 & 0.55 & 6.49 & 0.35 \\
\hline hsa-miR-18a-5p & 6.92 & 0.26 & 6.91 & 0.40 \\
\hline hsa-miR-18a-3p & 5.46 & 0.88 & 6.20 & 0.12 \\
\hline hsa-miR-18b-5p & 5.78 & 0.49 & 5.48 & 0.52 \\
\hline hsa-miR-18b-3p & 4.70 & 0.87 & 5.47 & 0.61 \\
\hline hsa-miR-190a-5p & 5.88 & 0.80 & 6.26 & 0.22 \\
\hline hsa-miR-1908-5p & 5.47 & 0.38 & 5.34 & 0.90 \\
\hline hsa-miR-1909-3p & 5.54 & 0.87 & 5.90 & 0.48 \\
\hline hsa-miR-1909-5p & 5.57 & 0.17 & 5.26 & 0.13 \\
\hline hsa-miR-190b & 5.91 & 0.35 & 5.39 & 0.39 \\
\hline hsa-miR-191-5p & 6.11 & 0.39 & 5.34 & 0.51 \\
\hline hsa-miR-191-3p & 6.34 & 0.19 & 5.91 & 0.86 \\
\hline hsa-miR-1910-5p & 4.93 & 0.25 & 5.33 & 0.38 \\
\hline hsa-miR-1911-5p & 5.45 & 0.24 & 5.28 & 0.42 \\
\hline hsa-miR-1911-3p & 5.52 & 0.32 & 5.64 & 0.23 \\
\hline hsa-miR-1912 & 5.98 & 0.24 & 5.52 & 0.08 \\
\hline hsa-miR-1913 & 5.46 & 0.77 & 5.53 & 0.40 \\
\hline hsa-miR-1914-5p & 5.08 & 0.19 & 5.39 & 0.18 \\
\hline hsa-miR-1914-3p & 7.30 & 0.33 & 7.38 & 0.25 \\
\hline
\end{tabular}




\begin{tabular}{|c|c|c|c|c|}
\hline hsa-miR-1915-3p & 7.07 & 0.49 & 6.75 & 0.35 \\
\hline hsa-miR-1915-5p & 5.18 & 0.24 & 5.48 & 0.62 \\
\hline hsa-miR-192-5p & 7.70 & 0.21 & 7.82 & 0.15 \\
\hline hsa-miR-192-3p & 5.56 & 0.93 & 5.85 & 0.29 \\
\hline hsa-miR-193a-3p & 5.65 & 0.58 & 5.37 & 0.27 \\
\hline hsa-miR-193a-5p & 6.18 & 0.11 & 5.86 & 0.46 \\
\hline hsa-miR-193b-3p & 5.53 & 0.38 & 5.37 & 0.20 \\
\hline hsa-miR-193b-5p & 5.54 & 0.80 & 5.99 & 0.57 \\
\hline hsa-miR-194-5p & 6.37 & 0.29 & 6.24 & 0.12 \\
\hline hsa-miR-194-3p & 5.42 & 0.46 & 5.80 & 0.08 \\
\hline hsa-miR-195-5p & 5.72 & 0.13 & 5.95 & 0.35 \\
\hline hsa-miR-195-3p & 4.98 & 0.96 & 5.51 & 0.34 \\
\hline hsa-miR-196a-5p & 5.89 & 0.27 & 6.09 & 0.16 \\
\hline hsa-miR-196a-3p & 5.05 & 0.78 & 5.85 & 0.44 \\
\hline hsa-miR-196b-5p & 6.45 & 0.32 & 6.41 & 0.43 \\
\hline hsa-miR-197-3p & 6.90 & 0.27 & 7.08 & 0.43 \\
\hline hsa-miR-198 & 6.18 & 0.39 & 5.76 & 0.28 \\
\hline hsa-miR-199a-3p & 9.00 & 0.25 & 8.83 & 0.41 \\
\hline hsa-miR-199a-5p & 8.31 & 0.73 & 8.00 & 0.89 \\
\hline hsa-miR-19a-3p & 10.36 & 0.19 & 10.17 & 0.20 \\
\hline hsa-miR-19a-5p & 6.07 & 0.64 & 5.41 & 0.82 \\
\hline hsa-miR-19b-3p & 11.96 & 0.31 & 11.67 & 0.84 \\
\hline hsa-miR-19b-1-5p & 4.19 & 0.43 & 5.22 & 0.20 \\
\hline hsa-miR-19b-2-5p & 6.22 & 0.68 & 5.68 & 0.60 \\
\hline hsa-miR-200a-3p & 5.55 & 0.29 & 5.87 & 0.27 \\
\hline hsa-miR-200a-5p & 5.87 & 0.21 & 5.66 & 0.13 \\
\hline hsa-miR-200b-3p & 6.01 & 0.47 & 6.20 & 0.32 \\
\hline hsa-miR-200b-5p & 4.86 & 0.45 & 5.83 & 0.61 \\
\hline hsa-miR-200c-3p & 5.72 & 0.36 & 5.41 & 0.15 \\
\hline hsa-miR-200c-5p & 5.48 & 0.64 & 5.97 & 0.51 \\
\hline hsa-miR-202-3p & 6.27 & 0.25 & 6.05 & 0.72 \\
\hline hsa-miR-202-5p & 5.61 & 0.41 & 5.79 & 0.48 \\
\hline hsa-miR-203-3p & 6.23 & 0.25 & 6.00 & 0.51 \\
\hline hsa-miR-204-5p & 5.44 & 0.22 & 5.72 & 0.25 \\
\hline hsa-miR-205-5p & 5.56 & 0.38 & 5.23 & 0.36 \\
\hline hsa-miR-206 & 5.86 & 0.36 & 6.09 & 0.34 \\
\hline hsa-miR-208a-3p & 5.87 & 0.38 & 5.75 & 0.34 \\
\hline hsa-miR-208b-3p & 6.05 & 0.38 & 6.21 & 0.28 \\
\hline hsa-miR-20a-5p & 11.19 & 0.18 & 11.11 & 0.13 \\
\hline hsa-miR-20a-3p & 5.87 & 0.08 & 6.11 & 0.35 \\
\hline hsa-miR-20b-5p & 7.82 & 0.15 & 7.92 & 0.39 \\
\hline hsa-miR-20b-3p & 5.52 & 0.49 & 4.94 & 0.64 \\
\hline hsa-miR-21-5p & 13.79 & 0.36 & 13.51 & 0.61 \\
\hline hsa-miR-21-3p & 7.44 & 0.22 & 7.51 & 0.24 \\
\hline hsa-miR-210 & 6.01 & 0.33 & 5.83 & 0.37 \\
\hline hsa-miR-211-5p & 5.46 & 0.04 & 5.28 & 0.22 \\
\hline
\end{tabular}




\begin{tabular}{|c|c|c|c|c|}
\hline hsa-miR-212-3p & 6.74 & 0.53 & 6.23 & 1.10 \\
\hline hsa-miR-214-3p & 5.51 & 0.33 & 5.70 & 0.71 \\
\hline hsa-miR-214-5p & 5.36 & 0.44 & 5.72 & 0.57 \\
\hline hsa-miR-215-5p & 6.52 & 0.24 & 6.75 & 0.21 \\
\hline hsa-miR-216a-5p & 5.83 & 0.22 & 5.20 & 0.58 \\
\hline hsa-miR-216b-5p & 4.99 & 1.24 & 5.48 & 0.40 \\
\hline hsa-miR-217 & 5.24 & 0.63 & 5.82 & 0.68 \\
\hline hsa-miR-218-5p & 5.94 & 0.32 & 6.09 & 0.22 \\
\hline hsa-miR-218-1-3p & 5.28 & 0.53 & 5.59 & 0.38 \\
\hline hsa-miR-218-2-3p & 4.71 & 1.38 & 5.19 & 0.92 \\
\hline hsa-miR-219-1-3p & 5.75 & 0.39 & 5.17 & 0.52 \\
\hline hsa-miR-219-2-3p & 5.54 & 0.42 & 5.68 & 0.46 \\
\hline hsa-miR-219-5p & 6.17 & 0.41 & 5.81 & 0.43 \\
\hline hsa-miR-22-3p & 8.98 & 0.44 & 9.06 & 0.51 \\
\hline hsa-miR-22-5p & 5.96 & 0.19 & 6.19 & 0.32 \\
\hline hsa-miR-220a & 5.16 & 0.13 & 5.71 & 0.36 \\
\hline hsa-miR-220b & 4.93 & 0.89 & 5.58 & 0.72 \\
\hline hsa-miR-220c & 6.00 & 0.21 & 5.59 & 0.22 \\
\hline hsa-miR-221-3p & 8.62 & 0.53 & 8.55 & 0.72 \\
\hline hsa-miR-221-5p & 6.76 & 0.08 & 6.42 & 0.28 \\
\hline hsa-miR-222-3p & 7.77 & 0.37 & 7.80 & 0.66 \\
\hline hsa-miR-222-5p & 5.53 & 0.68 & 5.83 & 0.60 \\
\hline hsa-miR-223-3p & 12.76 & 0.38 & 12.64 & 0.34 \\
\hline hsa-miR-223-5p & 6.44 & 0.70 & 6.76 & 0.17 \\
\hline hsa-miR-224-5p & 6.11 & 0.48 & 6.28 & 0.30 \\
\hline hsa-miR-23a-3p & 10.11 & 0.49 & 10.17 & 0.66 \\
\hline hsa-miR-23a-5p & 5.98 & 0.26 & 6.56 & 0.34 \\
\hline hsa-miR-23b-3p & 8.58 & 0.31 & 8.68 & 0.24 \\
\hline hsa-miR-23b-5p & 6.07 & 0.43 & 5.88 & 0.18 \\
\hline hsa-miR-24-3p & 10.88 & 0.33 & 10.95 & 0.38 \\
\hline hsa-miR-24-1-5p & 5.72 & 0.44 & 5.83 & 0.29 \\
\hline hsa-miR-24-2-5p & 5.34 & 0.73 & 4.19 & 0.68 \\
\hline hsa-miR-25-3p & 8.41 & 0.55 & 8.60 & 0.62 \\
\hline hsa-miR-25-5p & 5.67 & 0.32 & 6.26 & 0.31 \\
\hline hsa-miR-26a-5p & 10.50 & 0.49 & 10.59 & 0.74 \\
\hline hsa-miR-26a-1-3p & 5.91 & 0.46 & 5.43 & 0.85 \\
\hline hsa-miR-26a-2-3p & 5.34 & 0.30 & 5.81 & 1.05 \\
\hline hsa-miR-26b-5p & 11.46 & 0.16 & 11.07 & 0.74 \\
\hline hsa-miR-26b-3p & 5.86 & 0.39 & 6.41 & 0.22 \\
\hline hsa-miR-27a-3p & 9.85 & 0.33 & 9.90 & 0.49 \\
\hline hsa-miR-27a-5p & 5.36 & 0.43 & 5.96 & 0.31 \\
\hline hsa-miR-27b-3p & 7.70 & 0.36 & 7.70 & 0.44 \\
\hline hsa-miR-27b-5p & 5.30 & 0.47 & 5.97 & 0.26 \\
\hline hsa-miR-28-3p & 5.80 & 0.55 & 5.11 & 0.72 \\
\hline hsa-miR-28-5p & 7.27 & 0.10 & 7.34 & 0.18 \\
\hline hsa-miR-296-3p & 5.59 & 0.59 & 4.79 & 1.15 \\
\hline
\end{tabular}




\begin{tabular}{|c|c|c|c|c|}
\hline hsa-miR-296-5p & 5.49 & 0.53 & 5.80 & 0.36 \\
\hline hsa-miR-297 & 5.20 & 0.54 & 5.93 & 0.28 \\
\hline hsa-miR-298 & 6.12 & 0.13 & 5.25 & 0.91 \\
\hline hsa-miR-299-3p & 5.92 & 0.55 & 5.32 & 0.20 \\
\hline hsa-miR-299-5p & 5.90 & 0.29 & 5.40 & 0.24 \\
\hline hsa-miR-29a-3p & 12.53 & 0.16 & 12.55 & 0.14 \\
\hline hsa-miR-29a-5p & 5.52 & 0.91 & 5.93 & 0.14 \\
\hline hsa-miR-29b-3p & 9.32 & 0.36 & 9.36 & 0.30 \\
\hline hsa-miR-29b-1-5p & 6.42 & 0.40 & 6.71 & 0.22 \\
\hline hsa-miR-29b-2-5p & 5.70 & 0.64 & 4.77 & 1.00 \\
\hline hsa-miR-29c-3p & 11.76 & 0.24 & 11.85 & 0.23 \\
\hline hsa-miR-29c-5p & 5.85 & 0.25 & 5.74 & 0.53 \\
\hline hsa-miR-300 & 5.98 & 0.56 & 5.05 & 0.34 \\
\hline hsa-miR-301a-3p & 6.86 & 0.46 & 6.61 & 0.34 \\
\hline hsa-miR-301b-3p & 6.20 & 0.60 & 6.00 & 0.62 \\
\hline hsa-miR-302a-3p & 5.89 & 0.35 & 6.01 & 0.28 \\
\hline hsa-miR-302a-5p & 5.81 & 0.34 & 6.27 & 0.30 \\
\hline hsa-miR-302b-3p & 5.67 & 0.60 & 5.44 & 0.79 \\
\hline hsa-miR-302b-5p & 5.79 & 0.26 & 6.13 & 0.47 \\
\hline hsa-miR-302c-3p & 5.26 & 0.47 & 5.08 & 0.32 \\
\hline hsa-miR-302c-5p & 5.29 & 0.22 & 5.59 & 0.55 \\
\hline hsa-miR-302d-3p & 5.86 & 0.40 & 6.11 & 0.49 \\
\hline hsa-miR-302d-5p & 5.77 & 0.45 & 5.22 & 0.19 \\
\hline hsa-miR-302e & 5.99 & 0.42 & 5.18 & 0.08 \\
\hline hsa-miR-302f & 5.84 & 0.50 & 5.57 & 0.74 \\
\hline hsa-miR-30a-5p & 6.06 & 0.37 & 6.01 & 0.38 \\
\hline hsa-miR-30a-3p & 5.77 & 0.34 & 5.96 & 0.38 \\
\hline hsa-miR-30b-5p & 11.32 & 0.23 & 11.14 & 0.23 \\
\hline hsa-miR-30b-3p & 5.61 & 0.06 & 6.16 & 0.05 \\
\hline hsa-miR-30c-5p & 8.18 & 0.66 & 8.29 & 0.69 \\
\hline hsa-miR-30c-1-3p & 5.71 & 0.45 & 5.31 & 0.86 \\
\hline hsa-miR-30c-2-3p & 6.00 & 0.33 & 5.63 & 0.82 \\
\hline hsa-miR-30d-5p & 8.91 & 0.27 & 8.58 & 0.36 \\
\hline hsa-miR-30d-3p & 5.07 & 1.12 & 5.93 & 0.41 \\
\hline hsa-miR-30e-5p & 8.79 & 0.46 & 8.88 & 0.58 \\
\hline hsa-miR-30e-3p & 7.45 & 0.19 & 7.53 & 0.26 \\
\hline hsa-miR-31-5p & 6.96 & 0.33 & 7.07 & 0.26 \\
\hline hsa-miR-31-3p & 6.00 & 0.08 & 5.70 & 0.48 \\
\hline hsa-miR-32-5p & 5.26 & 0.23 & 5.38 & 0.41 \\
\hline hsa-miR-32-3p & 6.03 & 0.43 & 6.37 & 0.22 \\
\hline hsa-miR-320a & 7.18 & 0.25 & 7.26 & 0.29 \\
\hline hsa-miR-320b & 7.78 & 0.04 & 7.54 & 0.48 \\
\hline hsa-miR-320c & 6.99 & 0.14 & 6.93 & 0.22 \\
\hline hsa-miR-320d & 9.88 & 0.12 & 9.98 & 0.08 \\
\hline hsa-miR-323a-3p & 5.87 & 0.42 & 5.62 & 0.28 \\
\hline hsa-miR-323a-5p & 5.67 & 0.24 & 5.98 & 0.57 \\
\hline
\end{tabular}




\begin{tabular}{|c|c|c|c|c|}
\hline hsa-miR-324-3p & 9.01 & 0.24 & 9.08 & 0.42 \\
\hline hsa-miR-324-5p & 6.98 & 0.25 & 6.82 & 0.44 \\
\hline hsa-miR-325 & 5.30 & 0.33 & 5.69 & 0.58 \\
\hline hsa-miR-326 & 5.63 & 0.77 & 6.02 & 0.67 \\
\hline hsa-miR-328-3p & 5.03 & 0.39 & 5.49 & 0.36 \\
\hline hsa-miR-329-3p & 5.98 & 0.30 & 5.83 & 0.46 \\
\hline hsa-miR-330-3p & 6.09 & 0.36 & 5.91 & 0.42 \\
\hline hsa-miR-330-5p & 5.83 & 0.31 & 5.37 & 0.37 \\
\hline hsa-miR-331-3p & 8.92 & 0.26 & 8.95 & 0.08 \\
\hline hsa-miR-331-5p & 5.39 & 0.22 & 4.94 & 1.47 \\
\hline hsa-miR-335-5p & 7.03 & 0.31 & 6.90 & 0.09 \\
\hline hsa-miR-335-3p & 5.72 & 0.56 & 5.33 & 0.15 \\
\hline hsa-miR-337-3p & 5.94 & 0.31 & 6.08 & 0.42 \\
\hline hsa-miR-337-5p & 5.66 & 0.57 & 6.21 & 0.37 \\
\hline hsa-miR-338-3p & 6.56 & 0.35 & 6.68 & 0.34 \\
\hline hsa-miR-338-5p & 6.72 & 1.07 & 6.51 & 1.25 \\
\hline hsa-miR-339-3p & 4.24 & 0.52 & 5.42 & 0.37 \\
\hline hsa-miR-339-5p & 5.67 & 0.23 & 5.09 & 0.94 \\
\hline hsa-miR-33a-5p & 6.21 & 0.31 & 5.85 & 0.37 \\
\hline hsa-miR-33a-3p & 4.83 & 0.53 & 4.23 & 1.11 \\
\hline hsa-miR-33b-5p & 5.63 & 0.40 & 5.97 & 0.40 \\
\hline hsa-miR-33b-3p & 5.55 & 0.93 & 5.98 & 0.63 \\
\hline hsa-miR-340-5p & 7.66 & 0.29 & 7.72 & 0.31 \\
\hline hsa-miR-340-3p & 6.99 & 0.24 & 6.66 & 0.45 \\
\hline hsa-miR-342-3p & 11.99 & 0.19 & 12.08 & 0.14 \\
\hline hsa-miR-342-5p & 8.89 & 0.12 & 8.97 & 0.27 \\
\hline hsa-miR-345-5p & 5.98 & 0.56 & 5.28 & 0.34 \\
\hline hsa-miR-346 & 5.43 & 0.09 & 4.92 & 1.26 \\
\hline hsa-miR-34a-5p & 6.28 & 0.31 & 5.95 & 0.55 \\
\hline hsa-miR-34a-3p & 5.69 & 0.15 & 5.42 & 0.34 \\
\hline hsa-miR-34b-3p & 5.48 & 0.26 & 5.66 & 0.28 \\
\hline hsa-miR-34b-5p & 5.98 & 0.21 & 6.19 & 0.39 \\
\hline hsa-miR-34c-3p & 5.27 & 0.37 & 4.55 & 0.77 \\
\hline hsa-miR-34c-5p & 6.19 & 0.41 & 5.84 & 0.22 \\
\hline hsa-miR-361-3p & 8.30 & 0.35 & 8.22 & 0.28 \\
\hline hsa-miR-361-5p & 8.26 & 0.39 & 8.36 & 0.46 \\
\hline hsa-miR-362-3p & 6.99 & 0.38 & 6.82 & 0.57 \\
\hline hsa-miR-362-5p & 6.50 & 0.29 & 6.01 & 0.22 \\
\hline hsa-miR-363-3p & 8.08 & 0.37 & 8.22 & 0.49 \\
\hline hsa-miR-363-5p & 4.55 & 0.99 & 5.70 & 0.09 \\
\hline hsa-miR-365-3p & 7.14 & 0.12 & 7.05 & 0.25 \\
\hline hsa-miR-367-3p & 6.08 & 0.27 & 5.35 & 1.21 \\
\hline hsa-miR-367-5p & 5.56 & 0.62 & 6.04 & 0.42 \\
\hline hsa-miR-369-3p & 6.25 & 0.32 & 5.65 & 0.39 \\
\hline hsa-miR-369-5p & 5.83 & 0.16 & 6.03 & 0.12 \\
\hline hsa-miR-370-3p & 5.67 & 0.45 & 5.88 & 0.31 \\
\hline
\end{tabular}




\begin{tabular}{|c|c|c|c|c|}
\hline hsa-miR-371a-3p & 5.32 & 0.78 & 5.71 & 0.50 \\
\hline hsa-miR-371a-5p & 6.23 & 0.47 & 6.40 & 0.46 \\
\hline hsa-miR-372-3p & 5.65 & 0.44 & 5.45 & 0.22 \\
\hline hsa-miR-373-3p & 5.85 & 0.30 & 5.73 & 0.23 \\
\hline hsa-miR-373-5p & 5.57 & 0.36 & 5.64 & 0.63 \\
\hline hsa-miR-374a-5p & 9.29 & 0.33 & 9.27 & 0.42 \\
\hline hsa-miR-374a-3p & 5.99 & 0.52 & 5.31 & 0.62 \\
\hline hsa-miR-374b-5p & 8.39 & 0.14 & 8.20 & 0.28 \\
\hline hsa-miR-374b-3p & 6.20 & 0.37 & 5.94 & 0.34 \\
\hline hsa-miR-375 & 5.14 & 0.26 & 5.45 & 0.35 \\
\hline hsa-miR-376a-3p & 6.11 & 0.36 & 6.21 & 0.23 \\
\hline hsa-miR-376a-5p & 6.02 & 0.24 & 6.24 & 0.39 \\
\hline hsa-miR-376b-3p & 5.58 & 0.47 & 5.71 & 0.78 \\
\hline hsa-miR-376c-3p & 7.10 & 0.30 & 6.82 & 0.38 \\
\hline hsa-miR-377-3p & 6.90 & 0.31 & 6.83 & 0.27 \\
\hline hsa-miR-377-5p & 5.64 & 0.49 & 4.87 & 0.84 \\
\hline hsa-miR-378a-3p & 7.35 & 0.16 & 7.29 & 0.18 \\
\hline hsa-miR-378a-5p & 5.90 & 0.27 & 6.25 & 0.39 \\
\hline hsa-miR-379-5p & 5.89 & 0.45 & 5.65 & 0.19 \\
\hline hsa-miR-379-3p & 5.84 & 0.17 & 5.41 & 0.54 \\
\hline hsa-miR-380-3p & 5.85 & 0.32 & 5.97 & 0.44 \\
\hline hsa-miR-380-5p & 5.74 & 0.40 & 5.10 & 0.76 \\
\hline hsa-miR-381-3p & 6.16 & 0.46 & 5.69 & 0.46 \\
\hline hsa-miR-382-5p & 5.55 & 0.21 & 5.86 & 0.56 \\
\hline hsa-miR-383-5p & 5.70 & 0.69 & 5.99 & 0.39 \\
\hline hsa-miR-384 & 5.97 & 0.15 & 5.95 & 0.18 \\
\hline hsa-miR-409-3p & 6.20 & 0.32 & 6.13 & 0.48 \\
\hline hsa-miR-409-5p & 5.90 & 0.72 & 5.46 & 1.38 \\
\hline hsa-miR-410-3p & 6.11 & 0.50 & 5.87 & 0.34 \\
\hline hsa-miR-411-5p & 5.84 & 0.42 & 5.47 & 0.30 \\
\hline hsa-miR-411-3p & 5.05 & 0.45 & 5.88 & 0.42 \\
\hline hsa-miR-412-3p & 6.10 & 0.51 & 5.38 & 0.64 \\
\hline hsa-miR-421 & 5.98 & 0.40 & 6.23 & 0.16 \\
\hline hsa-miR-422a & 6.11 & 0.29 & 5.51 & 0.80 \\
\hline hsa-miR-423-3p & 6.39 & 0.27 & 6.72 & 0.33 \\
\hline hsa-miR-423-5p & 6.66 & 0.14 & 6.59 & 0.20 \\
\hline hsa-miR-424-5p & 7.17 & 0.28 & 7.10 & 0.19 \\
\hline hsa-miR-424-3p & 5.68 & 0.44 & 5.83 & 0.48 \\
\hline hsa-miR-425-5p & 9.36 & 0.26 & 9.40 & 0.26 \\
\hline hsa-miR-425-3p & 6.06 & 0.34 & 6.15 & 0.12 \\
\hline hsa-miR-429 & 5.74 & 0.18 & 6.03 & 0.19 \\
\hline hsa-miR-431-5p & 6.32 & 0.23 & 6.00 & 0.33 \\
\hline hsa-miR-431-3p & 6.17 & 0.22 & 5.58 & 0.50 \\
\hline hsa-miR-432-5p & 6.12 & 0.22 & 6.37 & 0.16 \\
\hline hsa-miR-432-3p & 5.00 & 1.10 & 4.36 & 0.27 \\
\hline hsa-miR-433-3p & 6.01 & 0.34 & 5.77 & 0.28 \\
\hline
\end{tabular}




\begin{tabular}{|c|c|c|c|c|}
\hline hsa-miR-448 & 5.48 & 0.61 & 5.10 & 0.87 \\
\hline hsa-miR-449a & 6.12 & 0.19 & 6.20 & 0.20 \\
\hline hsa-miR-449b-5p & 5.40 & 0.92 & 6.00 & 0.60 \\
\hline hsa-miR-450a-5p & 6.16 & 0.17 & 5.59 & 0.43 \\
\hline hsa-miR-450b-3p & 5.39 & 0.44 & 5.93 & 0.37 \\
\hline hsa-miR-450b-5p & 5.46 & 0.38 & 6.03 & 0.61 \\
\hline hsa-miR-451a & 9.03 & 1.16 & 8.73 & 0.84 \\
\hline hsa-miR-452-5p & 5.94 & 0.22 & 5.63 & 0.58 \\
\hline hsa-miR-452-3p & 5.89 & 0.58 & 5.56 & 0.57 \\
\hline hsa-miR-453 & 5.07 & 0.65 & 5.55 & 0.43 \\
\hline hsa-miR-454-3p & 5.97 & 0.42 & 6.33 & 0.28 \\
\hline hsa-miR-454-5p & 5.09 & 0.98 & 5.66 & 0.50 \\
\hline hsa-miR-455-3p & 5.54 & 0.41 & 5.47 & 0.80 \\
\hline hsa-miR-455-5p & 5.63 & 0.40 & 5.34 & 0.64 \\
\hline hsa-miR-483-3p & 5.31 & 0.38 & 4.88 & 0.58 \\
\hline hsa-miR-483-5p & 6.82 & 0.52 & 6.30 & 0.14 \\
\hline hsa-miR-484 & 7.36 & 0.17 & 7.37 & 0.43 \\
\hline hsa-miR-485-3p & 6.15 & 0.15 & 5.76 & 0.15 \\
\hline hsa-miR-485-5p & 5.63 & 0.62 & 5.86 & 0.23 \\
\hline hsa-miR-486-3p & 5.84 & 0.42 & 5.32 & 0.78 \\
\hline hsa-miR-486-5p & 6.86 & 0.16 & 6.66 & 0.23 \\
\hline hsa-miR-487a-3p & 5.91 & 0.27 & 5.54 & 0.32 \\
\hline hsa-miR-487b-3p & 6.54 & 0.46 & 6.67 & 0.43 \\
\hline hsa-miR-488-3p & 5.69 & 0.24 & 6.16 & 0.39 \\
\hline hsa-miR-488-5p & 5.47 & 0.15 & 5.32 & 0.42 \\
\hline hsa-miR-489-3p & 5.74 & 0.22 & 5.58 & 0.42 \\
\hline hsa-miR-490-3p & 5.33 & 0.72 & 5.50 & 0.25 \\
\hline hsa-miR-490-5p & 5.19 & 0.66 & 5.63 & 0.49 \\
\hline hsa-miR-491-3p & 6.04 & 0.48 & 5.19 & 0.64 \\
\hline hsa-miR-491-5p & 5.94 & 0.31 & 5.35 & 0.32 \\
\hline hsa-miR-492 & 5.81 & 0.55 & 5.94 & 0.73 \\
\hline hsa-miR-493-3p & 5.58 & 0.08 & 5.09 & 0.65 \\
\hline hsa-miR-493-5p & 6.14 & 0.57 & 6.28 & 0.23 \\
\hline hsa-miR-494-3p & 9.27 & 1.28 & 8.71 & 0.95 \\
\hline hsa-miR-495-3p & 5.65 & 0.28 & 6.39 & 0.25 \\
\hline hsa-miR-496 & 4.91 & 0.76 & 5.40 & 0.60 \\
\hline hsa-miR-497-5p & 5.78 & 0.20 & 5.48 & 0.32 \\
\hline hsa-miR-497-3p & 5.52 & 0.83 & 6.28 & 0.12 \\
\hline hsa-miR-498 & 6.02 & 0.28 & 5.85 & 0.29 \\
\hline hsa-miR-499a-3p & 5.54 & 0.62 & 4.98 & 0.94 \\
\hline hsa-miR-499a-5p & 5.91 & 0.21 & 5.94 & 0.23 \\
\hline hsa-miR-500a-5p & 6.91 & 0.27 & 6.47 & 0.17 \\
\hline hsa-miR-500a-3p & 6.18 & 0.23 & 5.91 & 0.38 \\
\hline hsa-miR-501-3p & 5.11 & 0.22 & 5.68 & 1.03 \\
\hline hsa-miR-501-5p & 6.97 & 0.14 & 6.41 & 0.40 \\
\hline hsa-miR-502-3p & 6.59 & 0.24 & 6.32 & 0.28 \\
\hline
\end{tabular}




\begin{tabular}{|c|c|c|c|c|}
\hline hsa-miR-502-5p & 5.48 & 0.58 & 5.87 & 0.42 \\
\hline hsa-miR-503-5p & 5.54 & 0.67 & 6.02 & 0.38 \\
\hline hsa-miR-504-5p & 5.86 & 0.35 & 5.17 & 0.87 \\
\hline hsa-miR-505-3p & 5.88 & 0.36 & 6.17 & 0.48 \\
\hline hsa-miR-505-5p & 5.70 & 0.44 & 6.04 & 0.39 \\
\hline hsa-miR-506-3p & 5.94 & 0.23 & 5.42 & 0.90 \\
\hline hsa-miR-507 & 5.86 & 0.61 & 5.65 & 0.23 \\
\hline hsa-miR-508-3p & 5.96 & 0.11 & 6.12 & 0.36 \\
\hline hsa-miR-508-5p & 6.04 & 0.52 & 5.81 & 0.34 \\
\hline hsa-miR-509-3-5p & 5.56 & 0.36 & 5.37 & 0.64 \\
\hline hsa-miR-509-3p & 5.51 & 0.48 & 5.76 & 0.21 \\
\hline hsa-miR-509-5p & 5.66 & 0.42 & 5.24 & 0.46 \\
\hline hsa-miR-510-5p & 5.50 & 0.39 & 5.18 & 0.97 \\
\hline hsa-miR-511-5p & 5.77 & 0.68 & 6.25 & 0.36 \\
\hline hsa-miR-512-3p & 5.91 & 0.37 & 5.64 & 0.33 \\
\hline hsa-miR-512-5p & 5.69 & 0.19 & 5.43 & 0.64 \\
\hline hsa-miR-513a-3p & 6.04 & 0.18 & 5.66 & 0.79 \\
\hline hsa-miR-513a-5p & 6.54 & 0.73 & 6.13 & 0.54 \\
\hline hsa-miR-513b-5p & 6.54 & 0.29 & 5.83 & 0.59 \\
\hline hsa-miR-513c-5p & 6.12 & 0.37 & 5.07 & 0.58 \\
\hline hsa-miR-514-3p & 5.88 & 0.44 & 5.48 & 0.52 \\
\hline hsa-miR-515-3p & 6.03 & 0.23 & 5.83 & 0.50 \\
\hline hsa-miR-515-5p & 5.10 & 1.25 & 5.75 & 0.51 \\
\hline hsa-miR-516a-3p & 5.54 & 0.29 & 6.13 & 0.35 \\
\hline hsa-miR-516a-5p & 5.44 & 0.25 & 5.94 & 0.38 \\
\hline hsa-miR-516b-5p & 5.88 & 0.11 & 6.08 & 0.18 \\
\hline hsa-miR-517-5p & 5.76 & 0.25 & 5.47 & 0.53 \\
\hline hsa-miR-517a-3p & 5.90 & 0.43 & 5.53 & 0.11 \\
\hline hsa-miR-517b-3p & 5.58 & 0.48 & 5.92 & 0.35 \\
\hline hsa-miR-517c-3p & 5.60 & 0.36 & 5.80 & 0.39 \\
\hline hsa-miR-518a-3p & 5.63 & 0.09 & 5.34 & 0.65 \\
\hline hsa-miR-518a-5p & 5.73 & 0.49 & 5.59 & 0.38 \\
\hline hsa-miR-518b & 5.26 & 0.41 & 5.77 & 0.41 \\
\hline hsa-miR-518c-3p & 5.37 & 0.31 & 5.96 & 0.36 \\
\hline hsa-miR-518c-5p & 6.08 & 0.23 & 5.67 & 0.31 \\
\hline hsa-miR-518d-3p & 5.17 & 0.49 & 5.36 & 0.26 \\
\hline hsa-miR-518e-3p & 5.39 & 0.25 & 5.64 & 0.26 \\
\hline hsa-miR-518e-5p & 5.85 & 0.44 & 6.18 & 0.27 \\
\hline hsa-miR-518f-3p & 5.47 & 0.65 & 5.68 & 0.47 \\
\hline hsa-miR-518f-5p & 5.91 & 0.36 & 5.84 & 0.44 \\
\hline hsa-miR-519b-3p & 6.13 & 0.29 & 5.67 & 0.35 \\
\hline hsa-miR-519c-3p & 6.32 & 0.45 & 5.89 & 0.53 \\
\hline hsa-miR-519d-3p & 5.28 & 0.08 & 5.92 & 0.58 \\
\hline hsa-miR-519e-3p & 5.43 & 0.33 & 6.00 & 0.29 \\
\hline hsa-miR-519e-5p & 6.04 & 0.21 & 5.60 & 0.24 \\
\hline hsa-miR-520a-3p & 5.78 & 0.50 & 5.95 & 0.41 \\
\hline
\end{tabular}




\begin{tabular}{|c|c|c|c|c|}
\hline hsa-miR-520a-5p & 5.61 & 0.29 & 5.66 & 0.46 \\
\hline hsa-miR-520b & 6.13 & 0.09 & 5.74 & 0.38 \\
\hline hsa-miR-520c-3p & 5.96 & 0.23 & 6.07 & 0.43 \\
\hline hsa-miR-520d-3p & 5.75 & 0.56 & 6.06 & 0.55 \\
\hline hsa-miR-520e & 5.42 & 0.42 & 5.71 & 0.19 \\
\hline hsa-miR-520f-3p & 5.90 & 0.55 & 6.04 & 0.19 \\
\hline hsa-miR-520g-3p & 5.58 & 0.25 & 6.07 & 0.15 \\
\hline hsa-miR-520h & 6.21 & 0.19 & 5.83 & 0.23 \\
\hline hsa-miR-521 & 5.60 & 0.43 & 5.82 & 0.26 \\
\hline hsa-miR-522-3p & 6.16 & 0.20 & 5.93 & 0.23 \\
\hline hsa-miR-523-3p & 5.81 & 0.44 & 4.99 & 0.49 \\
\hline hsa-miR-524-3p & 5.75 & 0.37 & 5.37 & 0.47 \\
\hline hsa-miR-525-3p & 5.24 & 0.43 & 5.57 & 0.82 \\
\hline hsa-miR-525-5p & 5.63 & 0.61 & 6.09 & 0.09 \\
\hline hsa-miR-526b-5p & 5.79 & 0.52 & 5.90 & 0.42 \\
\hline hsa-miR-526b-3p & 5.63 & 0.29 & 5.87 & 0.22 \\
\hline hsa-miR-532-3p & 5.81 & 0.41 & 5.73 & 0.61 \\
\hline hsa-miR-532-5p & 6.42 & 0.27 & 6.50 & 0.27 \\
\hline hsa-miR-539-5p & 5.77 & 0.19 & 6.15 & 0.24 \\
\hline hsa-miR-541-3p & 5.92 & 0.16 & 5.44 & 0.88 \\
\hline hsa-miR-541-5p & 5.70 & 0.41 & 5.30 & 0.50 \\
\hline hsa-miR-542-3p & 6.01 & 0.82 & 6.47 & 0.25 \\
\hline hsa-miR-542-5p & 6.32 & 0.20 & 6.22 & 0.23 \\
\hline hsa-miR-543 & 5.89 & 0.31 & 5.98 & 0.56 \\
\hline hsa-miR-544a & 5.36 & 0.50 & 5.60 & 0.66 \\
\hline hsa-miR-545-3p & 5.43 & 0.49 & 6.03 & 0.08 \\
\hline hsa-miR-545-5p & 6.51 & 0.39 & 6.02 & 0.59 \\
\hline hsa-miR-548a-3p & 5.55 & 0.57 & 5.78 & 0.71 \\
\hline hsa-miR-548a-5p & 5.88 & 0.67 & 6.24 & 0.29 \\
\hline hsa-miR-548b-3p & 6.06 & 0.54 & 5.73 & 0.89 \\
\hline hsa-miR-548b-5p & 6.47 & 0.11 & 6.00 & 0.20 \\
\hline hsa-miR-548c-3p & 5.88 & 0.86 & 5.08 & 1.20 \\
\hline hsa-miR-548c-5p & 6.36 & 0.22 & 5.99 & 0.75 \\
\hline hsa-miR-548d-3p & 5.69 & 0.42 & 5.12 & 0.97 \\
\hline hsa-miR-548d-5p & 6.30 & 0.17 & 6.11 & 0.35 \\
\hline hsa-miR-548e-3p & 5.90 & 0.39 & 5.97 & 0.27 \\
\hline hsa-miR-548f-3p & 5.78 & 0.26 & 5.81 & 0.41 \\
\hline hsa-miR-548g-3p & 5.73 & 0.49 & 5.63 & 0.64 \\
\hline hsa-miR-548h-5p & 5.33 & 0.78 & 4.87 & 0.42 \\
\hline hsa-miR-548i & 5.70 & 0.32 & 6.11 & 0.31 \\
\hline hsa-miR-548j-5p & 5.76 & 0.44 & 6.07 & 0.61 \\
\hline hsa-miR-548k & 5.19 & 0.42 & 5.35 & 0.31 \\
\hline hsa-miR-548I & 5.60 & 0.22 & 5.87 & 0.25 \\
\hline hsa-miR-548m & 6.11 & 0.17 & 5.94 & 0.33 \\
\hline hsa-miR-548n & 6.03 & 0.32 & 6.20 & 0.44 \\
\hline hsa-miR-548o-3p & 5.46 & 0.45 & 5.90 & 0.32 \\
\hline
\end{tabular}




\begin{tabular}{|c|c|c|c|c|}
\hline hsa-miR-548p & 6.00 & 0.56 & 5.87 & 0.20 \\
\hline hsa-miR-549a & 5.28 & 0.64 & 5.96 & 0.41 \\
\hline hsa-miR-550-5p & 5.48 & 0.45 & 5.75 & 0.65 \\
\hline hsa-miR-550-3p & 5.89 & 0.43 & 5.15 & 0.65 \\
\hline hsa-miR-551a & 5.13 & 0.75 & 5.80 & 0.81 \\
\hline hsa-miR-551b-3p & 6.47 & 0.10 & 5.92 & 0.65 \\
\hline hsa-miR-551b-5p & 5.20 & 1.24 & 5.88 & 0.32 \\
\hline hsa-miR-552-3p & 5.85 & 0.36 & 5.42 & 0.48 \\
\hline hsa-miR-553 & 6.17 & 0.39 & 6.00 & 0.40 \\
\hline hsa-miR-554 & 5.48 & 0.60 & 5.00 & 0.68 \\
\hline hsa-miR-555 & 5.62 & 0.21 & 4.55 & 0.68 \\
\hline hsa-miR-556-3p & 5.09 & 0.62 & 5.78 & 0.56 \\
\hline hsa-miR-556-5p & 5.44 & 0.93 & 6.00 & 0.40 \\
\hline hsa-miR-557 & 6.33 & 0.21 & 5.89 & 0.12 \\
\hline hsa-miR-558 & 5.57 & 0.27 & 5.91 & 0.49 \\
\hline hsa-miR-559 & 5.82 & 0.51 & 5.15 & 0.39 \\
\hline hsa-miR-561-3p & 5.74 & 0.69 & 5.95 & 0.45 \\
\hline hsa-miR-562 & 5.41 & 0.42 & 6.16 & 0.42 \\
\hline hsa-miR-563 & 4.89 & 1.15 & 5.74 & 0.30 \\
\hline hsa-miR-564 & 6.76 & 0.14 & 6.38 & 0.29 \\
\hline hsa-miR-566 & 5.80 & 0.44 & 5.02 & 0.50 \\
\hline hsa-miR-567 & 5.72 & 0.30 & 5.33 & 0.39 \\
\hline hsa-miR-568 & 6.18 & 0.30 & 5.95 & 0.44 \\
\hline hsa-miR-569 & 6.12 & 0.43 & 5.55 & 0.70 \\
\hline hsa-miR-570-3p & 5.99 & 0.32 & 5.06 & 1.09 \\
\hline hsa-miR-571 & 5.68 & 0.37 & 5.60 & 0.26 \\
\hline hsa-miR-572 & 5.68 & 0.88 & 6.32 & 0.14 \\
\hline hsa-miR-573 & 5.55 & 0.45 & 4.58 & 1.48 \\
\hline hsa-miR-574-3p & 6.82 & 0.21 & 6.68 & 0.22 \\
\hline hsa-miR-574-5p & 6.94 & 0.18 & 6.58 & 0.29 \\
\hline hsa-miR-575 & 7.48 & 0.33 & 7.58 & 0.23 \\
\hline hsa-miR-576-3p & 5.68 & 0.64 & 6.12 & 0.18 \\
\hline hsa-miR-576-5p & 5.72 & 0.15 & 6.22 & 0.40 \\
\hline hsa-miR-577 & 6.12 & 0.07 & 5.67 & 0.64 \\
\hline hsa-miR-578 & 5.64 & 0.42 & 5.30 & 0.51 \\
\hline hsa-miR-579-3p & 5.83 & 0.49 & 6.30 & 0.11 \\
\hline hsa-miR-580-3p & 5.67 & 1.05 & 5.50 & 0.62 \\
\hline hsa-miR-581 & 5.05 & 1.55 & 5.81 & 0.52 \\
\hline hsa-miR-582-3p & 5.52 & 0.42 & 5.67 & 0.21 \\
\hline hsa-miR-582-5p & 6.99 & 0.20 & 6.70 & 0.32 \\
\hline hsa-miR-583 & 5.88 & 0.37 & 5.50 & 0.46 \\
\hline hsa-miR-584-5p & 6.15 & 0.34 & 5.90 & 0.48 \\
\hline hsa-miR-585-3p & 5.87 & 0.63 & 6.06 & 0.47 \\
\hline hsa-miR-586 & 5.47 & 0.82 & 5.98 & 0.41 \\
\hline hsa-miR-587 & 5.76 & 0.36 & 4.92 & 1.16 \\
\hline hsa-miR-588 & 5.16 & 0.71 & 5.90 & 0.40 \\
\hline
\end{tabular}




\begin{tabular}{|c|c|c|c|c|}
\hline hsa-miR-589-5p & 5.46 & 0.36 & 5.95 & 0.60 \\
\hline hsa-miR-589-3p & 4.84 & 0.86 & 5.65 & 0.45 \\
\hline hsa-miR-590-3p & 6.68 & 0.13 & 6.16 & 0.72 \\
\hline hsa-miR-590-5p & 7.42 & 0.16 & 7.47 & 0.10 \\
\hline hsa-miR-591 & 5.27 & 0.58 & 5.64 & 0.46 \\
\hline hsa-miR-592 & 6.06 & 0.35 & 5.52 & 0.80 \\
\hline hsa-miR-593-3p & 5.38 & 0.49 & 5.95 & 0.39 \\
\hline hsa-miR-593-5p & 4.88 & 1.05 & 5.81 & 0.06 \\
\hline hsa-miR-595 & 5.59 & 0.26 & 6.19 & 0.48 \\
\hline hsa-miR-596 & 5.39 & 0.73 & 5.00 & 0.42 \\
\hline hsa-miR-597-5p & 5.25 & 0.14 & 5.64 & 0.08 \\
\hline hsa-miR-598-3p & 5.80 & 0.22 & 5.65 & 0.51 \\
\hline hsa-miR-599 & 5.39 & 0.48 & 6.02 & 0.26 \\
\hline hsa-miR-600 & 5.96 & 0.44 & 5.36 & 0.55 \\
\hline hsa-miR-601 & 6.56 & 0.32 & 6.08 & 0.14 \\
\hline hsa-miR-602 & 5.85 & 0.29 & 5.72 & 0.42 \\
\hline hsa-miR-603 & 5.74 & 0.29 & 6.22 & 0.33 \\
\hline hsa-miR-604 & 5.69 & 0.57 & 5.77 & 0.48 \\
\hline hsa-miR-605-5p & 5.29 & 0.54 & 5.56 & 0.43 \\
\hline hsa-miR-606 & 5.96 & 0.40 & 5.24 & 1.23 \\
\hline hsa-miR-607 & 5.33 & 0.79 & 5.73 & 0.49 \\
\hline hsa-miR-608 & 5.38 & 0.21 & 5.53 & 0.11 \\
\hline hsa-miR-609 & 5.48 & 0.81 & 6.11 & 0.41 \\
\hline hsa-miR-610 & 5.23 & 1.02 & 5.76 & 0.42 \\
\hline hsa-miR-611 & 5.12 & 0.30 & 5.43 & 0.25 \\
\hline hsa-miR-612 & 5.82 & 0.24 & 5.19 & 1.35 \\
\hline hsa-miR-613 & 6.27 & 0.31 & 5.22 & 0.36 \\
\hline hsa-miR-614 & 5.92 & 0.47 & 6.05 & 0.53 \\
\hline hsa-miR-615-3p & 5.43 & 0.26 & 5.66 & 0.39 \\
\hline hsa-miR-615-5p & 5.76 & 0.28 & 4.96 & 0.64 \\
\hline hsa-miR-616-3p & 5.12 & 1.13 & 6.07 & 0.44 \\
\hline hsa-miR-616-5p & 5.86 & 0.62 & 5.38 & 0.99 \\
\hline hsa-miR-617 & 5.40 & 0.42 & 4.93 & 1.25 \\
\hline hsa-miR-618 & 5.76 & 0.69 & 5.52 & 0.15 \\
\hline hsa-miR-619-3p & 5.71 & 0.86 & 5.96 & 0.11 \\
\hline hsa-miR-620 & 6.02 & 0.14 & 5.73 & 0.15 \\
\hline hsa-miR-621 & 5.34 & 0.53 & 4.38 & 0.84 \\
\hline hsa-miR-622 & 5.95 & 0.44 & 6.34 & 0.48 \\
\hline hsa-miR-623 & 6.10 & 0.53 & 5.86 & 0.13 \\
\hline hsa-miR-624-3p & 5.31 & 0.45 & 5.63 & 0.91 \\
\hline hsa-miR-624-5p & 5.43 & 0.33 & 5.88 & 0.56 \\
\hline hsa-miR-625-5p & 7.52 & 0.10 & 7.67 & 0.22 \\
\hline hsa-miR-625-3p & 5.47 & 0.70 & 6.00 & 0.34 \\
\hline hsa-miR-626 & 5.68 & 0.48 & 6.10 & 0.30 \\
\hline hsa-miR-627-5p & 6.12 & 0.56 & 6.52 & 0.07 \\
\hline hsa-miR-628-3p & 6.05 & 0.38 & 5.40 & 0.85 \\
\hline
\end{tabular}




\begin{tabular}{|c|c|c|c|c|}
\hline hsa-miR-628-5p & 5.80 & 0.50 & 6.21 & 0.45 \\
\hline hsa-miR-629-5p & 5.89 & 0.64 & 5.42 & 0.52 \\
\hline hsa-miR-629-3p & 6.08 & 0.38 & 5.07 & 0.39 \\
\hline hsa-miR-630 & 5.79 & 0.55 & 5.85 & 0.31 \\
\hline hsa-miR-631 & 5.63 & 0.30 & 5.13 & 0.41 \\
\hline hsa-miR-632 & 5.12 & 0.94 & 5.85 & 0.49 \\
\hline hsa-miR-633 & 6.22 & 0.21 & 5.29 & 0.12 \\
\hline hsa-miR-634 & 5.79 & 0.13 & 4.99 & 0.54 \\
\hline hsa-miR-635 & 6.18 & 0.02 & 5.22 & 0.50 \\
\hline hsa-miR-636 & 5.24 & 0.31 & 5.64 & 0.45 \\
\hline hsa-miR-637 & 5.61 & 0.56 & 4.83 & 0.56 \\
\hline hsa-miR-638 & 7.98 & 0.71 & 7.42 & 0.31 \\
\hline hsa-miR-639 & 5.93 & 0.49 & 5.51 & 0.25 \\
\hline hsa-miR-640 & 5.91 & 0.28 & 5.43 & 0.49 \\
\hline hsa-miR-641 & 5.52 & 0.43 & 5.18 & 0.58 \\
\hline hsa-miR-642a-5p & 5.97 & 0.45 & 5.65 & 0.38 \\
\hline hsa-miR-643 & 5.22 & 0.68 & 5.83 & 0.15 \\
\hline hsa-miR-644 & 4.65 & 1.25 & 4.99 & 1.03 \\
\hline hsa-miR-645 & 5.64 & 0.61 & 5.27 & 0.61 \\
\hline hsa-miR-646 & 5.83 & 0.55 & 5.05 & 0.41 \\
\hline hsa-miR-647 & 4.56 & 0.09 & 5.34 & 0.54 \\
\hline hsa-miR-648 & 4.78 & 0.94 & 5.33 & 0.53 \\
\hline hsa-miR-649 & 5.10 & 0.95 & 5.95 & 0.31 \\
\hline hsa-miR-650 & 5.53 & 0.49 & 5.78 & 0.48 \\
\hline hsa-miR-651-5p & 5.87 & 0.40 & 6.16 & 0.26 \\
\hline hsa-miR-652-3p & 6.17 & 0.21 & 6.00 & 0.38 \\
\hline hsa-miR-653-5p & 4.93 & 0.84 & 6.05 & 0.38 \\
\hline hsa-miR-654-3p & 6.17 & 0.33 & 6.31 & 0.54 \\
\hline hsa-miR-654-5p & 5.27 & 0.59 & 5.91 & 0.23 \\
\hline hsa-miR-655-3p & 5.59 & 0.56 & 6.24 & 0.29 \\
\hline hsa-miR-656-3p & 5.67 & 0.34 & 6.11 & 0.24 \\
\hline hsa-miR-657 & 5.26 & 0.68 & 5.74 & 0.52 \\
\hline hsa-miR-658 & 5.72 & 0.15 & 5.45 & 0.74 \\
\hline hsa-miR-659-3p & 6.02 & 0.43 & 5.29 & 0.81 \\
\hline hsa-miR-660-5p & 7.79 & 0.24 & 7.82 & 0.36 \\
\hline hsa-miR-661 & 5.69 & 0.41 & 5.17 & 0.44 \\
\hline hsa-miR-662 & 6.05 & 0.27 & 5.38 & 0.42 \\
\hline hsa-miR-663a & 5.44 & 0.50 & 5.17 & 0.68 \\
\hline hsa-miR-663b & 5.21 & 0.30 & 5.45 & 0.47 \\
\hline hsa-miR-664-3p & 6.95 & 0.26 & 6.85 & 0.44 \\
\hline hsa-miR-664-5p & 5.91 & 0.25 & 6.17 & 0.26 \\
\hline hsa-miR-665 & 5.32 & 0.30 & 5.90 & 0.55 \\
\hline hsa-miR-668-3p & 5.19 & 0.69 & 4.90 & 0.56 \\
\hline hsa-miR-671-3p & 5.22 & 0.47 & 5.75 & 0.53 \\
\hline hsa-miR-671-5p & 6.33 & 0.23 & 5.63 & 0.26 \\
\hline hsa-miR-675-5p & 5.05 & 0.21 & 5.53 & 0.91 \\
\hline
\end{tabular}




\begin{tabular}{|c|c|c|c|c|}
\hline hsa-miR-675-3p & 5.61 & 0.26 & 5.25 & 0.25 \\
\hline hsa-miR-7-5p & 7.27 & 0.26 & 7.42 & 0.30 \\
\hline hsa-miR-708-5p & 5.56 & 0.67 & 5.97 & 0.61 \\
\hline hsa-miR-708-3p & 5.79 & 0.34 & 5.43 & 0.29 \\
\hline hsa-miR-7-1-3p & 6.68 & 0.19 & 6.61 & 0.27 \\
\hline hsa-miR-7-2-3p & 5.05 & 0.70 & 5.91 & 0.54 \\
\hline hsa-miR-720 & 14.52 & 0.67 & 14.30 & 0.26 \\
\hline hsa-miR-744-5p & 6.39 & 0.38 & 6.00 & 0.39 \\
\hline hsa-miR-744-3p & 5.30 & 0.56 & 4.83 & 0.66 \\
\hline hsa-miR-758-3p & 6.04 & 0.47 & 5.38 & 0.45 \\
\hline hsa-miR-760 & 5.82 & 0.40 & 6.16 & 0.52 \\
\hline hsa-miR-765 & 6.23 & 0.47 & 5.92 & 0.20 \\
\hline hsa-miR-766-3p & 5.85 & 0.67 & 5.05 & 1.21 \\
\hline hsa-miR-767-3p & 5.09 & 0.51 & 5.47 & 0.43 \\
\hline hsa-miR-767-5p & 5.70 & 0.36 & 6.07 & 0.44 \\
\hline hsa-miR-769-3p & 5.99 & 0.38 & 5.52 & 0.40 \\
\hline hsa-miR-769-5p & 6.80 & 0.10 & 6.40 & 0.24 \\
\hline hsa-miR-770-5p & 6.02 & 0.57 & 5.52 & 0.64 \\
\hline hsa-miR-802 & 5.23 & 0.42 & 5.91 & 0.51 \\
\hline hsa-miR-873-5p & 5.90 & 0.46 & 5.69 & 0.40 \\
\hline hsa-miR-874-3p & 6.94 & 0.29 & 6.65 & 0.14 \\
\hline hsa-miR-875-3p & 5.81 & 0.77 & 4.84 & 0.79 \\
\hline hsa-miR-875-5p & 5.58 & 0.10 & 6.53 & 0.14 \\
\hline hsa-miR-876-3p & 5.62 & 0.97 & 5.96 & 0.57 \\
\hline hsa-miR-876-5p & 5.58 & 0.64 & 5.93 & 0.26 \\
\hline hsa-miR-877-5p & 6.03 & 0.21 & 5.08 & 0.66 \\
\hline hsa-miR-877-3p & 5.69 & 0.91 & 5.99 & 0.31 \\
\hline hsa-miR-885-3p & 4.92 & 1.28 & 6.09 & 0.47 \\
\hline hsa-miR-885-5p & 5.31 & 0.23 & 5.68 & 0.46 \\
\hline hsa-miR-886-3p & 5.66 & 0.14 & 6.08 & 0.21 \\
\hline hsa-miR-886-5p & 5.49 & 0.19 & 6.15 & 0.46 \\
\hline hsa-miR-887-3p & 5.66 & 0.34 & 4.78 & 0.94 \\
\hline hsa-miR-888-5p & 5.29 & 0.79 & 5.65 & 0.30 \\
\hline hsa-miR-888-3p & 6.12 & 0.12 & 5.29 & 0.46 \\
\hline hsa-miR-889-3p & 6.05 & 0.52 & 5.53 & 0.74 \\
\hline hsa-miR-890 & 5.41 & 0.50 & 5.19 & 0.38 \\
\hline hsa-miR-891a-5p & 5.50 & 0.16 & 5.35 & 0.91 \\
\hline hsa-miR-891b & 5.47 & 0.32 & 5.30 & 0.49 \\
\hline hsa-miR-892a & 5.77 & 0.08 & 6.02 & 0.28 \\
\hline hsa-miR-892b & 7.22 & 0.54 & 7.47 & 0.44 \\
\hline hsa-miR-9-5p & 5.84 & 0.39 & 6.03 & 0.29 \\
\hline hsa-miR-9-3p & 5.75 & 0.26 & 6.10 & 0.32 \\
\hline hsa-miR-920 & 5.66 & 0.55 & 5.43 & 0.28 \\
\hline hsa-miR-921 & 5.82 & 0.42 & 5.11 & 0.51 \\
\hline hsa-miR-922 & 5.45 & 0.54 & 5.93 & 0.44 \\
\hline hsa-miR-923 & 11.31 & 1.32 & 10.94 & 1.56 \\
\hline
\end{tabular}




\begin{tabular}{lcccc} 
hsa-miR-924 & 5.69 & 0.90 & 5.95 & 0.37 \\
hsa-miR-92a-3p & 10.15 & 0.22 & 10.24 & 0.49 \\
hsa-miR-92a-1-5p & 5.60 & 0.31 & 6.22 & 0.22 \\
hsa-miR-92a-2-5p & 5.44 & 0.83 & 5.82 & 0.52 \\
hsa-miR-92b-3p & 5.12 & 0.70 & 5.58 & 0.13 \\
hsa-miR-92b-5p & 5.73 & 0.34 & 5.34 & 0.13 \\
hsa-miR-93-5p & 9.77 & 0.26 & 9.84 & 0.40 \\
hsa-miR-93-3p & 5.06 & 0.68 & 5.43 & 0.72 \\
hsa-miR-933 & 5.24 & 0.79 & 5.66 & 0.40 \\
hsa-miR-934 & 5.08 & 0.33 & 5.48 & 0.47 \\
hsa-miR-935 & 4.67 & 0.85 & 4.82 & 0.80 \\
hsa-miR-936 & 5.90 & 0.43 & 6.07 & 0.24 \\
hsa-miR-937-3p & 4.53 & 1.22 & 5.13 & 0.41 \\
hsa-miR-938 & 5.24 & 0.79 & 6.29 & 0.29 \\
hsa-miR-939-5p & 7.75 & 0.48 & 7.61 & 0.35 \\
hsa-miR-940 & 8.10 & 0.38 & 7.97 & 0.38 \\
hsa-miR-941 & 5.06 & 0.75 & 5.86 & 0.53 \\
hsa-miR-942-5p & 5.41 & 0.24 & 5.03 & 0.93 \\
hsa-miR-943 & 5.48 & 0.74 & 5.79 & 0.64 \\
hsa-miR-944 & 5.98 & 0.63 & 5.59 & 0.35 \\
hsa-miR-95-3p & 6.07 & 0.49 & 6.29 & 0.20 \\
hsa-miR-96-5p & 5.91 & 0.45 & 5.63 & 0.20 \\
hsa-miR-96-3p & 5.48 & 0.66 & 5.66 & 0.45 \\
hsa-miR-98-5p & 7.96 & 0.29 & 7.79 & 0.27 \\
hsa-miR-99a-5p & 6.69 & 0.26 & 6.50 & 0.67 \\
hsa-miR-99a-3p & 5.56 & 1.16 & 5.87 & 0.46 \\
hsa-miR-99b-5p & 5.97 & 0.28 & 5.82 & 0.32 \\
hsa-miR-99b-3p & 6.15 & 0.49 & 5.49 & 0.49 \\
\hline
\end{tabular}

SD, standard deviation $(n=4)$. 
Table S2. Differentially affected miRNAs in PBMCs of healthy volunteers at fasting and after the ingestion of a standardized high-saturated fat meal.

\begin{tabular}{|c|c|c|c|c|c|c|c|}
\hline \multirow{2}{*}{ hsa-miRNA } & \multirow{2}{*}{$\begin{array}{c}\begin{array}{c}\text { At fasting } \\
(\mathrm{F})\end{array} \\
\begin{array}{c}\text { Signal } \\
\text { intensity }\end{array}\end{array}$} & \multirow[b]{2}{*}{ SD } & \multirow{2}{*}{$\begin{array}{c}\text { At postprandial } \\
(P)\end{array}$} & \multirow[b]{2}{*}{ SD } & \multicolumn{2}{|l|}{$\mathrm{P} v s \mathrm{~F}$} & \multirow[b]{2}{*}{$p$-value } \\
\hline & & & & & $\begin{array}{c}\text { Fold } \\
\text { change }\end{array}$ & SD & \\
\hline \multicolumn{8}{|l|}{ Downregulation } \\
\hline let-7i-3p & 5.96 & 0.53 & 5.21 & 0.79 & -0.20 & 0.25 & 0.036 \\
\hline miR-24-2-5p & 5.34 & 0.73 & 4.19 & 0.68 & -0.35 & 0.31 & 0.049 \\
\hline$m i R-136-3 p$ & 6.13 & 0.32 & 5.62 & 0.30 & -0.13 & 0.11 & 0.049 \\
\hline miR-148a-5p & 5.69 & 0.56 & 4.76 & 0.54 & -0.26 & 0.21 & 0.006 \\
\hline miR-298 & 6.12 & 0.13 & 5.25 & 0.91 & -0.24 & 0.28 & 0.049 \\
\hline miR-299-3p & 5.92 & 0.55 & 5.32 & 0.20 & -0.15 & 0.15 & 0.047 \\
\hline miR-300 & 5.98 & 0.56 & 5.05 & 0.34 & -0.24 & 0.17 & 0.006 \\
\hline $\mathrm{miR}-302 \mathrm{e}$ & 5.99 & 0.42 & 5.18 & 0.08 & -0.21 & 0.10 & 0.041 \\
\hline miR-369-3p & 6.25 & 0.32 & 5.65 & 0.39 & -0.15 & 0.12 & 0.048 \\
\hline miR-491-3p & 6.04 & 0.48 & 5.19 & 0.64 & -0.23 & 0.21 & 0.025 \\
\hline miR-513c-5p & 6.12 & 0.37 & 5.07 & 0.58 & -0.28 & 0.19 & 0.029 \\
\hline miR-523-3p & 5.81 & 0.44 & 4.99 & 0.49 & -0.22 & 0.18 & 0.016 \\
\hline miR-550-3p & 5.89 & 0.43 & 5.15 & 0.65 & -0.20 & 0.21 & 0.041 \\
\hline miR-555 & 5.62 & 0.21 & 4.55 & 0.68 & -0.32 & 0.21 & 0.003 \\
\hline miR-566 & 5.80 & 0.44 & 5.02 & 0.50 & -0.21 & 0.19 & 0.006 \\
\hline miR-570-3p & 5.99 & 0.32 & 5.06 & 1.09 & -0.27 & 0.34 & 0.030 \\
\hline miR-613 & 6.27 & 0.31 & 5.22 & 0.36 & -0.26 & 0.12 & 0.046 \\
\hline miR-615-5p & 5.76 & 0.28 & 4.96 & 0.64 & -0.22 & 0.20 & 0.035 \\
\hline miR-621 & 5.34 & 0.53 & 4.38 & 0.84 & -0.30 & 0.33 & 0.033 \\
\hline miR-629-3p & 6.08 & 0.38 & 5.07 & 0.39 & -0.26 & 0.15 & 0.020 \\
\hline miR-633 & 6.22 & 0.21 & 5.29 & 0.12 & -0.23 & 0.06 & 0.039 \\
\hline miR-634 & 5.79 & 0.13 & 4.99 & 0.54 & -0.22 & 0.16 & 0.011 \\
\hline miR-635 & 6.18 & 0.02 & 5.22 & 0.50 & -0.25 & 0.14 & 0.023 \\
\hline miR-646 & 5.83 & 0.55 & 5.05 & 0.41 & -0.21 & 0.18 & 0.006 \\
\hline miR-659-3p & 6.02 & 0.43 & 5.29 & 0.81 & -0.20 & 0.25 & 0.028 \\
\hline miR-662 & 6.05 & 0.27 & 5.38 & 0.42 & -0.17 & 0.13 & 0.041 \\
\hline miR-671-5p & 6.33 & 0.23 & 5.63 & 0.26 & -0.17 & 0.09 & 0.030 \\
\hline miR-875-3p & 5.81 & 0.77 & 4.84 & 0.79 & -0.27 & 0.31 & 0.015 \\
\hline miR-877-5p & 6.03 & 0.21 & 5.08 & 0.66 & -0.25 & 0.19 & 0.027 \\
\hline miR-887-3p & 5.66 & 0.34 & 4.78 & 0.94 & -0.27 & 0.33 & 0.035 \\
\hline miR-888-3p & 6.12 & 0.12 & 5.29 & 0.46 & -0.21 & 0.13 & 0.036 \\
\hline miR-921 & 5.82 & 0.42 & 5.11 & 0.51 & -0.19 & 0.18 & 0.022 \\
\hline$m i R-1224-5 p$ & 6.50 & 0.54 & 5.86 & 0.12 & -0.15 & 0.12 & 0.018 \\
\hline miR-1226-3p & 5.47 & 0.66 & 4.48 & 1.05 & -0.31 & 0.39 & 0.023 \\
\hline miR-1229-3p & 5.32 & 0.55 & 4.49 & 0.63 & -0.25 & 0.25 & 0.048 \\
\hline
\end{tabular}


Upregulation

\begin{tabular}{|c|c|c|c|c|c|c|c|}
\hline miR-7-2-3p & 5.05 & 0.70 & 5.91 & 0.54 & 0.23 & 0.24 & 0.037 \\
\hline miR-18a-3p & 5.46 & 0.88 & 6.20 & 0.12 & 0.20 & 0.25 & 0.03 \\
\hline miR-19b-1-5p & 4.19 & 0.43 & 5.22 & 0.20 & 0.32 & 0.16 & 0.049 \\
\hline miR-25-5p & 5.67 & 0.32 & 6.26 & 0.31 & 0.15 & 0.11 & 0.036 \\
\hline miR-26b-3p & 5.86 & 0.39 & 6.41 & 0.22 & 0.13 & 0.11 & 0.002 \\
\hline$m i R-30 b-3 p$ & 5.61 & 0.06 & 6.16 & 0.05 & 0.13 & 0.02 & 0.049 \\
\hline miR-30d-3p & 5.07 & 1.12 & 5.93 & 0.41 & 0.25 & 0.36 & 0.044 \\
\hline$m i R-129-5 p$ & 5.37 & 0.45 & 6.04 & 0.40 & 0.17 & 0.15 & 0.020 \\
\hline $\operatorname{miR}-138-1-3 p$ & 4.52 & 0.17 & 5.26 & 0.60 & 0.21 & 0.18 & 0.044 \\
\hline miR-138-2-3p & 5.58 & 0.79 & 6.20 & 0.21 & 0.16 & 0.21 & 0.010 \\
\hline$m i R-143-3 p$ & 5.43 & 0.31 & 6.05 & 0.20 & 0.16 & 0.09 & 0.025 \\
\hline miR-1468-5p & 5.06 & 0.32 & 5.69 & 0.23 & 0.17 & 0.11 & 0.047 \\
\hline miR-146a-3p & 5.30 & 0.48 & 6.13 & 0.33 & 0.21 & 0.15 & 0.014 \\
\hline miR-148b-5p & 4.74 & 1.14 & 5.89 & 0.27 & 0.35 & 0.40 & 0.002 \\
\hline miR-181a-2-3p & 5.93 & 0.48 & 6.62 & 0.11 & 0.16 & 0.12 & 0.046 \\
\hline miR-181c-3p & 5.08 & 0.16 & 5.78 & 0.43 & 0.18 & 0.12 & 0.029 \\
\hline miR-200b-5p & 4.86 & 0.45 & 5.83 & 0.61 & 0.26 & 0.20 & 0.029 \\
\hline miR-297 & 5.20 & 0.54 & 5.93 & 0.28 & 0.20 & 0.17 & 0.038 \\
\hline miR-339-3p & 4.24 & 0.52 & 5.42 & 0.37 & 0.36 & 0.21 & 0.027 \\
\hline miR-363-5p & 4.55 & 0.99 & 5.70 & 0.09 & 0.35 & 0.32 & 0.013 \\
\hline$m i R-411-3 p$ & 5.05 & 0.45 & 5.88 & 0.42 & 0.22 & 0.16 & 0.048 \\
\hline miR-491-5p & 5.35 & 0.32 & 5.94 & 0.31 & 0.15 & 0.11 & 0.038 \\
\hline miR-495-3p & 5.65 & 0.28 & 6.39 & 0.25 & 0.18 & 0.09 & 0.047 \\
\hline miR-518c-3p & 5.37 & 0.31 & 5.96 & 0.36 & 0.15 & 0.12 & 0.006 \\
\hline miR-519d-3p & 5.28 & 0.08 & 5.92 & 0.58 & 0.16 & 0.14 & 0.021 \\
\hline miR-519e-3p & 5.43 & 0.33 & 6.00 & 0.29 & 0.14 & 0.11 & 0.026 \\
\hline miR-562 & 5.41 & 0.42 & 6.16 & 0.42 & 0.19 & 0.15 & 0.012 \\
\hline miR-588 & 5.16 & 0.71 & 5.90 & 0.40 & 0.20 & 0.23 & 0.039 \\
\hline miR-593-5p & 4.88 & 1.05 & 5.81 & 0.06 & 0.28 & 0.33 & 0.012 \\
\hline miR-599 & 5.39 & 0.48 & 6.02 & 0.26 & 0.16 & 0.14 & 0.037 \\
\hline miR-616-3p & 5.12 & 1.13 & 6.07 & 0.44 & 0.27 & 0.36 & 0.023 \\
\hline miR-632 & 5.12 & 0.94 & 5.85 & 0.49 & 0.21 & 0.31 & 0.030 \\
\hline miR-647 & 4.56 & 0.09 & 5.34 & 0.54 & 0.22 & 0.15 & 0.013 \\
\hline miR-649 & 5.10 & 0.95 & 5.95 & 0.31 & 0.24 & 0.28 & 0.010 \\
\hline miR-653-5p & 4.93 & 0.84 & 6.05 & 0.38 & 0.31 & 0.27 & 0.023 \\
\hline miR-665 & 5.32 & 0.30 & 5.90 & 0.55 & 0.15 & 0.16 & 0.006 \\
\hline miR-802 & 5.23 & 0.42 & 5.91 & 0.51 & 0.18 & 0.17 & 0.010 \\
\hline miR-875-5p & 5.58 & 0.10 & 6.53 & 0.14 & 0.23 & 0.04 & 0.002 \\
\hline miR-885-3p & 4.92 & 1.28 & 6.09 & 0.47 & 0.35 & 0.45 & 0.038 \\
\hline miR-886-5p & 5.49 & 0.19 & 6.15 & 0.46 & 0.16 & 0.12 & 0.018 \\
\hline miR-938 & 5.24 & 0.79 & 6.29 & 0.29 & 0.27 & 0.23 & 0.041 \\
\hline miR-941 & 5.06 & 0.75 & 5.86 & 0.53 & 0.22 & 0.26 & 0.034 \\
\hline miR-1185-5p & 5.52 & 0.25 & 6.01 & 0.23 & 0.12 & 0.08 & 0.028 \\
\hline miR-1237-3p & 5.12 & 0.31 & 5.90 & 0.30 & 0.21 & 0.12 & 0.018 \\
\hline miR-1286 & 5.07 & 0.76 & 5.86 & 0.58 & 0.22 & 0.27 & 0.035 \\
\hline
\end{tabular}


$\mathrm{SD}$, standard deviation $(n=4)$. Downregulated miRNAs are depicted in green colour, while upregulated miRNAs in orange colour. 
Table S3. Number of target genes for differentially affected miRNAs in PBMCs of healthy volunteers at fasting and after the ingestion of a standardized high-saturated fat meal.

\begin{tabular}{|c|c|c|c|}
\hline hsa-miRNA & $\begin{array}{l}\text { Putative target } \\
\text { gene number }\end{array}$ & hsa-miRNA & $\begin{array}{l}\text { Putative target } \\
\text { gene number }\end{array}$ \\
\hline Downregulation & & Upregulation & \\
\hline let-7i-3p & 7 & miR-1185-5p & 108 \\
\hline miR-1224-5p & 271 & miR-1237 & 741 \\
\hline miR-1226-3p & 479 & miR-1286 & 334 \\
\hline $\mathrm{miR}-1229$ & 216 & $m i R-129-5 p$ & 1605 \\
\hline miR-136-3p & 106 & miR-138-1-3p & 167 \\
\hline miR-148a-5p & 567 & miR-138-2-3p & 398 \\
\hline miR-24-2-5p & 111 & miR-143-3p & 531 \\
\hline miR-298 & 361 & miR-1468 & 23 \\
\hline miR-299-3p & 253 & miR-146a-3p & 539 \\
\hline miR-300 & 1293 & $m i R-148 b-5 p$ & 427 \\
\hline $\mathrm{miR}-302 \mathrm{e}$ & 626 & $m i R-181 a-2-3 p$ & 220 \\
\hline miR-369-3p & 1195 & $\mathrm{miR}-181 c-3 p$ & 4 \\
\hline miR-491-3p & 179 & miR-18a-3p & 48 \\
\hline miR-491-5p & 296 & miR-19b-1-5p & 156 \\
\hline miR-513c-5p & 166 & miR-200b-5p & 251 \\
\hline miR-523-3p & 2 & $m i R-25-5 p$ & 26 \\
\hline $\operatorname{miR}-550 a-3 p$ & 214 & miR-26b-3p & 214 \\
\hline miR-555 & 64 & miR-297 & 80 \\
\hline miR-566 & 7 & miR-30b-3p & 495 \\
\hline miR-570-3p & 568 & miR-30d-3p & 226 \\
\hline miR-613 & 398 & miR-339-3p & 27 \\
\hline miR-615-5p & 114 & miR-363-5p & 122 \\
\hline miR-621 & 61 & miR-411-3p & 655 \\
\hline miR-629-3p & 587 & miR-495-3p & 2618 \\
\hline miR-633 & 172 & miR-518c-3p & 10 \\
\hline miR-634 & 250 & miR-519d-3p & 852 \\
\hline miR-635 & 218 & miR-519e-3p & 167 \\
\hline miR-646 & 660 & miR-562 & 376 \\
\hline miR-659-3p & 379 & miR-588 & 625 \\
\hline miR-662 & 62 & $m i R-593-5 p$ & 241 \\
\hline miR-671-5p & 377 & miR-599 & 174 \\
\hline miR-875-3p & 454 & miR-616-3p & 185 \\
\hline miR-877-5p & 142 & miR-632 & 271 \\
\hline miR-887 & 10 & miR-647 & 434 \\
\hline miR-888-3p & 189 & miR-649 & 228 \\
\hline miR-921 & 60 & miR-653 & 316 \\
\hline
\end{tabular}




$\begin{array}{lc}\text { miR-665 } & 341 \\ \text { miR-7-2-3p } & 1448 \\ \text { miR-802 } & 99 \\ \text { miR-875-5p } & 214 \\ \text { miR-885-3p } & 107 \\ \text { miR-938 } & 198 \\ \text { miR-941 } & 29\end{array}$

Total affected downregulated and upregulated genes were 11114 and 16330 , respectively. Downregulated miRNAs are depicted in green colour, while upregulated miRNAs in orange colour. 
Table S4. Overrepresented GO terms by dysregulated miRNAs ${ }^{a}$.

\begin{tabular}{|c|c|c|c|c|}
\hline \multicolumn{2}{|c|}{ Downregulated miRNAs } & \multirow[b]{2}{*}{ Description } & \multirow[b]{2}{*}{ FDR } & \multirow[b]{2}{*}{ Genes (the five most involved) } \\
\hline Category & Term & & & \\
\hline BP & GO:0014065 & PI3K cascade & 0.02640344 & IGF1R, ERBB3, ERBB2, NF1, PIK3R1 \\
\hline BP & GO:0048010 & VEGF receptor signalling pathway & 0.00838648 & VEGFC, NRP1, PDGFRA, BMPR2, PDGFRB \\
\hline BP & GO:0060389 & Pathway-restricted SMAD protein phosphorylation & 0.01407007 & BMP2, SMAD7, GDF6, TGFBR1, TGFBR2 \\
\hline BP & GO:0001569 & Patterning of blood vessels & 0.00115075 & SEMA5A, FLT1, NRP1, CXCR4, TGFBR2 \\
\hline BP & GO:0030509 & BMP signalling pathway & 2.61E-10 & BMP2, NOG, SMAD9, SMAD7, SMAD6 \\
\hline BP & GO:0001952 & Regulation of cell-matrix adhesion & 4.98E-04 & BCL2, CSF1, NF1, SMAD3, CDK6 \\
\hline BP & GO:0018105 & Peptidyl-serine phosphorylation & $9.20 \mathrm{E}-04$ & AKT1, GSK3B, BCL2, NLK, TGFBR1 \\
\hline BP & GO:0008543 & Fibroblast growth factor receptor signalling pathway & $9.20 \mathrm{E}-04$ & FGFR2, FGFR1, FGF5, FGF18, FGF7 \\
\hline BP & GO:0018108 & Peptidyl-tyrosine phosphorylation & 1.68E-07 & FLT1, ERBB4, ERBB3, ERBB2, KIT \\
\hline BP & GO:0045732 & Positive regulation of protein catabolic process & 0.00767994 & AKT1, CBLB, SMAD7, IFNG, MDM2 \\
\hline BP & GO:0018212 & Peptidyl-tyrosine modification & 3.04E-07 & FLT1, ERBB4, ERBB3, ERBB2, KIT \\
\hline BP & GO:0045778 & Positive regulation of ossification & 0.04793414 & ACVR2A, BMP2, BMPR2, SMAD3, BMPR1B \\
\hline BP & GO:0042476 & Odontogenesis & $1.14 \mathrm{E}-07$ & BMP2, ERBB4, ERBB3, CSF1, LEF1 \\
\hline BP & GO:0030199 & Collagen fibril organization & 0.01290553 & TGFBR1, NF1, COL1A2, COL2A1, COL1A1 \\
\hline BP & GO:0030335 & Positive regulation of cell migration & $7.12 \mathrm{E}-14$ & EGFR, FLT1, ERBB4, MAP2K1, PDGFA \\
\hline BP & GO:0050679 & Positive regulation of epithelial cell proliferation & $1.22 \mathrm{E}-04$ & EGFR, VEGFC, NOG, FGF7, ERBB4 \\
\hline BP & GO:0032388 & Positive regulation of intracellular transport & 0.01645978 & SMO, GSK3B, TGFBR1, RHOA, SMAD4 \\
\hline BP & GO:0051272 & Positive regulation of cell motion & 4.15E-15 & ERBB4, PDGFA, CSF1, RPS6KB1, KIT \\
\hline BP & GO:0040017 & Positive regulation of locomotion & 4.15E-15 & ERBB4, PDGFA, CSF1, FGF10, RPS6KB1 \\
\hline BP & GO:0018209 & Peptidyl-serine modification & 9.35E-04 & AKT1, GSK3B, BCL2, NLK, TGFBR1 \\
\hline BP & GO:0051781 & Positive regulation of cell division & $9.35 \mathrm{E}-04$ & VEGFC, FGF5, FGF7, FGF9, PDGFA \\
\hline BP & GO:0001541 & Ovarian follicle development & 0.00147656 & INHBB, CCNE1, INHBA, FGF7, CCND2 \\
\hline BP & GO:0050678 & Regulation of epithelial cell proliferation & 4.89E-08 & EGFR, NOG, FGF7, ERBB4, FGF9 \\
\hline BP & GO:0031346 & Positive regulation of cell projection organization & 4.90E-04 & CDC42, LIMK1, ROBO1, TGFBR1, RAC1 \\
\hline BP & GO:0048638 & Regulation of developmental growth & 4.90E-04 & COL4A4, NOG, NRP1, FGF9, LIMK1 \\
\hline
\end{tabular}


Upregulated miRNAs

\begin{tabular}{llll} 
Category & Term & Description \\
\hline BP & GO:0043550 & Regulation of lipid kinase activity \\
BP & GO:0060070 & Wnt receptor signalling pathway through beta-catenin \\
BP & GO:0045646 & Regulation of erythrocyte differentiation \\
BP & GO:0048538 & Thymus development \\
BP & GO:0007214 & Gamma-aminobutyric acid signalling pathway \\
BP & GO:0030509 & BMP signalling pathway \\
BP & GO:0000209 & Protein polyubiquitination \\
BP & GO:0006512 & Ubiquitin cycle \\
BP & GO:0045778 & Positive regulation of ossification \\
BP & GO:0045669 & Positive regulation of osteoblast differentiation \\
BP & GO:0048730 & Epidermis morphogenesis \\
BP & GO:0000082 & G1/S transition of mitotic cell cycle \\
BP & GO:0048661 & Positive regulation of smooth muscle cell proliferation \\
BP & GO:0048146 & Positive regulation of fibroblast proliferation \\
BP & GO:0051781 & Positive regulation of cell division \\
BP & GO:0001657 & Ureteric bud development \\
BP & GO:0030856 & Regulation of epithelial cell differentiation \\
BP & GO:0007179 & TGF beta receptor signalling pathway \\
BP & GO:0030178 & Negative regulation of Wnt receptor signalling \\
BP & GO:0051302 & Regulation of cell division \\
BP & GO:0001656 & Metanephros development \\
BP & GO:0048754 & Branching morphogenesis of a tube \\
BP & GO:0007178 & Transmembrane receptor protein serine/threonine \\
& & \\
\hline
\end{tabular}

FDR

$1.61 \mathrm{E}-03$

0.00488947

0.00771607

2.82E-03

$1.75 \mathrm{E}-02$

$1.5383 \mathrm{E}-08$

0.00100132

0.00603251

6.03E-03

0.00855149

0.00855149

7.1443E-10

0.00049576

0.01190695

$5.6928 \mathrm{E}-05$

0.00176651

0.02930361

3.22E-07

3.85E-02

6.3266E-05

2.54E-04

1.4214E-07

$2.00 \mathrm{E}-13$
Genes (the five most involved)

CDC42, VAV3, RBL1, RAC1, RB1

TBL1XR1, CCND1, GSK3B, LRP6, TBL1X ACVR2A, INHBA, ETS1, STAT5A, STAT5B CRKL, BCL2, TGFBR1, SIX1, PBX1 GABRG1, GABRA2, GABRA1, GABRA4, GABRA3

SMAD9, SMAD7, SMAD6, GDF6, SMAD5

ERCC8, HUWE1, UBE4A, MAP3K1, PPIL2 UBE2D2, UBE3A, SOCS3, UBE2W ACVR2A, ADRB2, BMPR2, TGFB3, BMP7 ACVR2A, JUND, SMAD5, BMPR2, BMP7 NOTCH1, FGF7, BCL2, FST, COL1A2 CAMK2G, SKP2, RB1, PPP1CB, CUL3 PRKCA, PTGS2, PDGFB, EREG, STAT5B BMI1, CDKN1A, PDGFB, EREG, PDGFA FGF5, FGF7, PDGFB, PDGFA, FGF9 EYA1, RET, BDNF, BCL2, SIX1 CCND1, NOTCH1, CDKN2B, STAT5A, TGFBR1 SMAD9, PDGFB, FUT8, PDGFA, NLK DKK2, CCND1, FGF9, NLK, LRP6

FGF5, FGF7, PDGFB, PDGFA, FGF9 RET, NF1, SMAD4, GLI3, SHH NRP1, TGFBR2, SMAD4, IGF1, GLI3 FUT8, PDGFB, PDGFA, GDF6, FST 


\begin{tabular}{lllll} 
& & kinase signalling pathway & & \\
BP & GO:0051272 & Positive regulation of cell motion & $2.7978 E-12$ & ERBB4, PDGFB, PDGFA, BCAR1, STAT5B \\
BP & GO:0045216 & Cell-cell junction organization & $1.62 E-02$ & CDC42, PARD6B, TJP1, SMAD7, TGFB3 \\
BP & GO:0030111 & Regulation of Wnt receptor signalling pathway & $4.34 E-04$ & FGF9, NLK, PPM1A, CXXC4, SENP2 \\
BP & GO:0045667 & Regulation of osteoblast differentiation & $1.72 E-03$ & ACVR2A, JUND, SMAD5, BMPR2, CDK6 \\
BP & GO:0032355 & Response to estradiol stimulus & $4.67 E-05$ & PRKCA, PDGFB, PTGS2, SOCS3, PDGFA \\
BP & GO:0001763 & Morphogenesis of a branching structure & $1.7947 E-07$ & NRP1, TGFBR2, SMAD4, IGF1, GLI3 \\
BP & GO:0045787 & Positive regulation of cell cycle & $9.876 E-05$ & SMAD6, STAT5A, STAT5B, IGF1, BRCA2 \\
\hline
\end{tabular}

BP, biological process; GO, gene ontology; PI3K, phosphoinositide 3-kinase; FDR, false discovery rate correction value; VEGF, vascular endothelial growth factor; SMAD, similar to the Drosophila gene mothers against decapentaplegic; BMP, bone morphogenetic protein;

TGF, transforming growth factor.

a This information was generated by the team of DAVID database. 